\title{
WestVirginiaUniversity
}

THE RESEARCH REPOSITORY @ WVU

Graduate Theses, Dissertations, and Problem Reports

2010

\section{Reservoir modeling of New Albany Shale}

Amirmasoud Kalantari-Dahaghi

West Virginia University

Follow this and additional works at: https://researchrepository.wvu.edu/etd

\section{Recommended Citation}

Kalantari-Dahaghi, Amirmasoud, "Reservoir modeling of New Albany Shale" (2010). Graduate Theses, Dissertations, and Problem Reports. 4610.

https://researchrepository.wvu.edu/etd/4610

This Thesis is protected by copyright and/or related rights. It has been brought to you by the The Research Repository @ WVU with permission from the rights-holder(s). You are free to use this Thesis in any way that is permitted by the copyright and related rights legislation that applies to your use. For other uses you must obtain permission from the rights-holder(s) directly, unless additional rights are indicated by a Creative Commons license in the record and/ or on the work itself. This Thesis has been accepted for inclusion in WVU Graduate Theses, Dissertations, and Problem Reports collection by an authorized administrator of The Research Repository @ WVU. For more information, please contact researchrepository@mail.wvu.edu. 
By

Amirmasoud Kalantari-Dahaghi

Thesis submitted to the

College of Engineering and Mineral Resources

at West Virginia University

in partial fulfillment of the requirements

for the degree of

Master of Science

in

Petroleum and Natural Gas Engineering

Approved by

Shahab D. Mohaghegh, PhD., Chair

Samuel Ameri, Ph.D.

Razi Gaskari, PhD.

Grant Bromhal, Ph.D

Department of Petroleum and Natural Gas Engineering

Morgantown, West Virginia

2010

Keywords: Shale Gas, Fracture Network, Production Rate, Artificial Intelligence, Top-down Model

Copyright 2010 Amirmasoud Kalantari-Dahaghi 


\section{ABSTRACT}

\section{Reservoir Modeling of New Albany Shale}

\section{Amirmasoud Kalantari-Dahaghi}

The intent of this study is to reassess the potential of New Albany Shale formation using a novel and integrated workflow, which incorporates field production data and well logs using a series of traditional reservoir engineering analyses complemented by artificial intelligence \& data mining techniques. The model developed using this technology is a full filed model and its objective is to predict future reservoir/well performance in order to recommend field development strategies.

The impact of different reservoir characteristics such as matrix porosity, matrix permeability, initial reservoir pressure and pay thickness as well as the length and the orientation of horizontal wells on gas production in New Albany Shale have been presented.

The study was conducted using publicly available numerical model, specifically developed to simulate gas production from naturally fractured reservoirs.

The study focuses on several New Albany Shale (NAS) wells in Western Kentucky. Production from these wells is analyzed and history matched. During the history matching process, natural fracture length, density and orientations as well as fracture bedding of the New Albany Shale are modeled using information found in the literature and outcrops and by performing sensitivity analysis on key reservoir and fracture parameters.

Sensitivity analysis is performed to identify the impact of reservoir characteristics and natural fracture aperture, density and length on gas production.

Then, the history-matched results of 87 NAS wells have been used to develop a full field reservoir model using an integrated workflow, named Top-Down, Intelligent Reservoir Modeling. In this integrated workflow unlike traditional reservoir simulation and modeling, we do not start from building a geo-cellular model. Top-Down intelligent reservoir modeling starts by analyzing the production data using traditional reservoir engineering techniques such as Decline Curve Analysis, Type Curve Matching, Single-well History Matching, Volumetric Reserve Estimation and Recovery Factor. These analyses are performed on individual wells in a multi-well New Albany Shale gas reservoir in Western Kentucky that has a reasonable production history. Data driven techniques are used to develop single-well predictive models from the production history and the well logs (and any other available geologic and petrophysical data).

Upon completion of the abovementioned analyses a large database is generated .This database includes a large number of spatio-temporal snap shots of reservoir behavior. Artificial intelligence and data mining techniques are used to fuse all these information into a cohesive reservoir model. The reservoir model is calibrated (history matched) using the production history of the most recent set of wells that have been drilled in the field. The calibrated reservoir model is utilized for predictive purposes to identify the most effective field development strategies including locations of infill wells, remaining reserves, and under- 
performer wells. Capabilities of this new technique, ease of use and much shorter development and analysis time are advantages of Top-Down modeling as compared to the traditional simulation and modeling.

In addition, 31 recently drilled well in Christian county Western Kentucky-Halley's Mills quadrangle have been used to perform Top-down modeling. Zone manager feature of Geographix software is used .The available production data are going to be the attributes in this feature. The contours are generated and the results have been compared with the result of Top-down modeling (Fuzzy pattern recognition). Structural map, isopach map and the other geological map has been generated using Geographix.

Additionally ,in order to indentify the effect of horizontal lateral length on well productivity from New Albany Shale, fracture network has been regenerated in order to represent the distribution of natural fracture in that formation. 
This work is dedicated especially to my wife Vida Mani who has helped me to succeed and instilled in me the confidence that $?$ am capable of doing anything $?$ put my mind to, and my parents who have raised me to be the person $?$ am today and have been with me every step of the way.

Thank you for all the unconditional love, guidance, and support that you have always given me. You are the main source of my inspiration and the strength of my will. Thank you for everything. I love you!

7 me Family.

iV 


\section{Acknowledgments}

First of all, I would like to show my gratitude and appreciation to my research advisor Dr. Shahab Mohaghegh for his advice, guidance, and encouragement during the course of this research. His enthusiasm and humor made these years at West Virginia enjoyable for me and He gave me a complement to increase my confidence and examples of professionalism on how tasks should be completed and presented.

My appreciation goes to Dr. Samule Ameri, Dr. Razi Gaskari and Dr.Grant Bromhal who generously accepted to be a member of my thesis committee and all made significant contribution to this work. Their continuous and constructive critiques and suggestions have helped me a lot to improve this work.

Special thanks go to my professors in the PNGE Department for their support and for their time to share their knowledge with me. I express my thankfulness to the administrative associate of PNGE department, Beverly Matheny, for her kindness, friendship, and her presence to help the students.

Also, I would like to acknowledge GTI and Research Partnership to Secure Energy for America (RPSEA) for partially funding this study and thank Intelligent Solutions, Inc. for supplying the IPDA and DOE-NETL for supplying FracGen/NFFlow software package

I would also like to express my sincere gratefulness to my friends and office-mates, Jalal Jalali, Yasaman Khazaeni, Camilo Calderon, Yorgi Gomez and Ognjen Gruic for providing a friendly environment and helpful discussions about different issues during the past two years. Good luck to each of you in your future endeavors.

My profound gratitude is expended to my parents. Although they have been miles away from me I have always been supported by their understanding, trust and wholehearted help they have been giving to me.

Finally, my special thanks to my wife, Vida. Was it not for her encouragement and her support in my personal and academic life, everything would be more difficult and challenging. Thank you for your continual love and support as I went through this journey. I could not have made it through without you by my side. 


\section{Table of Contents}

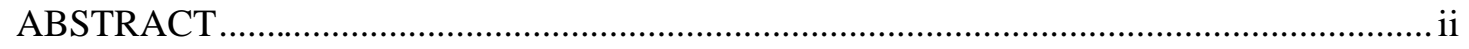

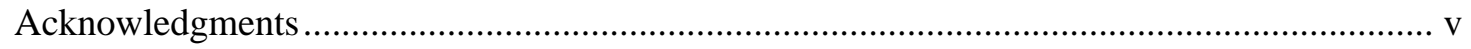

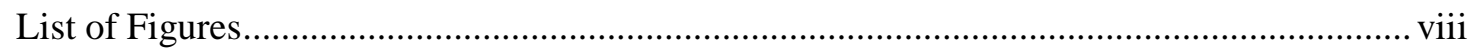

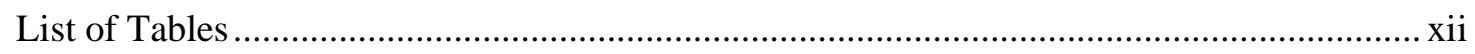

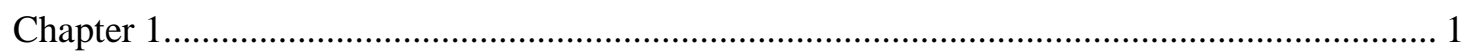

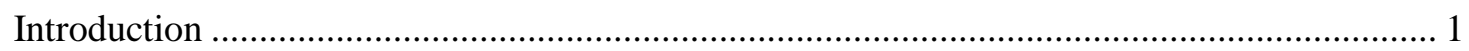

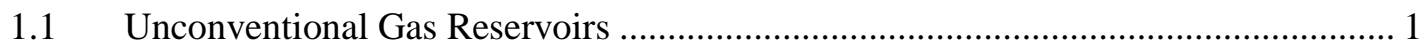

1.2 Naturally fractured Shale gas Reservoirs.................................................................. 3

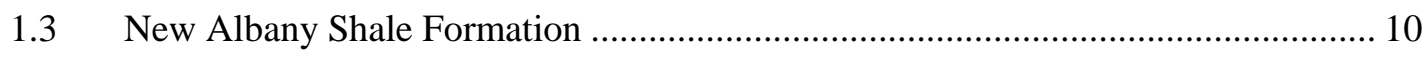

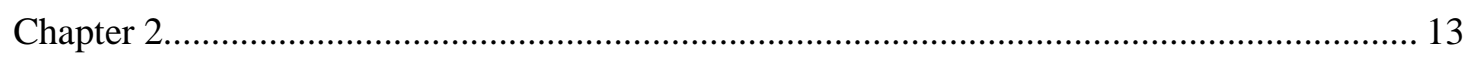

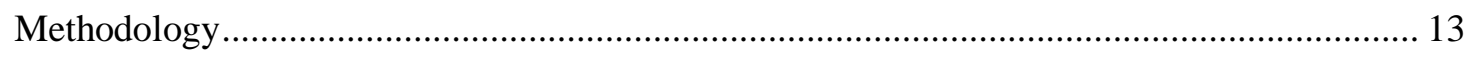

2.1 New Albany Shale Natural Fracture Network Modeling and Simulation ...................... 13

2.2 Top-Down Intelligent Reservoir Modeling of New Albany Shale................................ 14

2.2.1 Traditional Reservoir Simulation \& Modeling..................................................... 14

2.2.2 Top-Down Intelligent Reservoir Modeling as an Alternate/Complement to

Conventional Reservoir Modeling Techniques ............................................................... 15

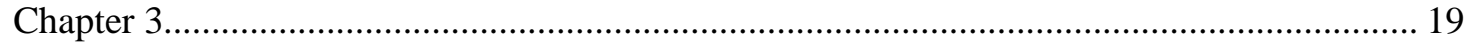

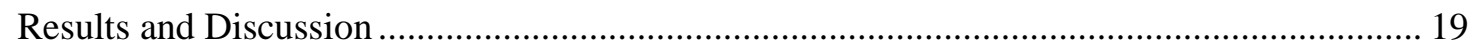

3.1 Sensitivity Analysis on Reservoir and Fracture Properties...................................... 22

3.2 History Matched Model............................................................................................ 26

3.3 Effect of lateral orientation on well productivity....................................................... 28

3.4 Horizontal Lateral Length Effect on Well Productivity ….......................................... 30

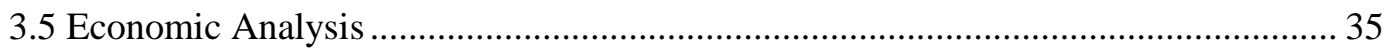

3.6 Data Preparation Procedure for Top-down Modeling ................................................ 37

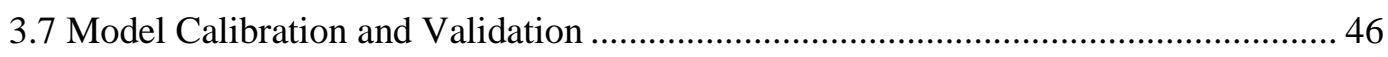

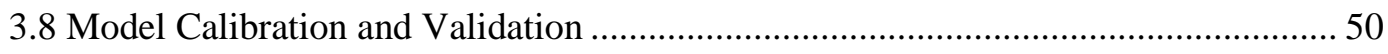

3.9 New Albany Shale Subsurface Modeling-Recently Completed Gas Wells ............... 52

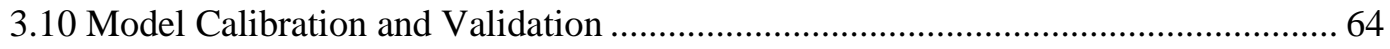




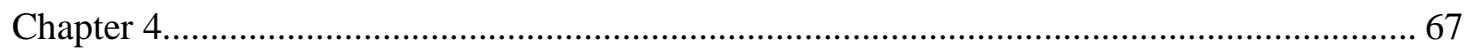

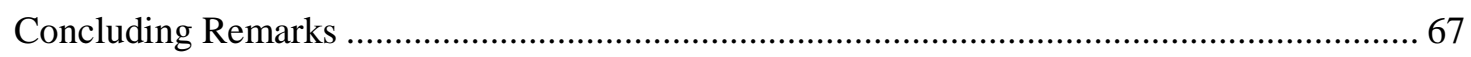

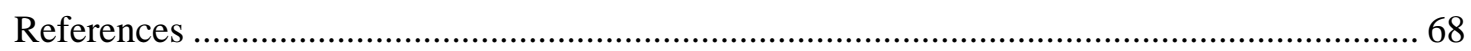

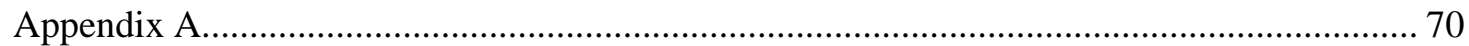




\section{List of Figures}

Figure 1.Gas shale storage and flow capacity diagram showing pore type, flow type, dominant particle motion within a given flow regime.(12)...

Figure 2.Major shale gas basins in the United States with total resource potential of 500 to 1,000 tcf.(13)

Figure 3. New Albany Shale formation throughout the Illinois basin and Under-study area... 10

Figure 4. Conventional Reservoir Simulation \&Modeling-A Bottom-Up Approach............... 15

Figure 5. Top-down Intelligent Reservoir Modeling Workflow ........................................... 16

Figure 6. Integrated workflow for New Albany Shale Reservoir Modeling ............................ 18

Figure 7. Schematic showing outcrop fracture features of the New Albany shale................... 19

Figure 8. Simulation result examples for one history-matched New Albany Shale Gas well .. 21

Figure 9. Sensitivity analysis on initial reservoir pressure

Figure 10. Sensitivity analysis on matrix porosity

Figure 11. Sensitivity analysis on matrix permeability

Figure 12. Sensitivity analysis on pay thickness

Figure 13. Sensitivity analysis on Aperture reduction

Figure 14. Sensitivity analysis - Effect of reservoir and fracture properties variation on initial gas rate factor (Monthly gas production)

Figure 15. Fracture Length Values

Figure 16. Fracture Density Values

Figure 17. Sensitivity analysis results (Monthly gas production)

Figure 18. Sensitivity analysis results (Monthly gas production)

Figure 19. Sensitivity analysis results (Monthly gas production)

Figure 20. Sensitivity analysis results (Monthly gas production) (Medium fracture network density with variable length)(High fracture network density with variable length)................. 25

Figure 21. Sensitivity analysis results (Monthly gas production) .......................................... 26

Figure 22. Single well history matching result, after changing the key ................................. 26

Figure 23. The well and fracture intersection for the history matched model (Based on 320

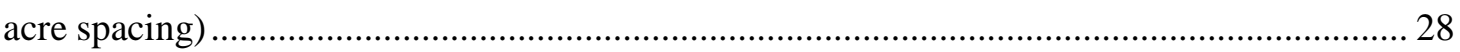

Figure 24. Horizontal well orientations in Y direction (0, 30, 45, 60, and 90 degrees) ........... 29

Figure 25. Single well history matching result-Zero and 30-degree well orientation (From left

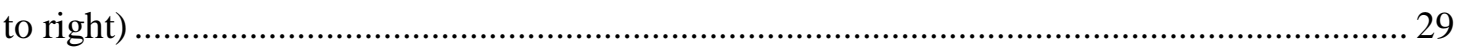

Figure 26.Effect of horizontal lateral length on well productivity from New Albany Shale ... 31

Figure 27.Cumulative gas production as a function of horizontal lateral length for 1, 3,5,10,

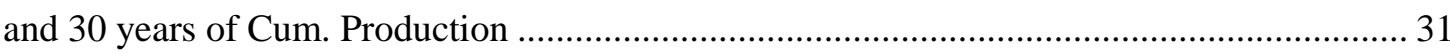

Figure 28. Initial rate as a function of horizontal lateral length............................................ 32

Figure 29.Pressure distribution in the reservoir as a function of time (2nd month and 30th

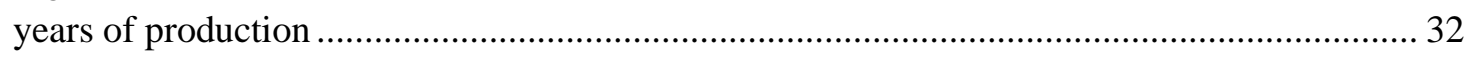


Figure 30.Pressure distribution in the reservoir as a function of time (2nd month and 30th years of production-from left to right) (Green represent the lower pressure and red shows max reservoir pressure)( 5 mile lateral length).

Figure 31.Pressure distribution in the reservoir as a function of time (2nd month and 30th years of production-from left to right) (Green represent the lower pressure and red shows max reservoir pressure)( 7.5 mile lateral length).

Figure 32.Pressure distribution in the reservoir as a function of time (2nd month and 30th years of production-from left to right) (Green represent the lower pressure and red shows max reservoir pressure) (9 mile lateral length).

Figure 33.Pressure distribution in the reservoir as a function of time (2nd month and 30th years of production-from left to right) (Green represent the lower pressure and red shows max reservoir pressure) (12 mile lateral length) 34

Figure 34. Sensitivity analysis on effect of normalized reservoir and fracture properties on normalized initial gas rate. 36

Figure 35.Effect of initial reservoir pressure on NPV

Figure 36.Effect of fracture aperture reduction factor on NPV 36

Figure 37.Effect of horizontal lateral length on NPV

Figure 38.Comparison the effect of different parameters on NPV . 36

Figure 39.NPV profile for different initial reservoir pressure values

Figure 40.NPV profile for different fracture aperture reduction factor values 37

Figure 41.NPV profile for different horizontal lateral length values. 37

Figure 42. Simulation result examples for two history-matched New Albany Shale Gas wells (Out of 87 wells) 38

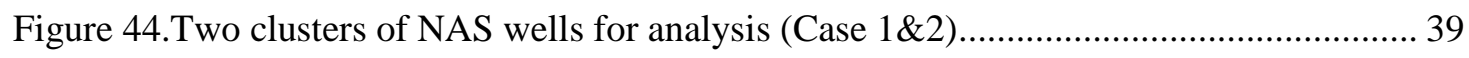

Figure 43. Location of under-study NAS gas wells.

Figure 45. Decline curve analysis sample for one of NAS Figure 46.Type curve matching sample for one of NAS Gas wells

Figure 47.History matching results in comparison with DCA

Figure 48.Generating the Voronoi cells for 55 NAS for one of the wells(Case 1).................. 41

Figure 49. Calculated recovery factor for individual wells as well as field recovery factor .... 41 Figure 50. Results of discrete predictive modeling showing the distribution of matrix porosity, and matrix permeability for the entire field (From left to right)

Figure 51. Results of discrete predictive modeling showing the distribution of total permeability from type curve and initial gas in place for the entire field (From left to right).. 42 Figure 52. Results of Fuzzy Pattern Recognition showing the sweet spots in the field for the

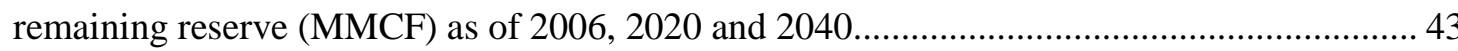

Figure 53. Remaining reserve as a function of time .......................................................... 43

Figure 54. Proposed infill drilling locations and drainage area before and after placement of new wells (From left to right)

Figure 55. Results of Fuzzy Pattern Recognition showing the sweet spots in the field for the remaining reserve (MMCF) as of 2006, 2020 and 2040 (After drilling 6 extra wells) ............ 44

Figure 56. Remaining reserve as a function of time (After drilling 6 extra wells).................. 45

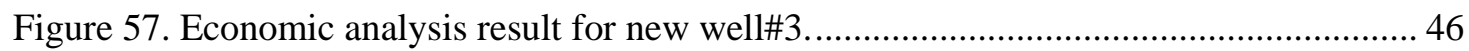


Figure 58. Results of Fuzzy Pattern Recognition showing the sweet spots in the field for the 1 Year cum for 55 wells (left) and 1 Year cum. Production for 49 wells (right).(Case 1) ........... 47

Figure 59. DCA sample for one of NAS Gas wells....................................................50

Figure 60. TCM sample for one NAS Gas wells....................................48

Figure 61. HM results in comparison with DCA

Figure 62. Generating the Voronoi cells for 32 NAS wells (Case 2) .................................... 48

Figure 63. Results of discrete predictive modeling showing the distribution of first 3 months, 5 year cum. Production and fracture half length for the entire field (From left to right)............. 49

Figure 64. Results of Fuzzy Pattern Recognition showing the sweet spots in the field for the first 3 months, 5-year cum. Production, and the fracture half-length (From left to right)........ 49 Figure 65. Results of discrete predictive modeling showing the distribution of total porosity, matrix porosity, and net pay thickness for the entire field (From left to right) ....................... 49 Figure 66. Results of Fuzzy Pattern Recognition showing the sweet spots in the field for the matrix porosity and total permeability from type curve and matrix permeability (From left to

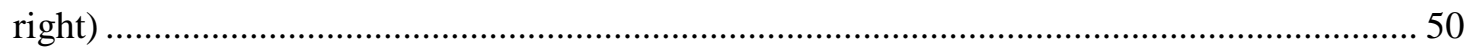

Figure 67. Remaining reserve as a function of time .......................................................... 50

Figure 68. Results of Fuzzy Pattern Recognition showing the sweet spots in the field for the 1 Year cum for 32 wells (left) and 1Year cum. Production for 28 wells (right).(Case 2 ......... 52

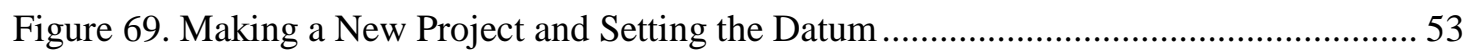

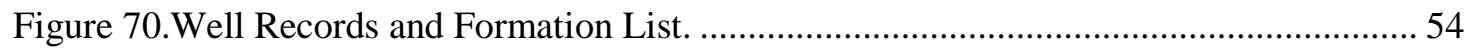

Figure 71.Interpreting the Shale Formations and Gas Effect in Prizm.................................. 54

Figure 72. Four cross sections were created for analyzing the well logs. …........................... 55

Figure 73. Picking the top and bottom of formations in Cross Section D.............................. 55

Figure 74.Picking the top and bottom of formations in Cross Section B. ............................. 56

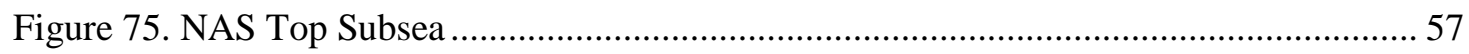

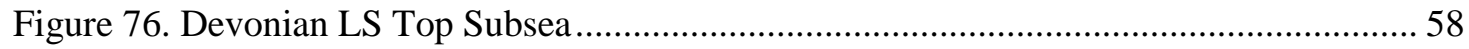

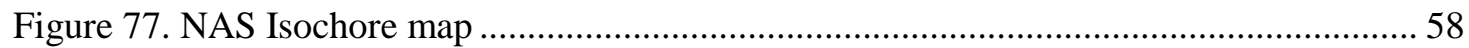

Figure 78.Decline curve analysis sample for one of New Albany

Figure 79.Type curve matching sample for one of New Albany............................................ 59

Figure 80.History matching results

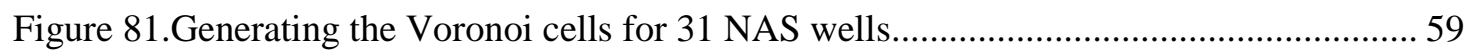

Figure 82.Calculated recovery factor for individual wells as well as field recovery factor ..... 60 Figure 83.Results of discrete predictive modeling in comparison with contour map (Geographix result) showing the distribution of total porosity, and gas saturation for the entire field..... 61

Figure 84.Results of discrete predictive modeling showing the distribution of total permeability from type curve and fracture aperture for the entire field (From left to right) .... 61 Figure 85.Results of Fuzzy Pattern Recognition showing the sweet spots in the field based on initial water saturation in comparison with the Geographix generated contour map. 62 Figure 86.Results of Fuzzy Pattern Recognition showing the sweet spots in the field based on initial reservoir pressure in comparison with the Geographix generated contour map. 62 Figure 87.Results of Fuzzy Pattern Recognition showing the sweet spots in the field based on matrix porosity in comparison with the Geographix generated contour map. 
Figure 88.Results of Fuzzy Pattern Recognition showing the sweet spots in the field for the first 3, 6 and 9 month of Cum.gas production in comparison with the corresponding contour maps from geographix.

Figure 89.Results of Fuzzy Pattern Recognition showing the sweet spots in the field for the

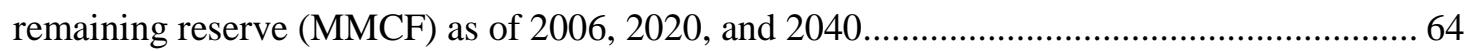
Figure 90. Results of Fuzzy Pattern Recognition showing the sweet spots in the field for the first 3-month cum. production for 31 wells (left) and first 3-month cum. Production for 28 wells (right) 


\section{List of Tables}

Table 1.Distribution of worldwide unconventional gas reservoirs. (2) .................................... 3

Table 2.List of common reservoir attributes used for force ranking gas-shale portfolios .......... 5

Table 3.List of common sources for the reservoir property list of Table2 ................................ 6

Table 4. Fracture network properties (Base model) ............................................................. 20

Table 5. The input variable for single well history matching .................................................. 21

Table 6. Multiple values for fracture length and density ..................................................... 24

Table 7. Shows the input parameters for single well history matching (Best match) .............. 27

Table 8. Fracture network properties (History matched model) ............................................... 27

Table 9. Initial rates based on different well orientation-History matched model ................... 29

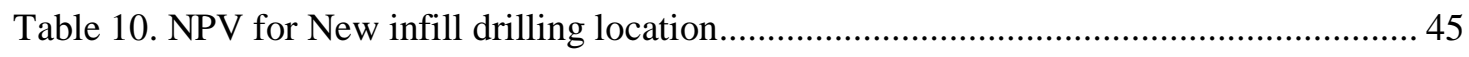

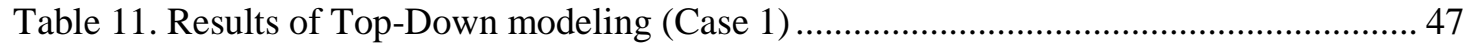

Table 12. Results of Top-Down modeling (Case 2) ............................................................... 51

Table 13.Results of Top-Down modeling- Model Calibration.................................................. 65 


\section{Chapter 1}

\section{Introduction}

\subsection{Unconventional Gas Reservoirs}

Unconventional Gas reservoirs continue to be a fast growing sector within the petroleum industry. These reservoirs include Coal Bed Methane, Shale Gas, and Tight Gas Sands.

Outside of the United States, with a few exceptions, unconventional gas resources have largely been overlooked and understudied. In most of the world, the natural gas industry is focusing on producing gas from conventional reservoirs and has yet to turn its attention to unconventional gas reservoirs. These unconventional gas reservoirs represent a vast, long-term, global source of natural gas and have not been appraised in any systematic way. Unconventional gas resources-including tight sands, coalbed methane, and gas shales_constitute some of the largest components of remaining natural gas resources in the United States. Research and development concerning the geologic controls and production technologies required to evaluate and produce these unconventional gas resources has provided many new technologies during the past several decades. These new technologies have enabled operators in the United States to unlock the vast potential of these challenging resources, boosting production levels to an estimated $30 \%$ of the natural gas production in the United States.

Around the world, unconventional gas resources are widespread, but with several exceptions, they have not received close attention from natural gas operators.This is due in part because geologic and engineering information on unconventional resources is scarce, and natural gas policies and market conditions have been unfavorable for development in many countries. In addition, there is a chronic 
shortage of expertise in the specific technologies needed to develop these resources successfully. As a result, only limited development has taken place to date outside of North America.

Interest is growing, however, and during the last decade development of unconventional gas reservoirs has occurred in Canada, Australia, Mexico, Venezuela, Argentina, Indonesia, China, Russia, Egypt, and Saudi Arabia. Many of those who have estimated the volumes of gas in place within unconventional gas reservoirs agree on one aspect: that it is a large resource. In Table 1, Kawata and Fujita summarized the work of Rogner, who estimated the worldwide unconventional gas resource (1) .Using the United States as an analogy, there is good reason to expect that unconventional gas production will increase significantly around the world in the coming decades for the following reasons:

- A significant number of geologic basins around the world contain unconventional gas reservoirs.

- Rogner estimates that in the world there are around

$\checkmark$ 9,000 Tcf of gas in place in coalbed methane,

$\checkmark$ 16,000 Tcf of gas in place in shale gas, and

$\checkmark \quad 7,400$ Tcf of gas in place in tight gas sands.

- Any reasonable recovery efficiency leads one to the conclusion that there is an ample opportunity in the future to develop unconventional gas worldwide.

- Tight gas sand development in the United States, critical to future U.S. gas supply, has to over 4 Tcf/year and is supported by ongoing technological development.

- The technology developed in the United States over the past 3 to 4 decades will be available for application around the world.

- New technology is rapidly becoming a worldwide commodity through efforts of major service companies.

- The global need for energy, particularly natural gas, will continue to be an incentive for worldwide unconventional gas resource development.

- Tight gas sands, gas shales, and coalbed methane are already critical to North America today and will be an important energy source worldwide during the 21st Century.

Unconventional Reservoir System Definition. Similar to conventional hydrocarbon systems, unconventional gas reservoirs are characterized by complex geological and petrophysical systems as well as heterogeneities — at all scales. However, unlike conventional reservoirs, unconventional gas reservoirs typically have very fine grain rock texture, exhibit gas storage and flow characteristics 
which are uniquely tied to nano-scale pore throat and pore size distribution and possess common organic and clay content that serve as gas sorption sites. The clays and organics impart an anisotropic

Table 1.Distribution of worldwide unconventional gas reservoirs. (2)

\begin{tabular}{|c|c|c|c|c|}
\hline Region & $\begin{array}{l}\text { Coalbed } \\
\text { Methane } \\
\text { (Tcf) }\end{array}$ & $\begin{array}{l}\text { Shale } \\
\text { Gas } \\
\text { (Tcf) }\end{array}$ & $\begin{array}{l}\text { Tight- } \\
\text { Sand } \\
\text { Gas } \\
\text { (Tcf) }\end{array}$ & $\begin{array}{l}\text { Total } \\
\text { (Tcf) }\end{array}$ \\
\hline North America & 3,017 & 3,842 & 1,371 & 8,228 \\
\hline Latin America & 39 & 2,117 & 1,293 & 3,448 \\
\hline Western Europe & 157 & 510 & 353 & 1,019 \\
\hline Central and Eastern Europe & 118 & 39 & 78 & 235 \\
\hline Former Soviet Union & 3,957 & 627 & 901 & 5,485 \\
\hline $\begin{array}{l}\text { Middle East and North } \\
\text { Africa }\end{array}$ & 0 & 2,548 & 823 & 3,370 \\
\hline Sub-Saharan Africa & 39 & 274 & 784 & 1,097 \\
\hline $\begin{array}{l}\text { Centrally planned Asia and } \\
\text { China }\end{array}$ & 1,215 & 3,528 & 353 & 5,094 \\
\hline $\begin{array}{l}\text { Pacific (Organization for } \\
\text { Economic Cooperation and } \\
\text { Development) }\end{array}$ & 470 & 2,313 & 705 & 3,487 \\
\hline Other Asia Pacific & 0 & 314 & 549 & 862 \\
\hline South Asia & 39 & 0 & 196 & 235 \\
\hline World & 9,051 & 16,112 & 7,406 & 32,560 \\
\hline
\end{tabular}

fabric to gas shales which affects their mechanical and transport properties. Gas-shale reservoir pore structures are defined in terms of nanometers to micrometers, whereas most tight gas reservoirs are described at a micrometer or larger scale. Both gas-shale and tight gas systems have free gas stored within the pores of the rock matrix. Gas-shale differs in possessing the characteristic of gas adsorption on surface areas associated with organic content and clay. Bustin et al. (2008)(3) states that the relative importance of adsorbed versus free gas varies as a function of the amount of organic matter present, pore size distribution, mineralogy, digenesis, rock texture and reservoir pressure and temperature. We choose to define unconventional systems simply as those systems, which have a sorbed gas component. This includes gas-shale, coal bed methane and gas hydrates but does not include tight gas sand which is henceforth considered as conventional.

\subsection{Naturally fractured Shale gas Reservoirs}

A Brief History of Gas Shale Assessment. Gas has been produced from shale since the first shalegas well in the organic rich Devonian Dunkirk Shale in New York in 1821. Shallow, low pressure wells first were concentrated in New York and Ohio. By 1935, operators recognized the dual role of 
matrix and fractures in shale systems (Browning 1935 and Lafferty 1935)(4). From 1927-1962, the Columbia Gas System Service Corp (now Chesapeake Energy), drilled tens to hundreds of wells per year into Devonian shales and promoted shale research (5). The interest in characterizing gas-shale systems began in earnest in the 60's when the Bureau of Mines (later to become ERDA, the Energy Research and Development Administration) defined and funded the Eastern Gas Shales Project which began in 1976(6). The objectives of ERDA were to determine the gas reserves potential, provide shale characterization, improve stimulation practices and permeability measurement. Expansion of interest in gas shale outside of the Appalachians began in 1981 with the first Barnett Shale well, drilled in the Fort Worth Basin in northern Texas by Mitchell Energy Corporation(7). Starting in the late 80's and into the early 90's, pioneering work on the measurement of shale properties was sponsored by the Gas Research Institute (GRI) resulting in numerous publications that describe new core analysis methods(8).Since the mid-90's, gas shales have advanced to economic gas play status thanks to a combination of high gas prices, improved shale reservoir characterization and advances in drilling and completion technology and environmental pressures.

Gas-shale Assessment Criteria. Gas-shale well productivity depends upon reservoir quality and successful execution of an effective hydraulic stimulation. Defining the quality of gas-shale reservoirs is based on a broad range of parameters. Most gas-shale operators have developed internal criteria by which to rank their portfolio of gas shale systems. Table 2 is a list of the most common gas shale reservoir attributes used for ranking purposes. The list is in alphabetical order and reflects no priority ranking.

Table 3 is a partial list of common sources for the reservoir property list of Table 2. We can measure reservoir properties from different sources and at multiple scales. The primary measurement sources include core tests, well logs, and pressure test methods (e.g. injection fall off tests). Of the core-based methods for measuring shale pore systems, gas storage capacity, flow capacity and elastic properties, many are borrowed from the coal bed methane and conventional reservoir protocols (9).The American Petroleum Institute (API) has not set any standard of measurement for shale systems such as exists for conventional core testing in the Recommended Practices 40 (API 1998). The result is an evolution of core test methods that differ from lab to lab for any given test type. This work will document some of these inconsistencies in measurement of rock storage, flow capacity, and provide a recommendation for future standards of testing. 
Table 2.List of common reservoir attributes used for force ranking gas-shale portfolios

\begin{tabular}{|c|c|}
\hline Parameter & Desired Result \\
\hline Dehydration Effects (Sw) & $<40 \% \mathrm{Sw}$ \\
\hline Depth & Shallowest Depth in Dry gas Window \\
\hline Fracture Fabric and Type & Vertical vs. horizontal orientation \\
\hline & Open vs. Filled with silica or calcite \\
\hline Gas Composition & low $\mathrm{CO} 2, \mathrm{~N}$, and $\mathrm{H} 2 \mathrm{~S}$ \\
\hline Gas-Filled Porosity (Bulk volume gas) & $>2 \%$ Gas Filled Porosity \\
\hline Gas type (biogenic, thermogenic, or mixed) & Thermogenic \\
\hline Internal Vertical Heterogeneity & Less is better \\
\hline \multirow[t]{4}{*}{ Mineralogy } & $>40 \%$ Quartz or Carbonates \\
\hline & $<30 \%$ Clays \\
\hline & Low expandablilty \\
\hline & Biogenic vs. detrital silica \\
\hline OGIP (free and sorbed) & $>100 \mathrm{BCF} /$ section \\
\hline Permeability & > 100 nanoDacry \\
\hline Poisson's Ratio (static) & $<0.25$ \\
\hline Pressure & $>0.5 \mathrm{psi} / \mathrm{ft}$ \\
\hline Reservoir Temperature & $>230 \mathrm{~F}$ \\
\hline Seals & Fracture Barriers Present Top and Base \\
\hline Shows & High gas Readings-Production \\
\hline Stress & $<2000$ psia Net Lateral Stress \\
\hline Thermal Maturity & Dry gas window $>1.4$ Ro \\
\hline Thickness & $>30 \mathrm{~m}$ \\
\hline Total Organic Content (and Type) & $>2 \%$ \\
\hline Wettability & Oil prone wetting of kerogen \\
\hline Young's Modulus & > 3.0 MMPSIA \\
\hline
\end{tabular}


Table 3.List of common sources for the reservoir property list of Table2.

\begin{tabular}{|c|c|}
\hline Reservoir Property Data Source & Reservoir Property Data Source \\
\hline Elastic Properties & $\begin{array}{l}\text { DSI (dynamic), Core-based } \\
\text { compressiontest (static) }\end{array}$ \\
\hline Fluid Properties & $\begin{array}{l}\text { Mud log, PVT, PDA, pressure } \\
\text { gradients }\end{array}$ \\
\hline Fracture and Closure Stress & IFOT, Frac job, log-based (DSI) \\
\hline Free \& Sorbed Gas & $\begin{array}{l}\text { Canister desorption \& Langmuir } \\
\text { Adsorption }\end{array}$ \\
\hline Maturity & Visual Ro, maserals, RockEval (calc) \\
\hline Permeability & $\begin{array}{l}\text { SS \& USS, IFOT, MICP, PDA, \& NMR } \\
\text { (calc) }\end{array}$ \\
\hline Pore Pressure & IFOT, PDA, log-based, “dip-in” \\
\hline Porosity & Gas expansion, MICP, NMR, \& logbased \\
\hline Rock Composition & $\begin{array}{l}\text { XRD, TS point counts, FTIR, ICP-MS, } \\
\text { EDAS (SEM) }\end{array}$ \\
\hline Temperature & OHL \& PL, frac job, \& IFOT \\
\hline TOC & Leco TOC \& RockEval (calc) \\
\hline Water Saturation & Core extraction, Pc, \& log-based \\
\hline
\end{tabular}

Gas Storage and Flow Regime Model. Shale gas storage and flow are controlled by the network of pores ranging in size from micrometers (10-6 m) to $\AA$ (10-10 m). Gas is stored as free compressed gas in the open pores and cracks, as adsorbed gas on the surfaces of kerogen and clay and as diffuse gas stored within the solid organic matter. Flow from larger connected pores and throats generally follow the Darcy equation and are referred to as continuum or no slip flow. When we consider gas flow in nanopores, both non-continuum effects (gas slippage) and surface interactive forces (diffusion) dominate. Javadpour et. al. 2007(10) and Javadpour 2009(11) present shale gas storage and flow schematics of gas evolution and production at different length scales. Figure 1 is another schematic of shale gas storage and flow capacity describing the range of pore types, flow type, the expected 
particle motion associated with each flow type and the Knudsen flow regime boundaries for each. The scale is relative but the inferred range is from angstroms to micrometers.

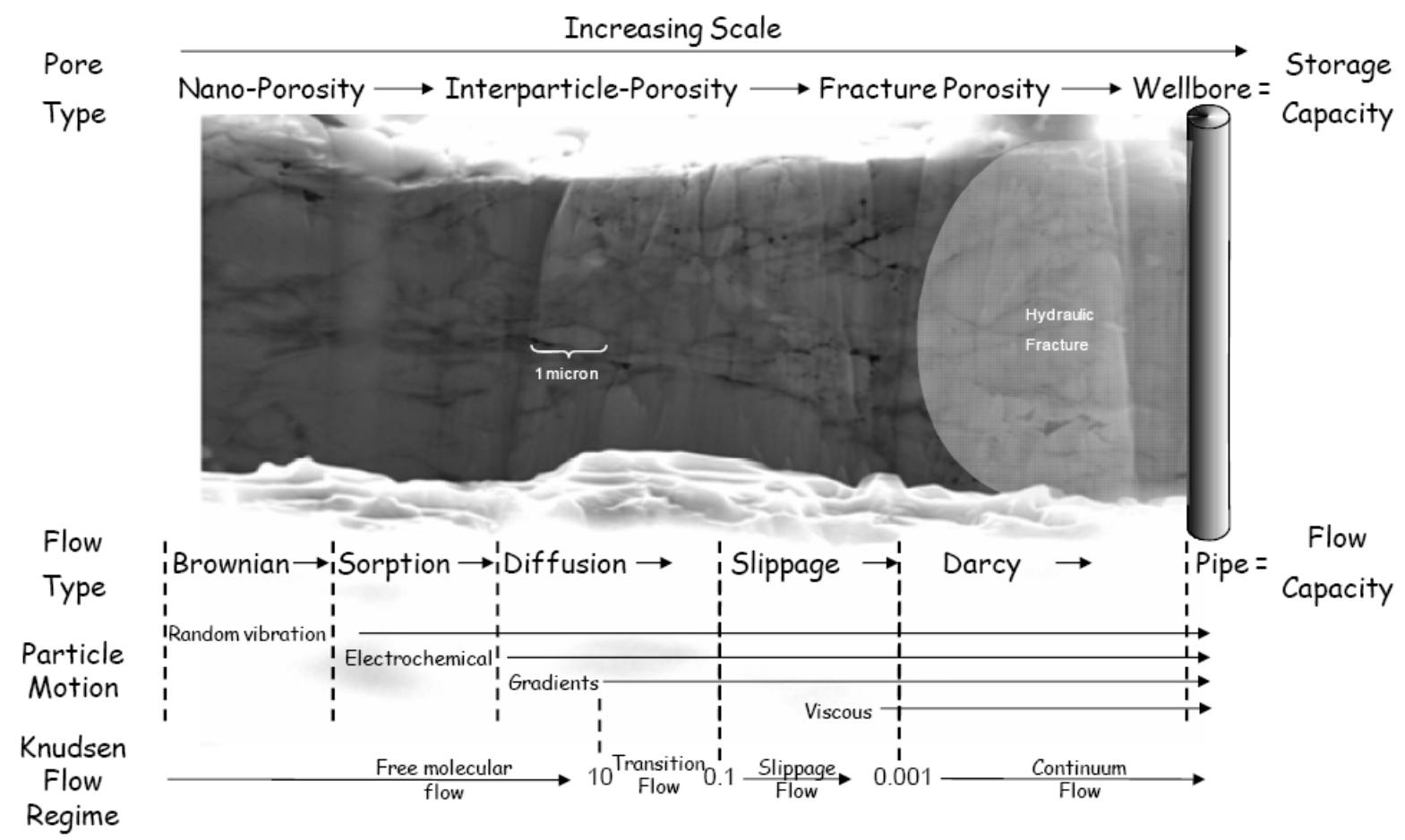

Figure 1.Gas shale storage and flow capacity diagram showing pore type, flow type, dominant particle motion within a given flow regime.(12)

Although it is difficult to extract, most shale gas is fairly clean and dry. That is because over time, there has been enough heat in the reservoir rock to break down any liquid hydrocarbons. The relative amounts of oil and gas contained in shale are one indication of how much heat has been in the reservoir, and for how long. Thermally mature shales have had enough heat and pressure to produce hydrocarbons. The most thermally mature shales will contain only dry gas. Less mature shales will have wetter gas, and the least thermally mature shales may contain only oil. In rare cases, the produced methane may have small percentages of carbon dioxide, nitrogen, ethane, and even propane. Carbon dioxide is more commonly found in biogenic gas shales.

Gas shale reservoirs in the United States tend to be found within three depth ranges between 250 and 8,000 ft. The New Albany and Antrim shales, for example, have some 9,000 wells in the range of 250 to 2,000 ft. In the Appalachian basin shales and the Devonian and Lewis shales, there are about 20,000 wells from 3,000 to 5,000 ft. Although the Barnett and Woodford shales are much deeper, the Caney and Fayetteville shales are from 2,000 ft to 6,000 ft, with most of the reservoirs between 2,500 and 4,500 ft. A good shale gas prospect has a shale thickness between 300 and $600 \mathrm{ft}$. 
Shale has such low permeability that it releases gas very slowly, which is why shale is the last major source of natural gas to be developed.

The good news is that shale can hold an enormous amount of natural gas. The most prolific shales are relatively flat, thick, and predictable, and the formations are so large that their wells will continue producing gas at a steady rate for decades.

Currently Producing Gas Shale Reservoirs-The Barnett Shale in the Fort Worth basin of North Central Texas is by far the most active shale gas play in the United States. The reservoir ranges from $100 \mathrm{ft}$ to more than 1,000 ft in gross thickness and holds from $50 \times 109 \mathrm{ft} 3$ (50 bcf) to $200 \mathrm{bcf}$ of gas per square mile. The Gas Technology Institute estimates that organic shale reservoirs in the United States contain up to 780 trillion $(780 \times 1012) \mathrm{ft} 3$ of gas. Equally, gas-rich organic shales almost certainly exist elsewhere around the world, but so far, the United States is the only country with a large shale gas industry.

Thomas Jefferson was still alive when the first commercial shale gas well was drilled in 1821. True, it was only $27 \mathrm{ft}$ deep into the Devonian Dunkirk shale, but residents of the nearby village of Fredonia, New York, were happy to use the gas to illuminate their homes. Until recently, however, shale has been seen as only a source rock or seal for oil and gas. Gas shale reservoirs were not considered significant or producible. Supply and demand has always driven the oil and gas business, so natural gas did not become an important commodity until after World War II. Figure 2 shows the main shale gas reservoirs in US.

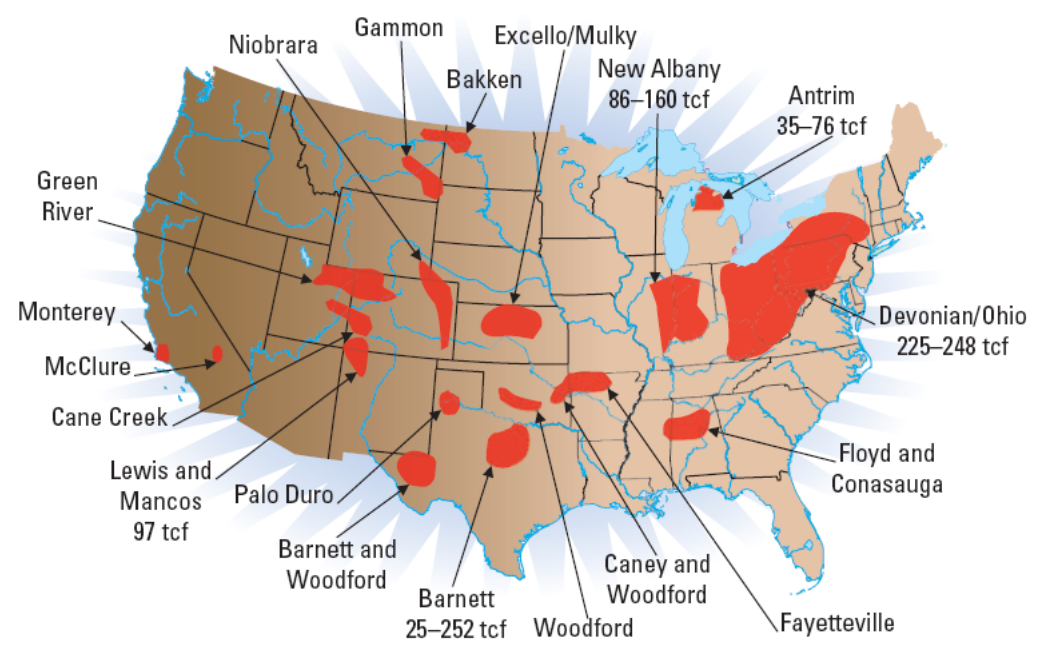

Figure 2.Major shale gas basins in the United States with total resource potential of 500 to 1,000 tcf.(13) 
Shale gas wells are not hard to drill, but they are difficult to complete. In almost every case, the rock around the wellbore must be hydraulically fractured before the well can produce significant amounts of gas. Fracturing involves isolating sections of the well in the producing zone, then pumping fluids and proppant (grains of sand or other material used to hold the cracks open) down the wellbore through perforations in the casing and out into the shale. The pumped fluid, under pressures up to $8,000 \mathrm{psi}$, is enough to crack shale as much as 3,000 $\mathrm{ft}$ in each direction from the wellbore. In the deeper high-pressure shales, operators pump slickwater (a low-viscosity waterbased fluid) and proppant. Nitrogen-foamed fracturing fluids are commonly pumped on shallower shales and shales with low reservoir pressures.

Fractures are the key to good production. The more fractures in the shale around the wellbore, the faster the gas will be produced. Because of shale's extremely low permeability, the best fracture treatments are those that expose as much of the shale as possible to the pressure drop that allows the gas to flow. The natural formation pressure of a large gas shale reservoir will decline only slightly over decades of production. Any pressure drop on individual wells is likely the result of fractures closing up, rather than depletion of the reservoir. The key to good shale gas production over time is having the proper distribution and placement of proppant to keep the fractures open.

Economics of Shale Gas-There are fundamental differences in the production of gas from shale and gas produced from other unconventional sources. Many tight gas sands, for example, yield a tremendous amount of gas for the first few months, but then production declines significantly and often becomes uneconomical after a relatively short time.

Shale gas is completely different. Shale gas wells do not come on as strong as tight gas, but once the production stabilizes, they will produce consistently for 30 years or more. Suppose that new horizontal wells in a typical shale gas play produce 1 million $\mathrm{ft} 3$ per day ( $1 \mathrm{MMcf} / \mathrm{d})$. If the operator puts 10 such wells on 1 square mile, that section will produce $10 \mathrm{MMcf} / \mathrm{d}$. With an estimated $120 \mathrm{bcf}$ of gas per square mile in the ground, these gas shale reservoirs will be producing gas for a very long time. That realization, plus increasingly effective horizontal drilling tools, 3D seismic imaging, and advanced reservoir modeling software, has many people looking at shale gas as an important new resource.

The price of gas is linked to oil and based on each fuel's heating value. The ratio is about 6 to 1 . In other words, $1 \mathrm{bbl}$ of oil contains about 6 times more heat energy than 1,000 ft3 of gas. If a barrel of oil sells for USD 50.00, then 1,000 ft3 of gas is worth about USD 8.00. As long as oil prices remain 
high, there is no reason for natural gas prices to go down. Although gas is abundant in much of the world, it is expensive and potentially dangerous to transport internationally.

\subsection{New Albany Shale Formation}

The name New Albany Black Slate was originally proposed by Borden (1874) for brownish-black shale exposed along the Ohio River at New Albany, Floyd County, Indiana. This unit is currently designated the New Albany Shale. The New Albany consists of brownish-black, organic-rich and greenish-gray, organic-poor shale and is present in the subsurface throughout much of the Illinois Basin. The New Albany Shale formation occurs in Illinois, Indiana, and Kentucky, but to date gas production has been primarily from western Indiana and southwest Kentucky.

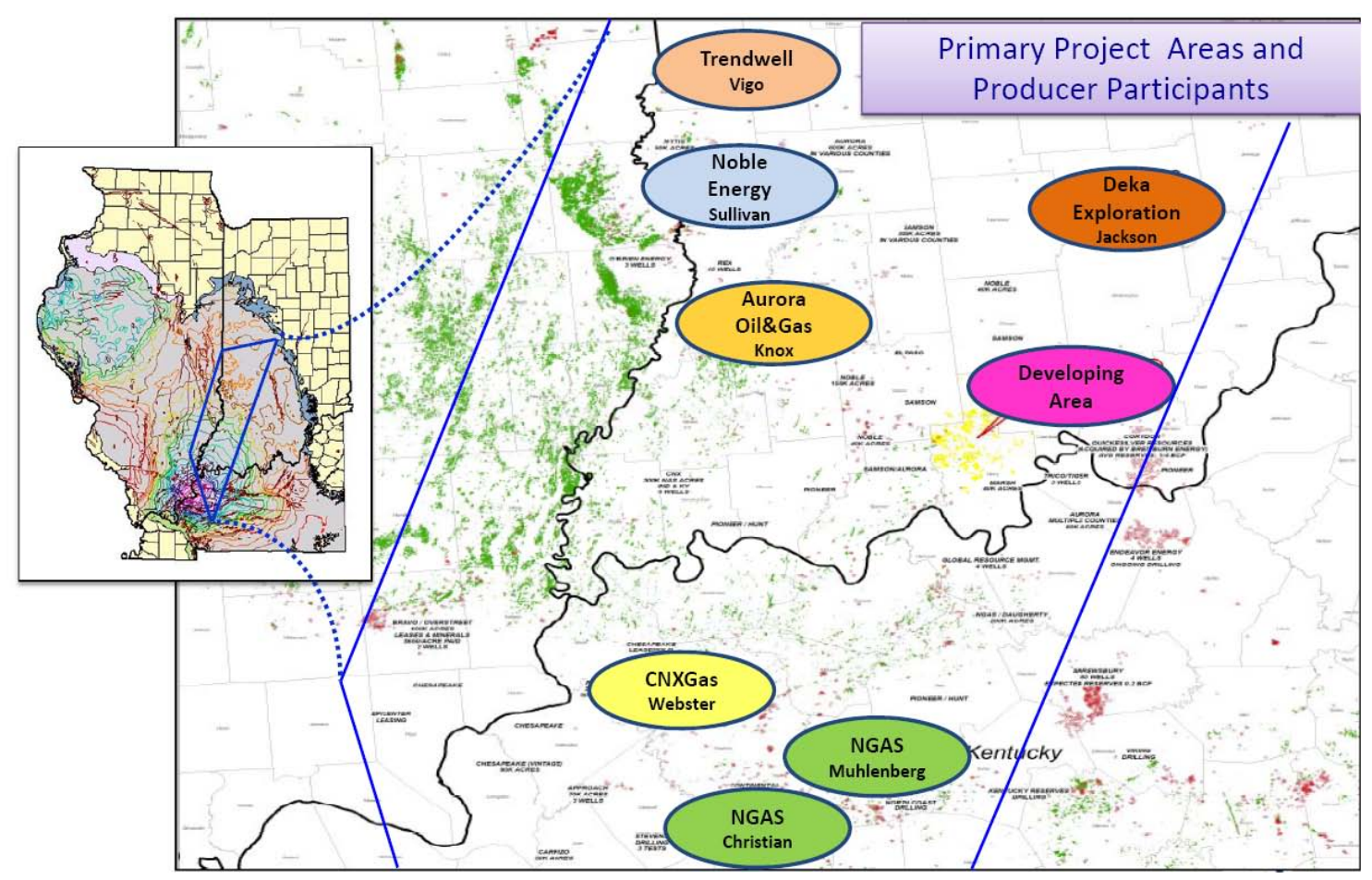

Figure 3. New Albany Shale formation throughout the Illinois basin and Under-study area.(14)

The elevation of the top of the New Albany ranges from about 750 feet above sea level near the outcrop to more than 4,500 feet below sea level in southeastern Illinois (Hamilton County). Unlike many other shale plays, the New Albany Shale in the Illinois Basin has a continuous 100-foot thick pay zone of shale, capped by very thick, dense, gray-green shale (Borden Shale). Prior to 1994, over 
600 New Albany Shale wells had been produced commercially in the Illinois Basin. Vertical fractures in the shale fed the gas flow at the top of the shale.

Porosity of the New Albany Shale in a core from Christian County, Kentucky, varies from 0.5 to 3.1 percent, averaging 1.8 percent. Porosity of the New Albany Shale in a core from Sullivan County, Indiana, varies from 0.6 to 9.3 percent, averaging 4.0 percent (Kalyoncu and others, 1979). Matrix permeability values in a core of the New Albany Shale from Clark County, Indiana, varied from2.5e $\mathrm{e}^{-6}$ to 1.9 millidarcies and had a geometric average of $1.4 \mathrm{e}^{-3}$ millidarcies (Zielinski and Moteff, 1980).

The New Albany Shale is affected by complex faulting in Western Kentucky and adjacent parts of Illinois and Indiana. Elsewhere, less intense deformation has locally produced folds and faults that influence its elevation and thickness.(15)

Natural fracturing is essential for effective reservoir permeability. In fields where detailed studies have been undertaken, fracturing appears to be related to structures such as faults, flexures, and local or regional carbonate buildups over which the shale is draped and compacted.

The dark-colored shale layers typically have parallel laminae, more than 2.5 weight percent organic carbon, amorphous (Type II) kerogen, high radioactivity, and high concentrations of natural gas released from cores. The lighter-colored shale layers commonly have bioturbated fabric, 1 to 2 weight percent organic carbon, humic (Type III) kerogen, moderate radioactivity, and lower concentrations of natural gas released from cores.(15)

The New Albany Shale in the Illinois Basin has promising gas production potential because of its high estimated gas content (86 TCF) and long history of production. Gas-in-place (GIP) measures from $8 \mathrm{bcfg} / \mathrm{square}$ mile to 20 or more bcfg/square mile, depending on locations and depths.

Gas has been produced from the New Albany Shale since 1858, from at least 40 fields in Kentucky, 19 in Indiana, and 1 in Illinois. Production data are not publicly available, and none have been disclosed by operators to date. Only IP data are generally available. Measured IP values for New Albany Shale wells range from less than 10 to 4,500 MCFGPD and average 187 MCFGPD.

Gas production is developed mainly in relatively organic rich shale beds of the Grassy Creek (Shale), Clegg Creek, and Blocher (Shale) Members. The limited evidence that production, where known, comes from the most organic-rich shale beds suggests that the gas produced from the New Albany is indigenous.

New Albany Shale gas is predominantly methane with significant and variable amounts of heavier hydrocarbons. Oil is occasionally produced in small amounts from the New Albany and the 
stratigraphically equivalent Chattanooga Shale in south-central Kentucky. Water generally is not produced in Kentucky, but is co-produced with gas in Indiana and along the Indiana and Kentucky border.(15)

The New Albany Shale reservoir contains natural gas both as free gas in open pore space, and as adsorbed gas on interior clay and kerogen surfaces. Analyses of New Albany Shale core samples from Sangamon, Effingham, and Tazewell Counties, Illinois, and from Christian County, Kentucky, indicate that between 30 and 80 percent of the methane in the shale was adsorbed gas, with the fraction of adsorbed gas showing a strong dependence on pressure.

Commercial production of gas from the New Albany Shale requires well stimulation that interconnects the well bore with the natural fracture system. Effective stimulation maintains permeability by introducing a proppant into the pressure-sensitive fractures near the well bore. Current stimulations are hydraulic-fracture treatments using nitrogen foam with a proppant; these treatments have replaced the older gelatinated nitroglycerine explosive shots.

The amount of organic carbon in the New Albany Shale is quite variable, ranging from near 0 weight percent in greenish-gray beds to 25 weight percent in brownish-black organic-rich beds; 86 percent of the samples analyzed by Frost (1980)(16) contain more than 1.0 weight percent organic carbon and 97 percent contain more than 0.5 weight percent organic carbon. More than 90 percent of the organic matter is amorphous; the remainder is composed of vitrinite, liptinite, and inertinite. Rock-Eval ${ }^{\circledR}$ data indicate that the New Albany Shale contains mostly Type II kerogen that still has substantial oil- and gas-generating potential.

The inorganic portion of the New Albany Shale is relatively uniform in composition, except for the carbonate and pyrite content, which are variable. The mineralogy and inorganic chemistry vary stratigraphically from bed to bed, but they are typically uniform within a given bed. (15)

Criteria that operators may use to identify areas where the New Albany Shale is likely to have the greatest gas-production potential are the presence of: (1) high organic-carbon content in the shale (2) thick organic-rich shale intervals (3) high radioactivity on the gamma-ray log and low density on the density log, which are generally indicative of organic-rich intervals, (4) natural fractures in the shale, (5) structural features where associated fracturing is likely, (6) proximity to historic production.

In general, deterrent to gas exploration and development in the New Albany Shale that need to be overcome include: (1) absence of current exploration and production activity, (2) inadequate gas pipeline infrastructure, (3) lack of gas production data, and (4) large tracts of acreage leased by coal companies. 


\section{Chapter 2}

\section{Methodology}

\subsection{New Albany Shale Natural Fracture Network Modeling and Simulation}

The modeling of fluid flow through fractured formations can be based on deterministic, stochastic or fractal formulations of flow paths and matrix volumes. Deterministic models, however, are generally unable to effectively describe many naturally fractured formations with respect to the distributions of flow path length, flow path connectivity, and matrix block size and shape. (17)

$\mathrm{NFFLOW}^{\mathrm{TM}}$ is a numerical model for naturally fractured gas reservoirs (Developed by NETL/DOE) that permits the modeling of irregular flow paths mimicking the complex system of interconnected natural fractures in such reservoirs. This type of natural fracture reservoir simulation permits a more accurate and realistic representation of fractured porous media when modeling fluid flow compared to the traditional deterministic formulations. The NFFLOW ${ }^{\mathrm{TM}}$ simulator is a single-phase (dry-gas), two-dimensional numerical model that solves fluid flow equations in the matrix and fracture domains sequentially for wells located in a bounded naturally fractured reservoir. The mathematical model “decouples" fluid flow in fractures and matrix, and solves a one-dimensional unsteady state flow problem in the matrix domain to compute the volumetric flow rates from matrix into fractures and wellbores.(18)

FRACGEN $^{\mathrm{TM}}$, the fracture network generator (Developed by NETL/DOE), implements four Boolean models of increasing complexity through a Monte Carlo process that samples fitted statistical distributions for various network attributes of each fracture set. Three models account for hierarchical 
relations among fracture sets, and two generate fracture swarming. Termination/intersection frequencies may be controlled implicitly or explicitly.

In this study, FRACGEN/NFFLOW is being used to model gas production from New Albany shale.

\subsection{Top-Down Intelligent Reservoir Modeling of New Albany Shale}

\subsubsection{Traditional Reservoir Simulation \& Modeling}

Reservoir simulation is the industry standard tool to understand the reservoir behavior and predict future performance. It is used in all phases of field development in the oil and gas industry. In order to predict reservoir performance, a series of models of reservoir process are constructed which yield information about the complex phenomena accompanying different recovery methods.

Full field reservoir simulation models which has been built by integration of static and dynamic measurements into the reservoir model have become the major source of information for analysis, prediction and decision making. Traditional reservoir simulation and modeling is a bottom-up approach that starts with building a geo-cellular model of the reservoir. Using modeling and geostatistical manipulation of the data the geo-cellular model is populated with the best available petrophysical and geophysical information at the time of development. Engineering fluid flow principles are then added and solved numerically in order to generate a dynamic reservoir model. Figure 4 shows the Conventional reservoir simulation workflow (A bottom-up approach).

Usually, the full field model is calibrated using historic pressure and production data in a process referred to as "history matching." Once the full field subsurface reservoir model has been successfully calibrated, it is used to predict future reservoir production under a series of potential scenarios, such as drilling new wells, injecting various fluids or stimulation.

For economical and technical point of view, building a complex geological model, which serves as the foundation of the reservoir simulation model, needs a significant investment (time and money).On the other hand, the history matching process itself can be very time consuming and frustrating. This is due to uncertainty about the reservoir, and the fact that a history match can usually be achieved through various configurations - a set of unique and distinctly different simulation models (which all condition to input data) can produce the same history match. How do we know which one is correct? (19) 
Despite aforementioned issues, conventional reservoir simulation and modeling is a well understood technology that usually works well in the hand of an experienced team of engineers and geoscientists.

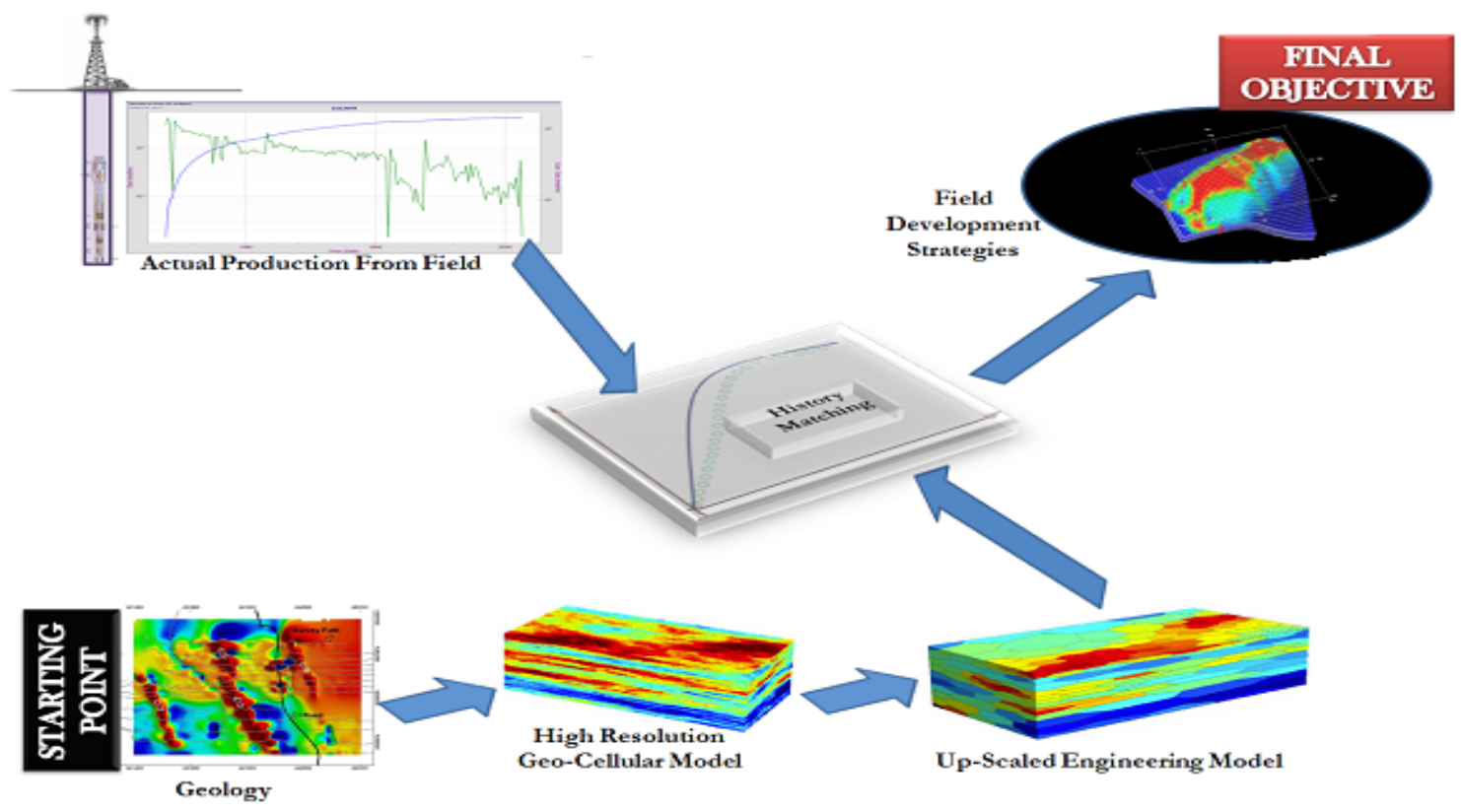

Figure 4. Conventional Reservoir Simulation \&Modeling-A Bottom-Up Approach

\subsubsection{Top-Down Intelligent Reservoir Modeling as an Alternate/Complement to Conventional Reservoir Modeling Techniques}

Top-Down modeling can be used as an alternative for short-term reservoir modeling and/or as a complementary method for long term, reservoir behavior modeling.

Top-Down Intelligent Reservoir Modeling approaches the reservoir simulation and modeling from reverse standpoint by attempting to make an insight into reservoir by starting with actual field measurements (well production history). The production history is augmented by core, log, well test, and seismic data in order to increase the accuracy of the Top-Down modeling technique. Although not intended as a substitute for the conventional reservoir simulation of large, complex fields, this unique approach to reservoir modeling can be used as an alternative (at a fraction of the cost) to traditional reservoir simulation and modeling in cases where performing conventional modeling is cost and man-power prohibitive specially for independent producer of mature fields. In cases where a conventional model of a reservoir already exists, Top-Down modeling should be considered a compliment to the conventional technique, to provide an independent look at the data coming from the reservoir/wells for optimum development strategy and recovery enhancement. 
Top-Down Intelligent Reservoir Modeling starts with well-known reservoir engineering techniques such as Decline Curve Analysis, Type Curve Matching, and History Matching using single well numerical reservoir simulation, Volumetric Reserve Estimation, and calculation of Recovery Factors. Using statistical techniques, multiple Production Indicators (First 3, 6, and 9 month cumulative production as well as 1, 3, 5, and 10-year cumulative oil, gas and water production and Gas Oil Ratio and Water Cut) are calculated. These analyses and statistics generate a large volume of data and information that are spatio-temporal snap shots of reservoir behavior. This large volume of data is processed using the state-of-the-art in artificial intelligence and data mining (neural modeling(20), genetic optimization(21), and fuzzy pattern recognition(22)) in order to generate a complete and cohesive model of the entire reservoir. This is accomplished by using a set of discrete modeling techniques to generate production related predictive models of well behavior, followed by intelligent models that integrate the discrete models into a cohesive picture and model of the reservoir as a whole, using a continuous fuzzy pattern recognition algorithm.

The Top-Down Intelligent Reservoir Model is calibrated using the most recent set of wells that have been drilled in the field. The calibrated model is then used for field development strategies and reservoir management to improve and enhance hydrocarbon recovery. Figure 5 shows the Top down intelligent reservoir modeling workflow.
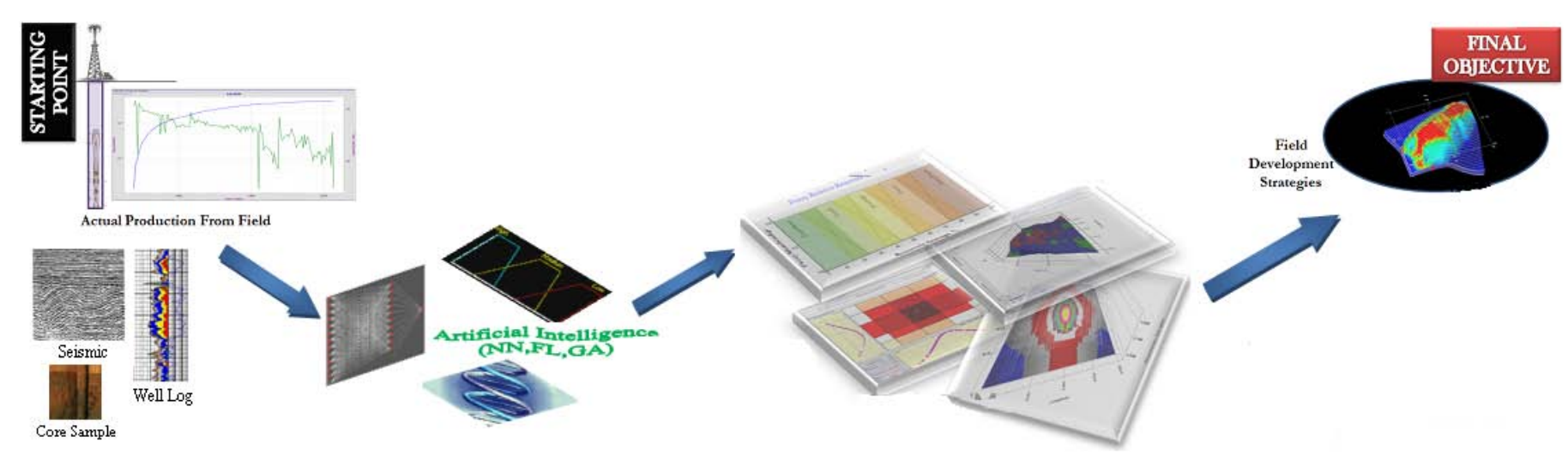

Figure 5. Top-down Intelligent Reservoir Modeling Workflow

\subsubsection{Top-Down Modeling Methodology-Conceptual Approach}

Top-Down Modeling is a well-designed integration of state-of-the-art in Artificial Intelligence \& Data Mining (AI\&DM) with solid reservoir engineering techniques and principles. It provides a unique perspective of the field and the reservoir using actual measurements. It provides qualitatively accurate reservoir characteristics that can play a key role in making important and strategic field 
development decisions. A brief summary of several components of this approach to reservoir modeling and management has been followed:

1. Decline Curve Analysis: Conventional hyperbolic decline curve analysis is performed on oil, gas and water production data of all the wells. Intelligent Decline Curve Analysis is used to model some production data such as GOR and Water Cut that does not usually exhibit a positive but rather a negative decline.

2. Type Curve Matching: Using the appropriate type curves, production data from all wells are analyzed. Special techniques are used to remove the inherent subjectivity associated with type curve matching process.

3. History Matching: History matching is performed on all individual wells using a single well radial numerical simulation model.

4. Production Statistics: General statistics are generated based on the available production data such as 3, 6, 9 months cumulative production and one, three, five and ten years cumulative productions. Similar data is generated for Gas Oil Ratio and water cut.

5. Volumetric Reserve Estimation: Using Voronoi graph theory in conjunction with well logs, estimated ultimate drainage area and volumetric reserves are estimated for each well, individually.

6. Recovery Factor Calculation: Using the results of Decline Curve analysis and Volumetric Reserve Estimation, a well-based Recovery Factor is calculated for all wells, individually. A field-wide Recovery Factor is also calculated. This would be an item that will be optimized in the consequent steps of the analysis.

7. Discrete Predictive Modeling: Results of the abovementioned analyses are a wealth of data and information that are generated based on individual wells. This information is indicative of reservoir/well behavior at specific time and space throughout the life of the reservoir. Using AI\&DM techniques discrete, intelligent, predictive models are developed based on the large amount of data and information that has been generated. The predictive models represent all aspects of reservoir characteristics that have been analyzed. 
8. Continuous Predictive Modeling: Using two-dimensional Fuzzy Pattern Recognition (FPR) technology, discrete predictive models are fused into a cohesive full-field reservoir model that is capable of providing a tool for integrated reservoir management.

9. Model Calibration: The full field model is calibrated based on classifying the reservoir into "most" to "least” prolific areas, prior to be used in the predictive mode. This is done using the latest drilled wells in the field. This practice is an analogy of history matching of the conventional reservoir simulation models. The calibrated model can then be used in predictive mode for field development strategies.

10. Field Development Strategies: Performing economic analysis, while taking into account the uncertainties associated with decision making, multiple field development strategies are examined in order to identify the optimum set of operations that would result in recovery enhancement. This process includes identification of remaining reserves, sweet spots for infill drilling as well as under-performer wells.

Figure 6 represent the general integrated workflow and steps that have been taken to model New Albany Shale reservoir in Western Kentucky.

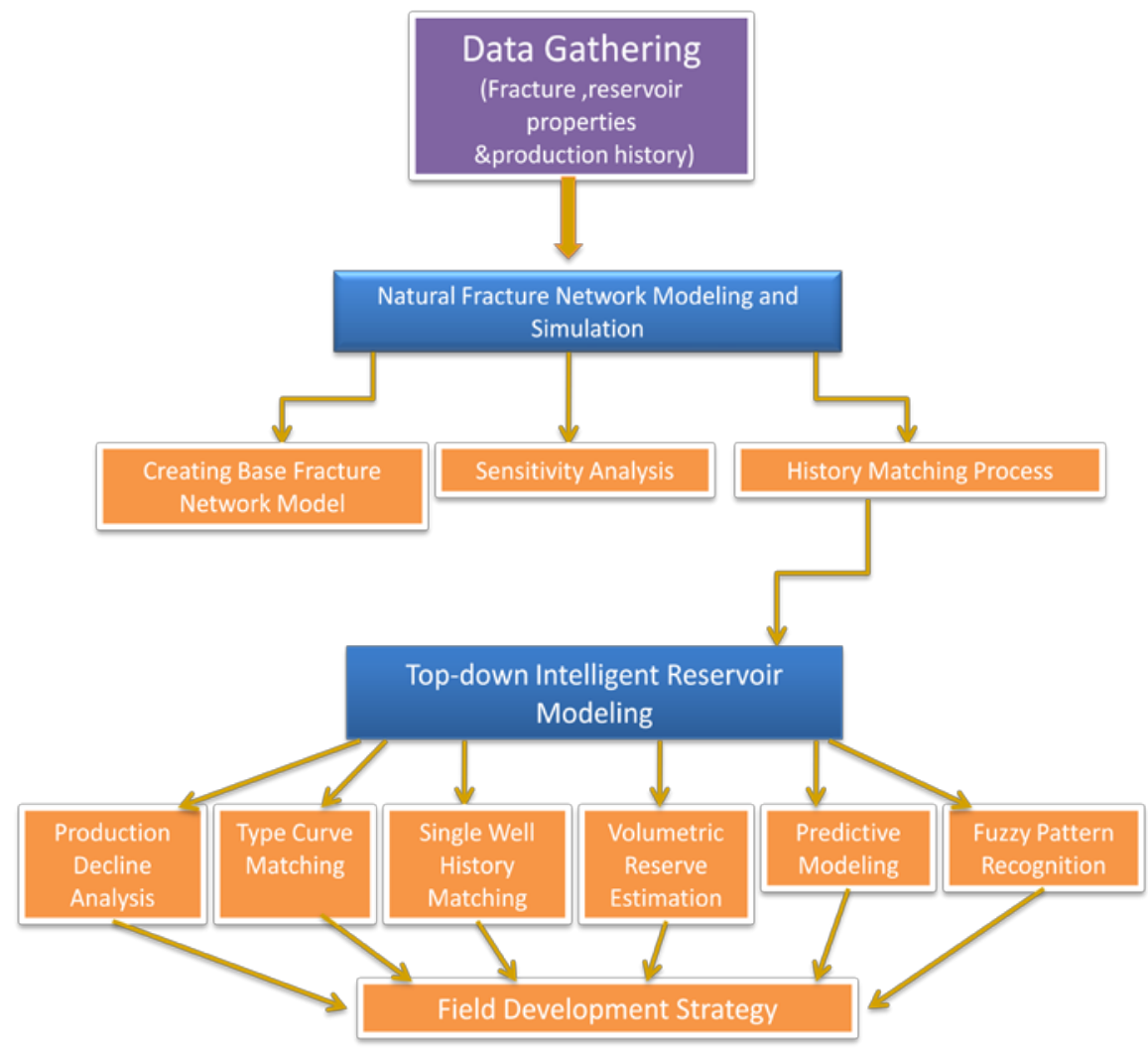

Figure 6. Integrated workflow for New Albany Shale Reservoir Modeling 


\section{Chapter 3}

\section{Results and Discussion}

New Albany shale reservoir contains high-angled (vertical or nearly so) orthogonal natural fractures with non-uniform spacing that are open to unimpeded flow. The predominant fracture system is oriented east-west with spacing between joints estimated to average five feet based on outcrop studies (Figure 7) and production simulations. Based on this information, it was concluded that increases in performance could be achieved with a horizontally drilled well compared to a vertically drilled well in the same reservoir.

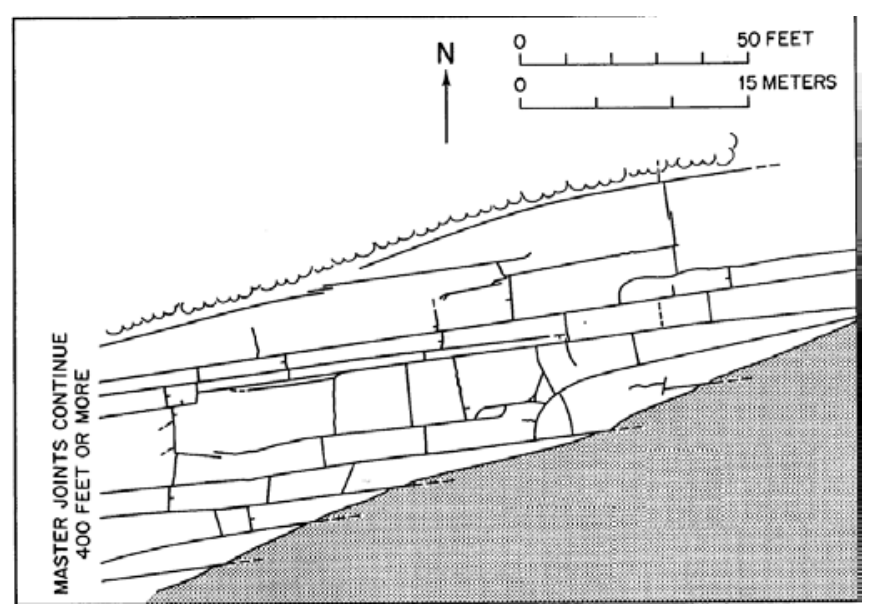

Figure 7. Schematic showing outcrop fracture features of the New Albany shale (23)

Fractures in a core of the New Albany Shale from the Energy Resources of Indiana No. 1 Phegley Farms Inc. well in Sullivan County, Indiana, were described by Kalyoncu and others (1979)(17)Twenty-one fractures were described over an interval of 104 feet. They were mainly vertical, but some had dips as low as 80 degrees. The strike of the fractures was predominantly northwest-southeast and a small secondary mode trended slightly to the north of east-west.(24)

Joint orientations in outcrops of the New Albany Shale in Indiana are parallel to this secondary eastwest trend of fractures in the Phegley Farms core. (10)Fractures in a core of the New Albany Shale 
from the Orbit No. 1 Clark well in Christian County, Kentucky, were described by Miller and Johnson (1979)(9). Natural fractures were regular planar sub vertical features striking northwestsoutheast. They generally were filled with calcite, or less commonly with pyrite, and had apertures as great as 3.0 millimeters $(0.0098 \mathrm{ft})$. In the vertical plane, these fractures were commonly continuous for 1 or 2 feet, succeeded by sub parallel fractures offset from each other at their terminations.(24)

There is a decrease in fracture from the top of the New Albany shale to the lower members. The Clegg Creek member is clearly contains the most fractures, both natural and induced. The Blocher member typically shows half the number of natural fractures when compared to the clegg creek. Therefore the Clegg Creek member contains the most natural fractures with fracture frequency decreasing down section.Because of the problem that we had during this study to access fracture detection tools like image logs, seismic or any other tools that can be used for fracture identification and characterization, the abovementioned fracture distribution characteristics has been used to build a base fracture network model in FracGen and the flow modeling was performed in NFflow. The Fracture network characteristics used for the base model and the reservoir parameters that have been used for history matching (in NFflow) are shown in Table 4 and Table 5. Results of this model are compared with the production from a well producing from the New Albany Shale as shown in Figure 8. Meanwhile, because only last 9 years of production history was available, our production modeling (and eventually the history match) included reservoir behavior from the well completion to the last available production date. The fracture network of the base model (model providing the best history match) consists of 4sets of fractures. Three of the sets are defined in order to generate the major fracture patterns that mostly contribute to flow (the orientation of those fractures are $\mathrm{E} 95^{\circ} \mathrm{W}, \mathrm{E} 97^{\circ}$ $\mathrm{W}$ and $\mathrm{E} 90^{\circ}$ ) and the remaining set are defined in order to generate the bedding.

Table 4. Fracture network properties (Base model)

\begin{tabular}{|c|c|c|c|c|c|}
\hline & $\begin{array}{l}\text { Fracture } \\
\text { Properties }\end{array}$ & $\begin{array}{l}\text { Fracture } \\
\text { Length(ft) }\end{array}$ & $\begin{array}{l}\text { Fracture } \\
\text { Aperture(ft) }\end{array}$ & $\begin{array}{l}\text { Fracture } \\
\text { Density }\left(\mathrm{ft} / \mathrm{ft}^{2}\right)\end{array}$ & $\begin{array}{l}\text { Major Fracture } \\
\text { orientation }\end{array}$ \\
\hline \multirow{3}{*}{$\begin{array}{l}\text { Major fracture } \\
\text { generator }\end{array}$} & Set 1 & $2-400$ & 0.0098 & 0.00003 & E $95^{\circ} \mathrm{W}$ \\
\hline & Set 2 & $2-400$ & 0.0098 & 0.00003 & E $97^{\circ} \mathrm{W}$ \\
\hline & Set 3 & $5-400$ & 0.0098 & 0.000003 & E $90^{\circ}$ \\
\hline $\begin{array}{l}\text { Minor } \\
\text { fracture } \\
\text { generato }\end{array}$ & Set 4 & $400-1000$ & 0.00025 & 0.00003 & $\mathrm{E} 24^{\circ} \mathrm{N}$ \\
\hline
\end{tabular}


Generations of fracture sets are based on two different models. Model 1 generates randomly located fractures, although the connectivity controls can be used to produce various degrees of clustering, including unintended clustering. Model 2 generates fracture swarms (elongated clusters), whereby the swarms are randomly located and can overlap.

Table 5. The input variable for single well history matching

\begin{tabular}{|c|c|c|c|c|}
\hline $\begin{array}{c}\text { Matrix } \\
\text { Permeability } \\
(\mathrm{md})\end{array}$ & $\begin{array}{c}\text { Matrix } \\
\text { Porosity } \\
(\%)\end{array}$ & $\begin{array}{c}\text { Initial } \\
\text { Pressure } \\
(\mathrm{psi})\end{array}$ & $\begin{array}{c}\text { Thickness } \\
(\mathrm{ft})\end{array}$ & $\begin{array}{c}\text { A } \\
\text { (Acres) }\end{array}$ \\
\hline 0.0000822 & 0.05 & 700 & 100 & 320 \\
\hline
\end{tabular}

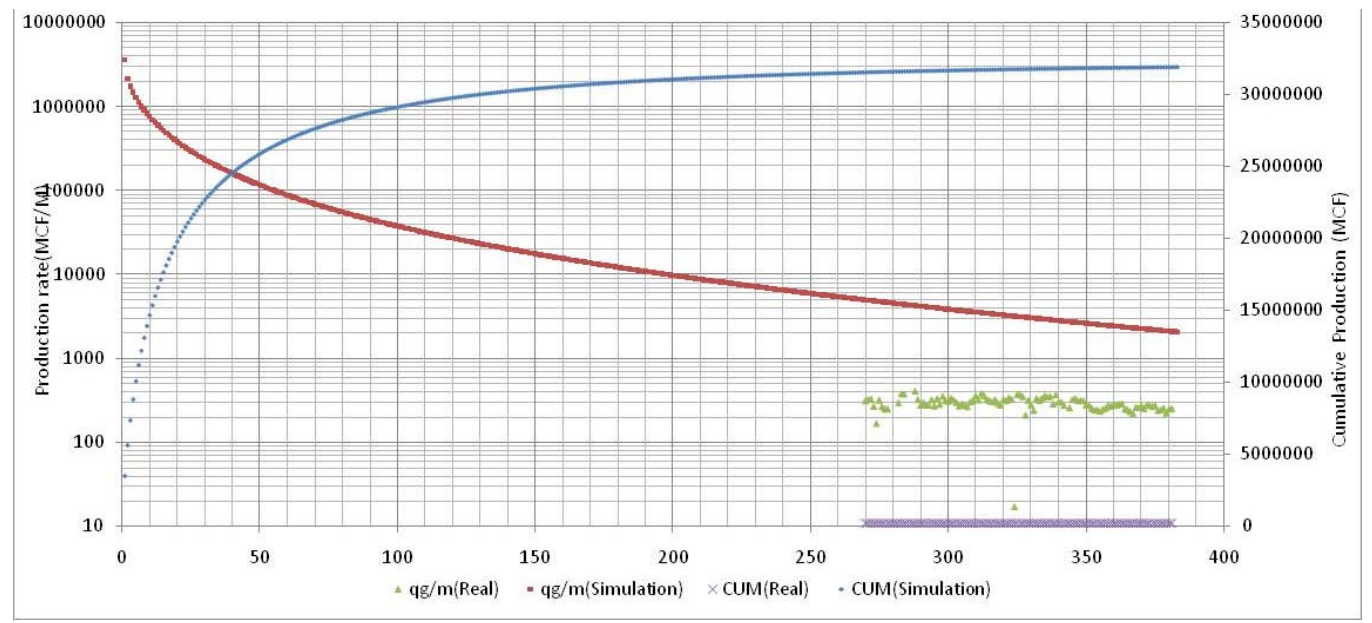

Figure 8. Simulation result examples for one history-matched New Albany Shale Gas well

The 9 years production data of a well which is completed in New Albany shale, western Kentucky has been used to verify the built fracture network and perform history matching. Figure 8 shows production rates and cumulative production from the well in green and purple dots, respectively while modeled production rate and cumulative production are shown as red and blue profiles. This figure shows that the base model has significantly overestimated the production from this well. According to the well completion report (11) the initial rate after the stimulation at July 1973 is around146 MCF/day while the model results start at 127,830 MCF/day and declines to more than $70 \mathrm{MCF} /$ day in about last nine years of production.

To match the production from the New Albany Shale with the FracGen/NFflow simulator, sensitivity analysis was performed on fracture network properties (Fracture Aperture, Length, and Density) and reservoir properties $\left(\mathrm{Pi}, \varphi_{\mathrm{m}}, \mathrm{Km}\right.$, and $\mathrm{h}$ ) in order to make the best estimation of NAS natural fracture network pattern. 


\subsection{Sensitivity Analysis on Reservoir and Fracture Properties}

The objective of sensitivity analysis is to study the impact of different parameter and identify the factors that have the most contribution to flow.

To investigate the effect of different reservoir and fracture property on flow behavior, several studies were performed. The approach used for this analysis, starts by building the fracture network model based on the available information in literature (in FracGen). After performing the sensitivity analysis, the fracture network and reservoir properties of base model are tuned in order to match the observed production for each of the gas wells in New Albany shale.

As shown in Figure 9 through Figure 13, sensitivity analysis is performed, with the purpose of scrutinizing the influence of Initial reservoir pressure, matrix porosity, matrix permeability, net pay thickness and aperture reduction factor on flow behavior.

Aperture reduction factor is a term that has been defined as a parameter that can be used in order to shrink the hydraulic apertures of the fractures nearby the well and/or the entire drainage area of the well to further improve the history matched model. Alternatively, the fracture apertures can remain unchanged (reduction factor $=1.0$ ). The process of reducing the aperture is a trial and- error process until the best possible match with production data or well test data is obtained for each of one or more networks.

As illustrated on Figure 9, which represent the comparison of the influence of reservoir and fracture properties on flow rate based on the sensitivity analysis results, the key parameters that have substantial effect on production behavior are initial reservoir pressure pay thickness and aperture reduction factor (ARF). 

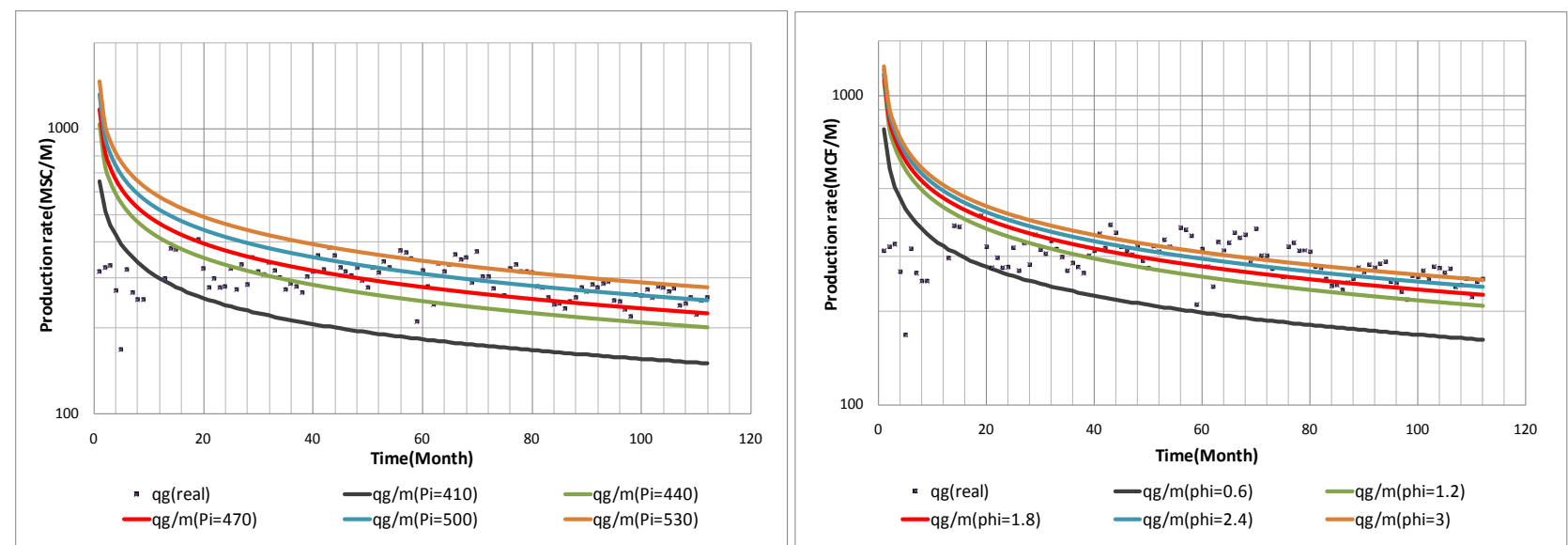

Figure 9. Sensitivity analysis on initial reservoir pressure Figure 10. Sensitivity analysis on matrix porosity (Monthly gas production) (Monthly gas production)

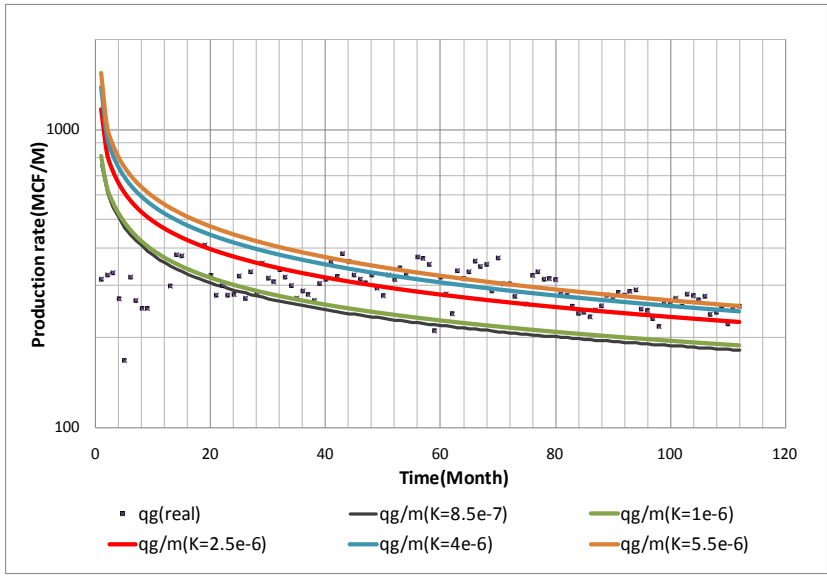

Figure 11. Sensitivity analysis on matrix permeability

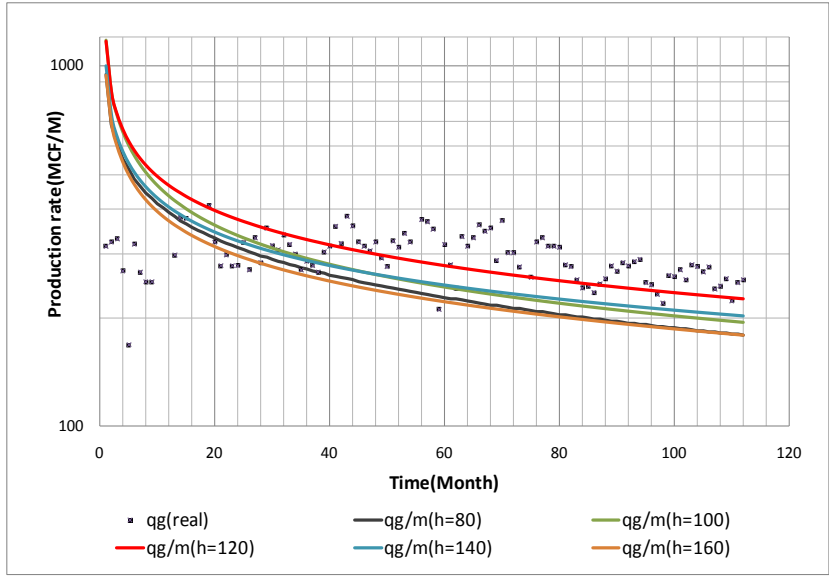

Figure 12. Sensitivity analysis on pay thickness

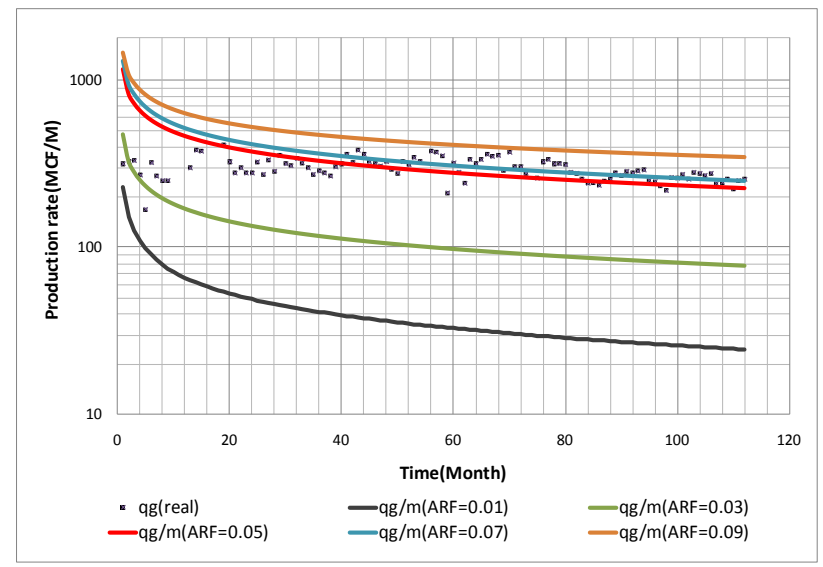

Figure 13. Sensitivity analysis on Aperture reduction factor

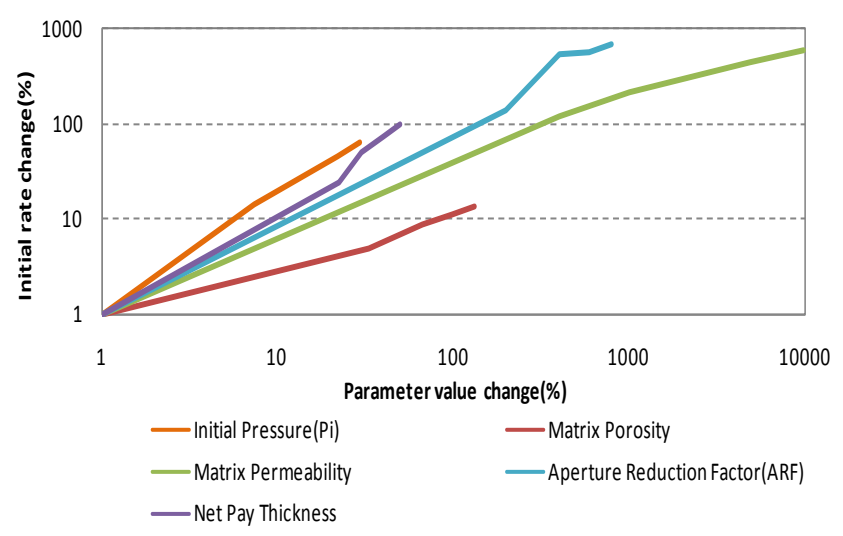

Figure 14. Sensitivity analysis - Effect of reservoir and fracture properties variation on initial gas rate 
In the next part of this study, we intend to understand the effect of fracture length and density on production and reservoir behavior. Reservoir properties (h, $\varphi m, \mathrm{Km}, \mathrm{Pi})$, fracture orientation, inner cluster fracture length \& density, fractures aperture and bedding properties were assumed to remain unchanged. Therefore, the only parameters that have been changed are fracture length ad density. Hence, sensitivity analysis was performed for values of fracture length and density. Table 6 represents the suggested values for fracture length and density for one of fracture set.

Table 6. Multiple values for fracture length and density

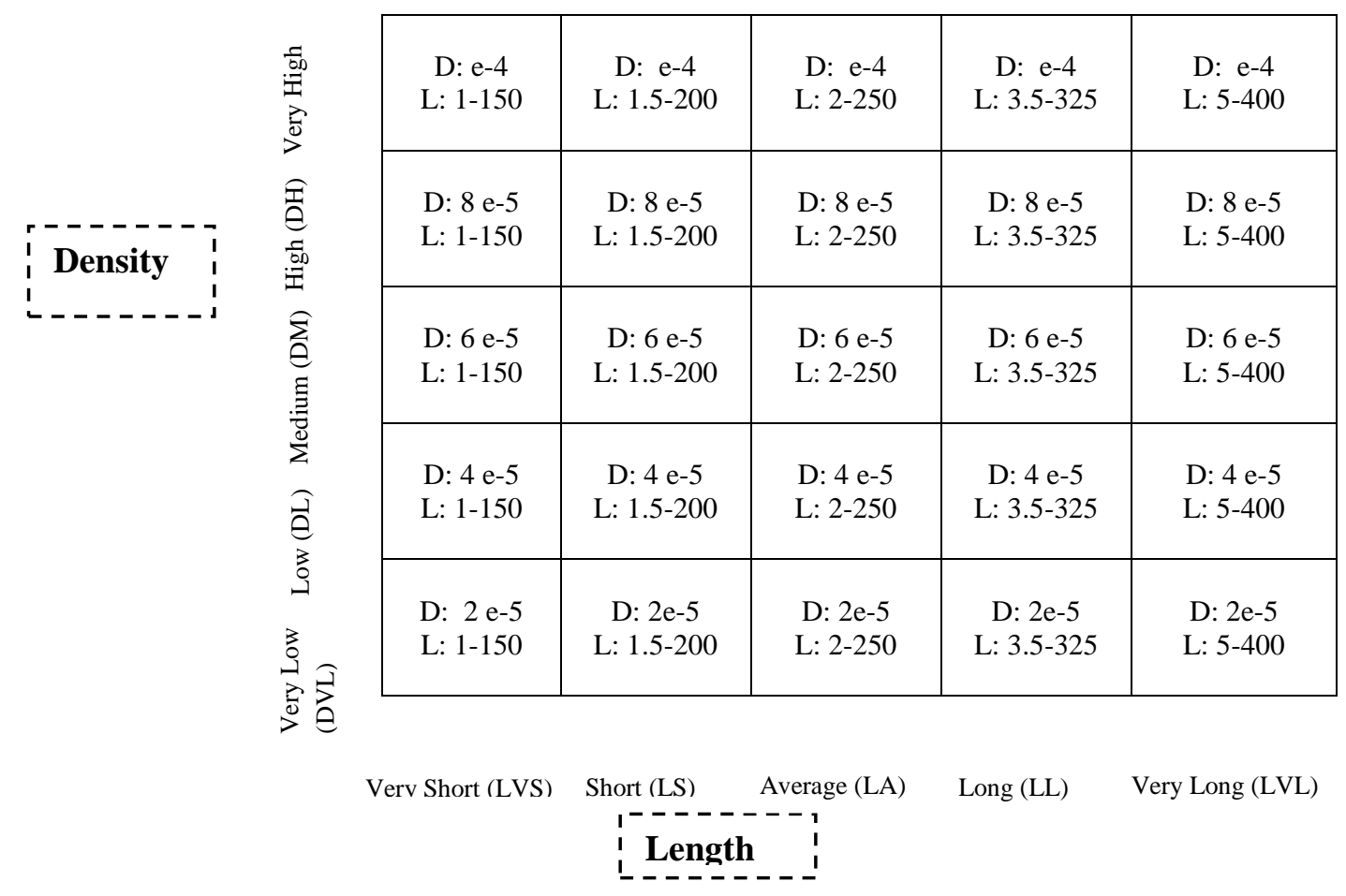

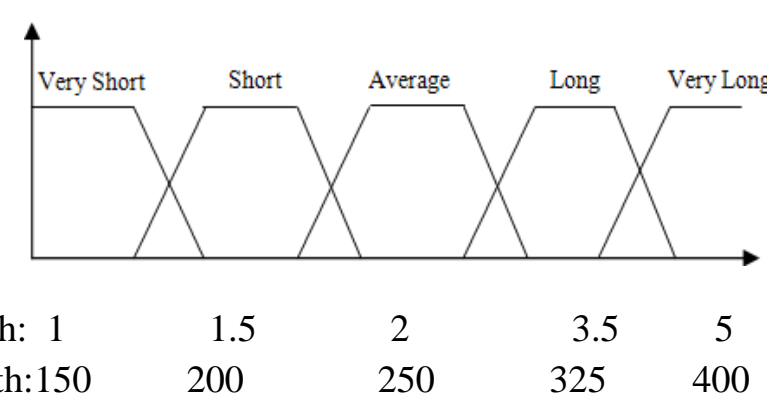

Figure 15. Fracture Length Values

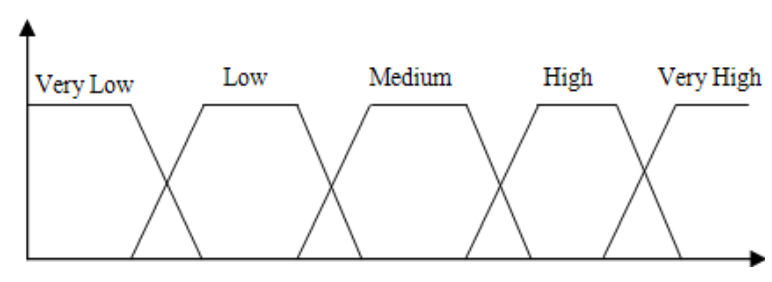

$$
\text { 2e-5 4e-5 6e-5 8e-5 e-4 }
$$

Figure 16. Fracture Density Values

Figure 17 through Figure 21 demonstrate the results of sensitivity analysis based on different values of fracture length and fracture network density. The production data was available for just a part of 
well's life so the complete production profile has been generated and initial rate after stimulation has been used to verify the predicted initial rate.

According to sensitivity analysis results, with increasing fracture length or fracture density the production will be increased. In the case that fracture length and/or density are low the fracture intersection will be decreased significantly, as a result some part of the reservoir will not be depleted, so the only way to put those parts of reservoir on production is performing some sort of stimulation (hydraulic fracturing).
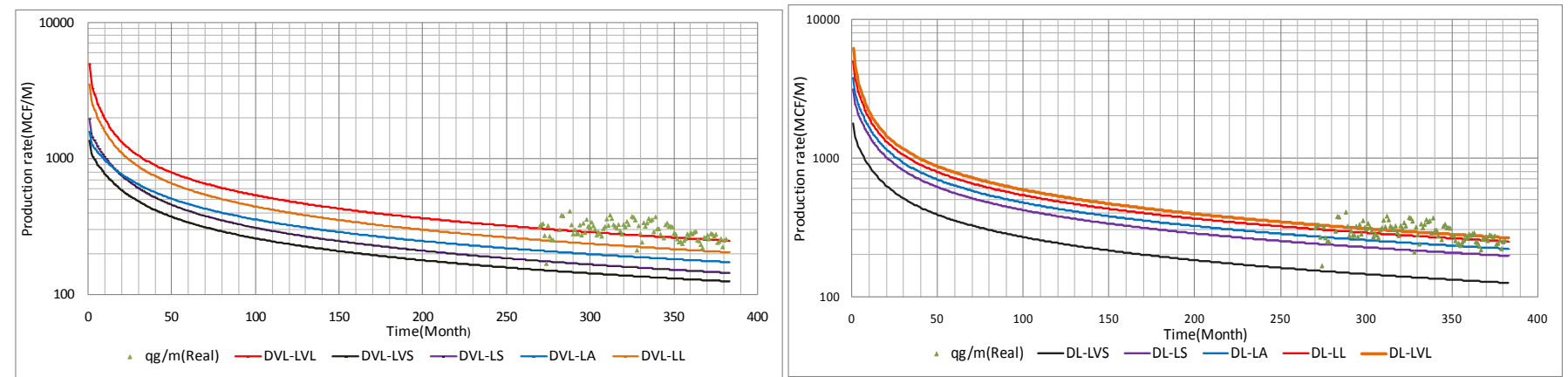

Figure 17. Sensitivity analysis results (Monthly gas production) Figure 18. Sensitivity analysis results (Monthly gas production) (Very low fracture network density with variable length) (Low fracture network density with variable length)
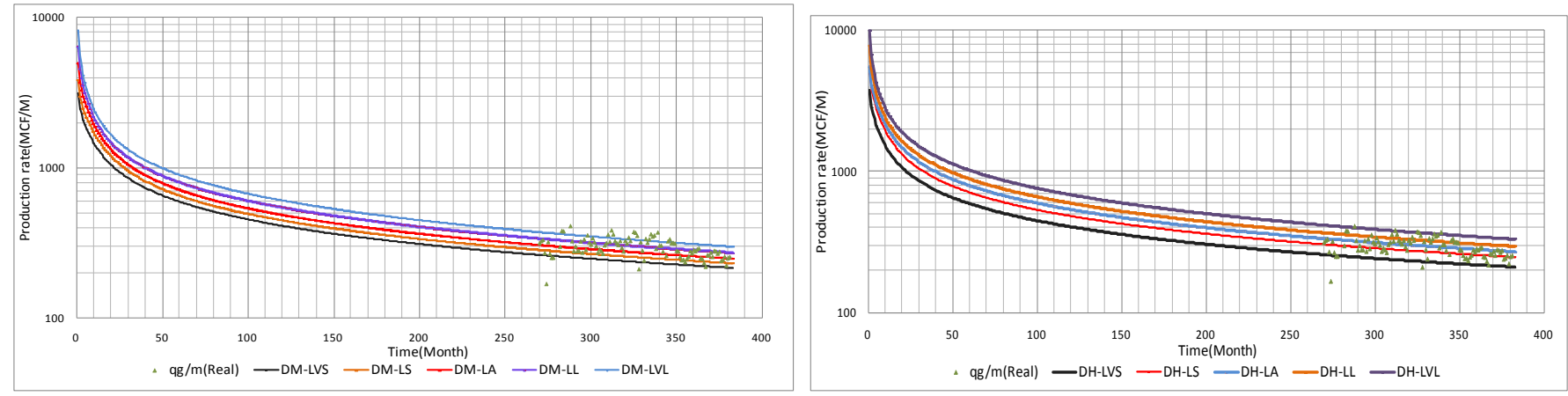

Figure 19. Sensitivity analysis results (Monthly gas production) (Medium fracture network density with variable length)

Figure 20. Sensitivity analysis results (Monthly gas production) (High fracture network density with variable length) 


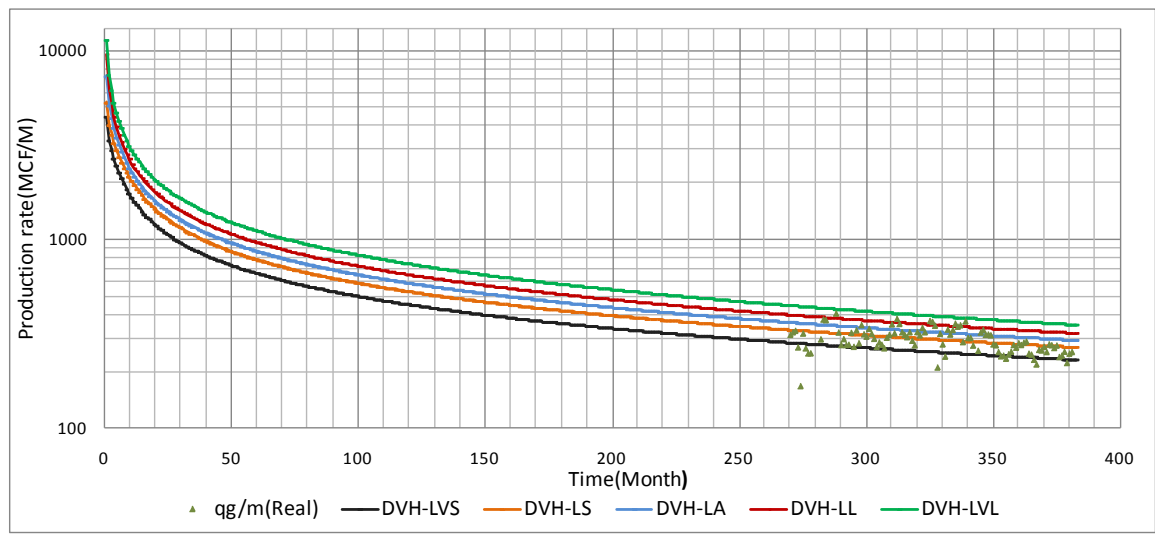

Figure 21. Sensitivity analysis results (Monthly gas production) (Very high fracture network density with variable length)

\subsection{History Matched Model}

Upon completion of the sensitivity, analysis and careful study of the impact of different parameters on production a new set of parameters were identified. This new set was used in the model. The result is shown in Figure 22.

According to the well completion report (10), the initial rate after the stimulation at July 1973 is 146 MCF/Day. The history matched model results in an initial production rate of 141 MCF/Day, which shows the reliability of fracture network and history matched model.

Figure 22 shows production rates and cumulative production from the well in green and purple dots, respectively while modeled production rate and cumulative production are shown as red and blue profiles.

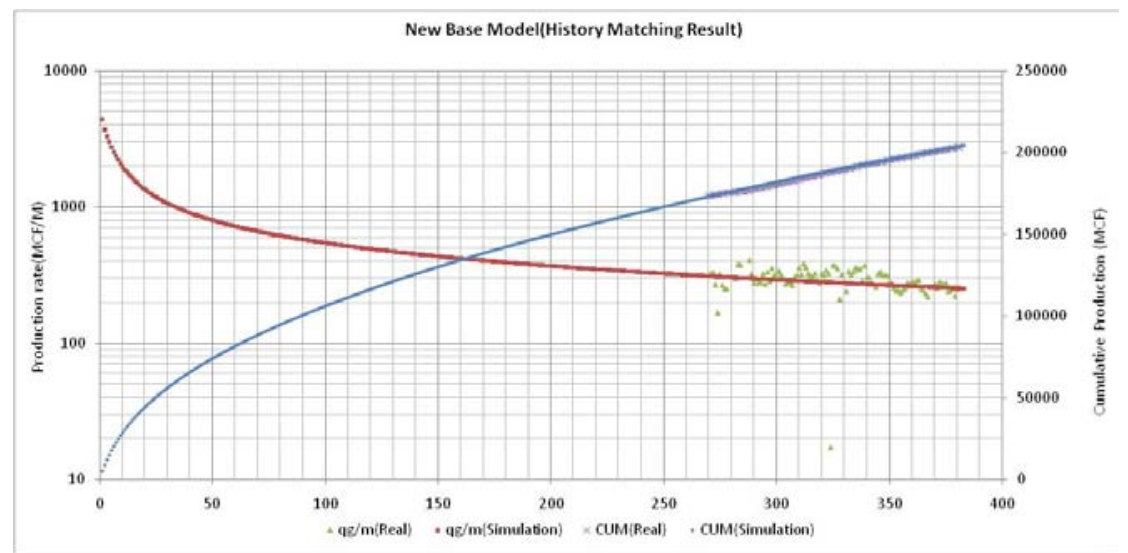

Figure 22. Single well history matching result, after changing the key 
The final values of input parameters that are used in simulation (final history matching) are illustrated in Table 7.

Table 7. Shows the input parameters for single well history matching (Best match)

\begin{tabular}{|c|c|c|c|c|c|}
\hline $\begin{array}{c}\text { Matrix } \\
\text { Permeability } \\
(\mathrm{md})\end{array}$ & $\begin{array}{c}\text { Matrix } \\
\text { Porosity } \\
(\%)\end{array}$ & $\begin{array}{c}\text { Initial } \\
\text { Pressure } \\
(\mathrm{psi})\end{array}$ & $\begin{array}{c}\text { Thickness } \\
(\mathrm{ft})\end{array}$ & $\begin{array}{c}\text { Aperture } \\
\text { reduction }\end{array}$ \\
\hline $1.5 \mathrm{E}-7$ & 2.2 & 500 & 100 & 320 & 0.056 \\
\hline
\end{tabular}

Fracture network characteristics used for the history-matched model are shown in Table 8 and the fracture network distribution for the base model is illustrated in Figure 23.

Table 8. Fracture network properties (History matched model)

\begin{tabular}{|c|c|c|c|c|c|}
\hline & $\begin{array}{l}\text { Fracture } \\
\text { Properties }\end{array}$ & $\begin{array}{l}\text { Fracture } \\
\text { Length(ft) }\end{array}$ & $\begin{array}{l}\text { Fracture } \\
\text { Aperture(ft) }\end{array}$ & $\begin{array}{l}\text { Fracture } \\
\text { Density }\end{array}$ & $\begin{array}{l}\text { Major Fracture } \\
\text { orientation }\end{array}$ \\
\hline \multirow{2}{*}{$\begin{array}{l}\text { Major } \\
\text { fracture } \\
\text { generator }\end{array}$} & Set 1 & $2-200$ & 0.00055 & 0.00006 & E $95^{\circ} \mathrm{W}$ \\
\hline & Set 2 & $2-200$ & 0.0004 & 0.00006 & E $97^{\circ} \mathrm{W}$ \\
\hline $\begin{array}{l}\text { Minor } \\
\text { fracture }\end{array}$ & Set 3 & $5-200$ & 0.0004 & 0.000009 & E $90^{\circ}$ \\
\hline generator & Set 4 & $400-1000$ & 0.00025 & 0.00002 & $\mathrm{E} 24^{\circ} \mathrm{N}$ \\
\hline
\end{tabular}

As shown in Table 4 and Table 8, the fracture network properties has been modified in order to get better history match is fracture aperture values. 


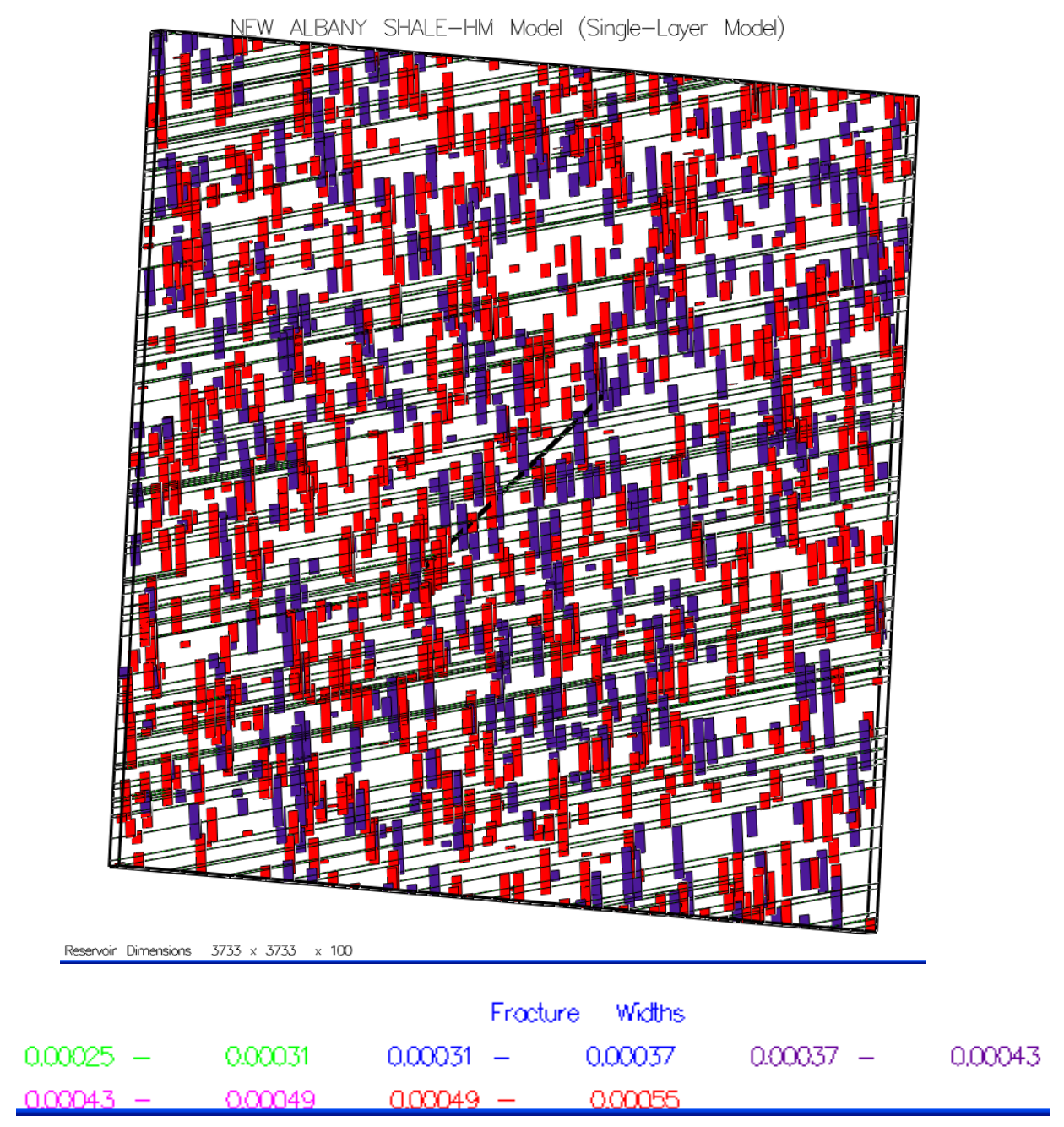

Figure 23. The well and fracture intersection for the history matched model (Based on $\mathbf{3 2 0}$ acre spacing)

\subsection{Effect of lateral orientation on well productivity}

In order to understand the impact of the orientation of horizontal wells on gas production in New Albany Shale the fracture network and reservoir properties are assumed to be the same for all the models to see the effect of different well orientations in horizontal plane (not Z-direction) on production and well performance. 
Figure 25, shows the history match results based on different well orientations in horizontal plane (0, 30,45,60,75 and 90 degree). The result of this study shows that the history-matched models of different well orientation in X-Y plane have only slight difference in production profile (Qi, Di and b) .Therefore, horizontal well orientation has not substantial effect on well performance. (Table 9)

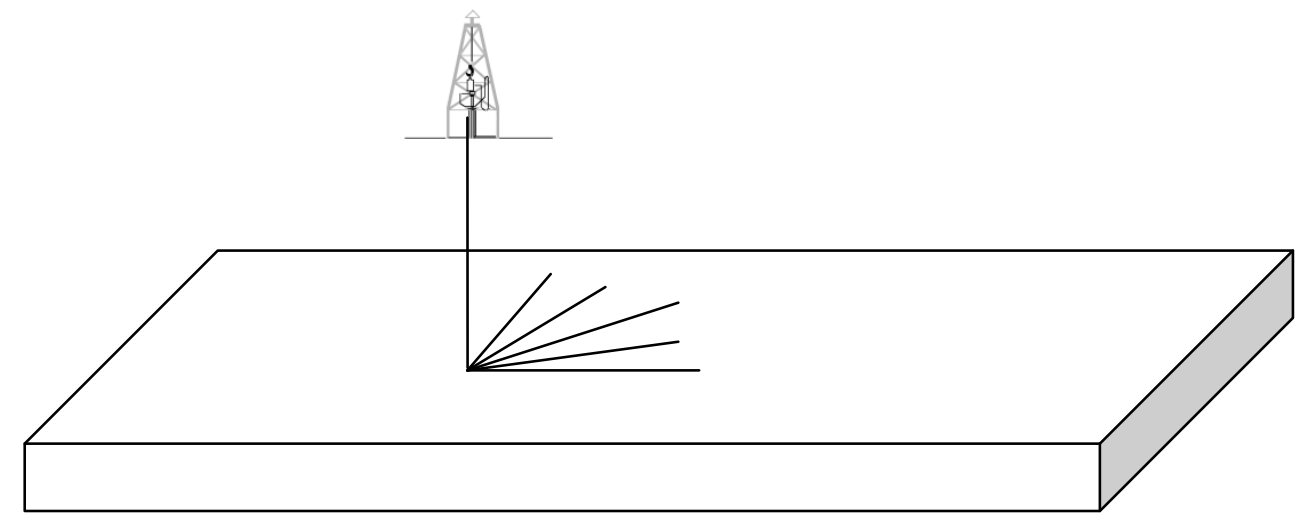

Figure 24. Horizontal well orientations in $\mathrm{Y}$ direction (0, 30, 45, 60, and 90 degrees)

Table 9. Initial rates based on different well orientation-History matched model

\begin{tabular}{|c|c|}
\hline $\begin{array}{c}\text { Well Orientation } \\
\text { (degree) }\end{array}$ & $\begin{array}{c}\mathrm{Q}_{\mathrm{i}} \\
\text { (MCF/day) }\end{array}$ \\
\hline 0 & 140.13 \\
\hline 30 & 140.24 \\
\hline 45 & 140.56 \\
\hline 60 & 140.76 \\
\hline 75 & 141.19 \\
\hline 90 & 140.01 \\
\hline
\end{tabular}
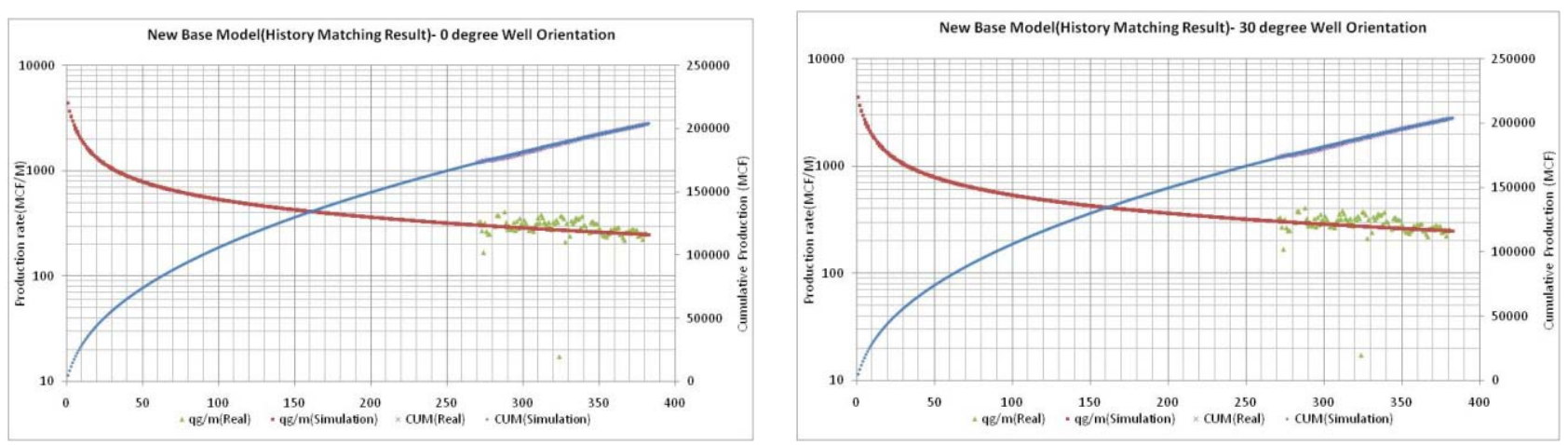

Figure 25. Single well history matching result-Zero and 30-degree well orientation (From left to right) 


\subsection{Horizontal Lateral Length Effect on Well Productivity}

In order to indentify the effect of horizontal lateral length on well productivity from New Albany Shale, fracture network has been regenerated in order to represent the distribution of natural fracture in that formation.

NFFLOW/FRACGEN is capable to handle the drainage area of less than $100,000 \mathrm{ft} * 100,000 \mathrm{ft}$ (230,000 Acre). Therefore, the understudy drainage area has been selected as 99,000ft*99,000 ft (225,000 acre).

In order to have reliable results, we should perform history matching for one of the wells with $1200 \mathrm{ft}$ lateral to calibrate the fracture network.

The HM process has been done. Then the History matched mode has been used as a basis for future analysis (To see the effect of different lateral length on well productivity)

The simulation study has been performed for 5, 7.5,9, and 12 miles of horizontal lateral length. Figure 26 shows clearly the monthly gas production (MCF) for 30 years.

Figure 27 shows the simulation result s as well as extrapolation results for cumulative gas production based on different lateral length.

Initial rate as a function of horizontal lateral length has been illustrated in Figure 28.

Figure 29 through Figure 33 illustrate the pressure distribution as a function of time for 2nd month

and 30th years of production based on different horizontal lateral length $(0.227,5,7.5,9$, and 12 miles) 


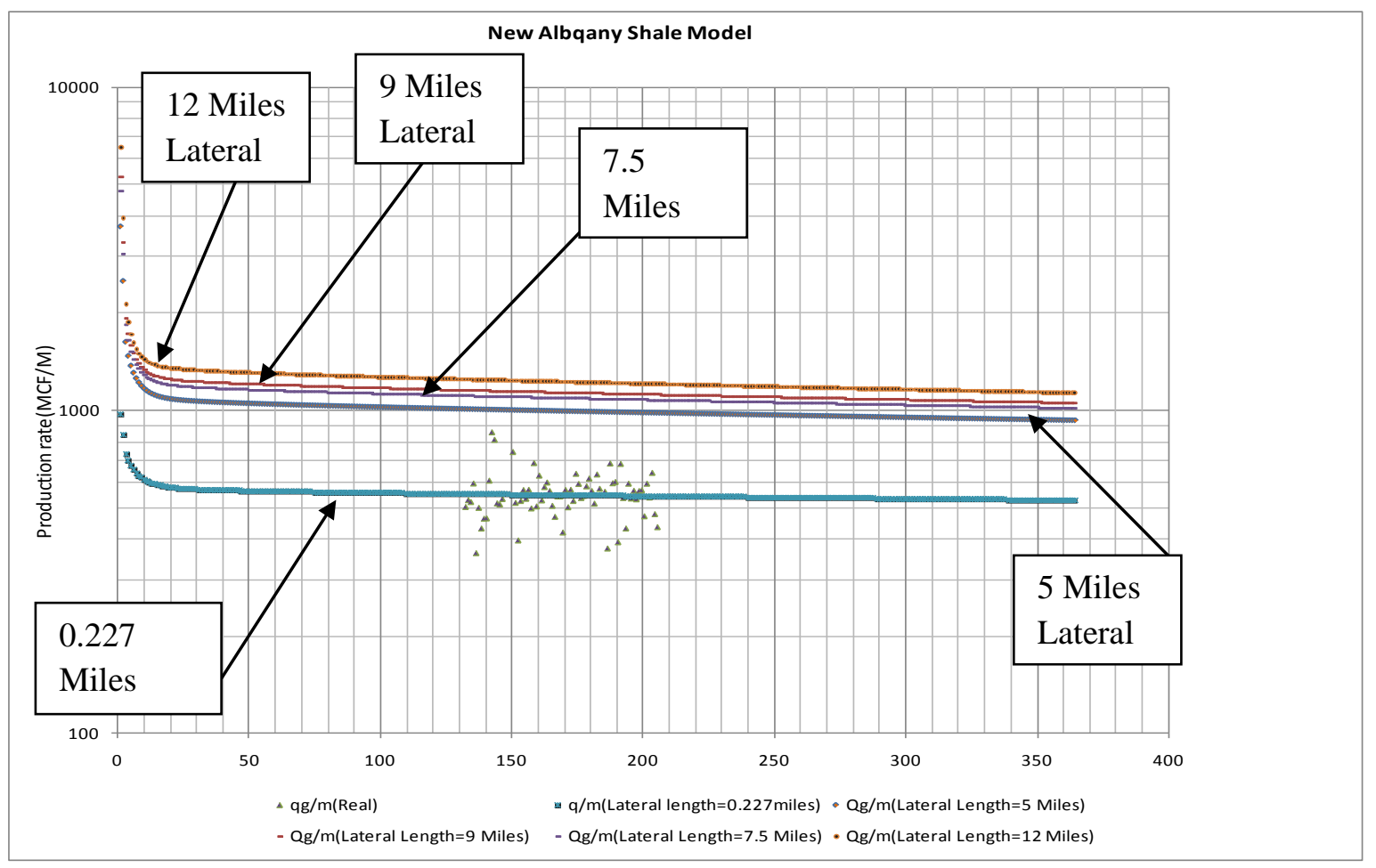

Figure 26.Effect of horizontal lateral length on well productivity from New Albany Shale

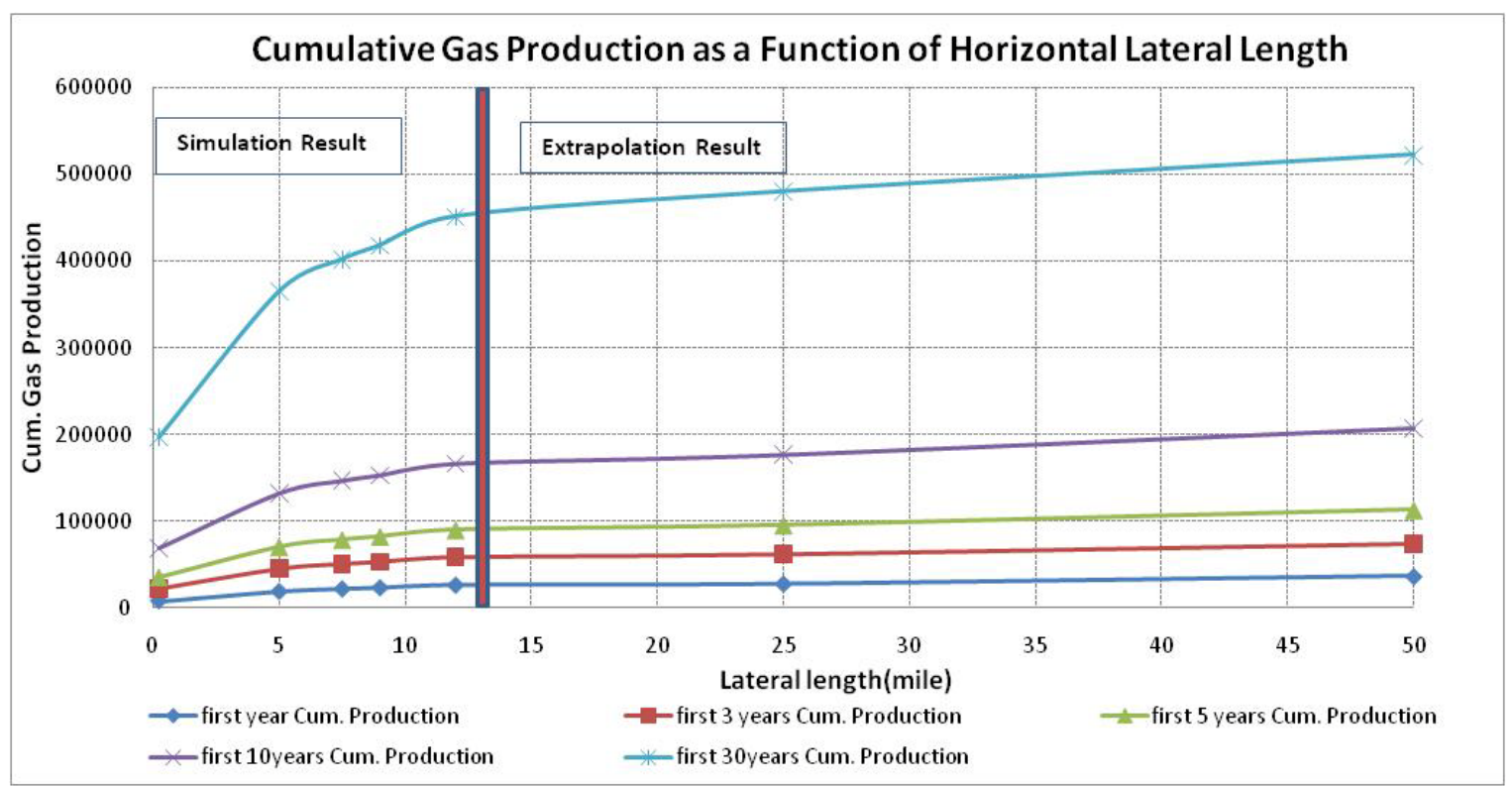

Figure 27.Cumulative gas production as a function of horizontal lateral length for $1,3,5,10$, and 30 years of Cum. Production 


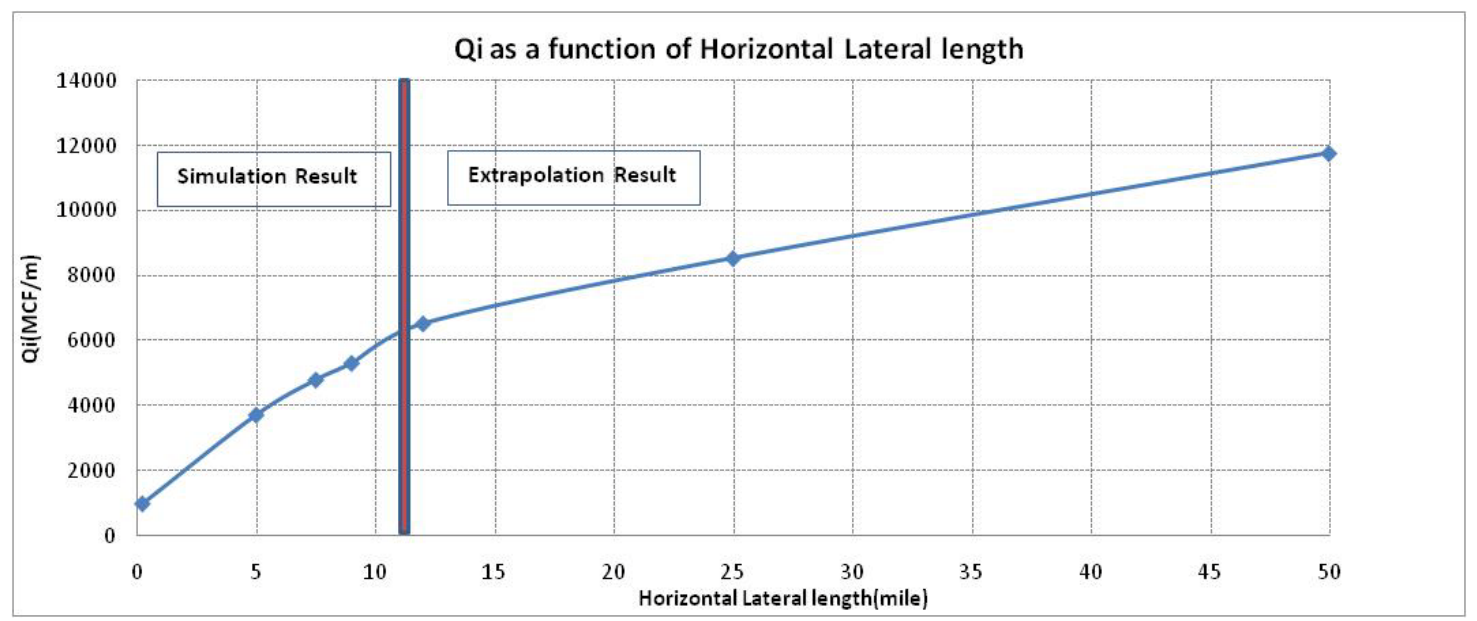

Figure 28. Initial rate as a function of horizontal lateral length

\begin{tabular}{|rccc|}
\hline & Pressures \\
$5000000-31000000$ & $31000000-430,00000$ & $43000000-49000000$ \\
$40000000-520000000$ & 52000000 & -56000000 \\
\hline
\end{tabular}

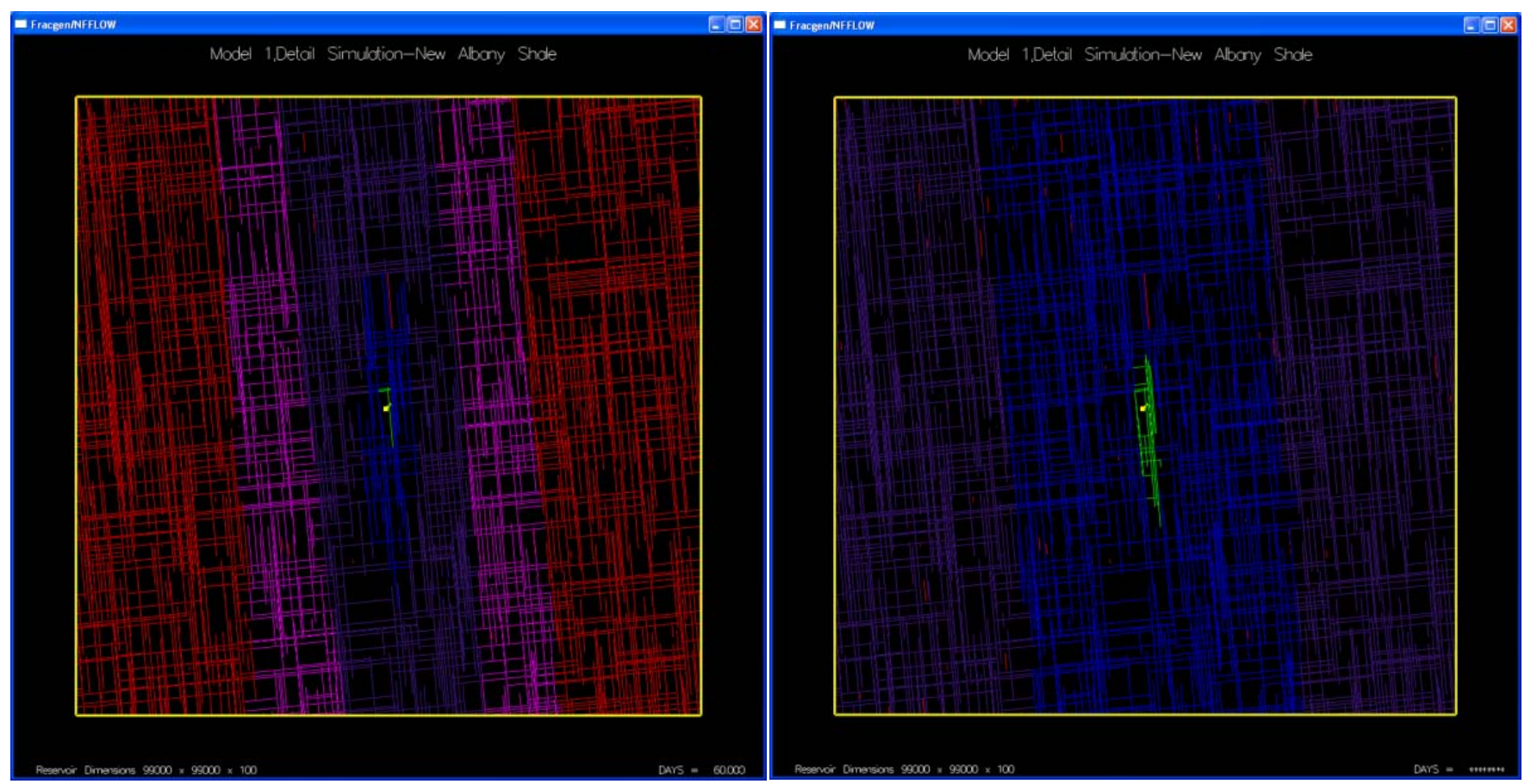

Figure 29.Pressure distribution in the reservoir as a function of time (2nd month and 30th years of production -from left to right) (Green represent the lower pressure and red shows max pressure) (0.227 mile lateral length) 


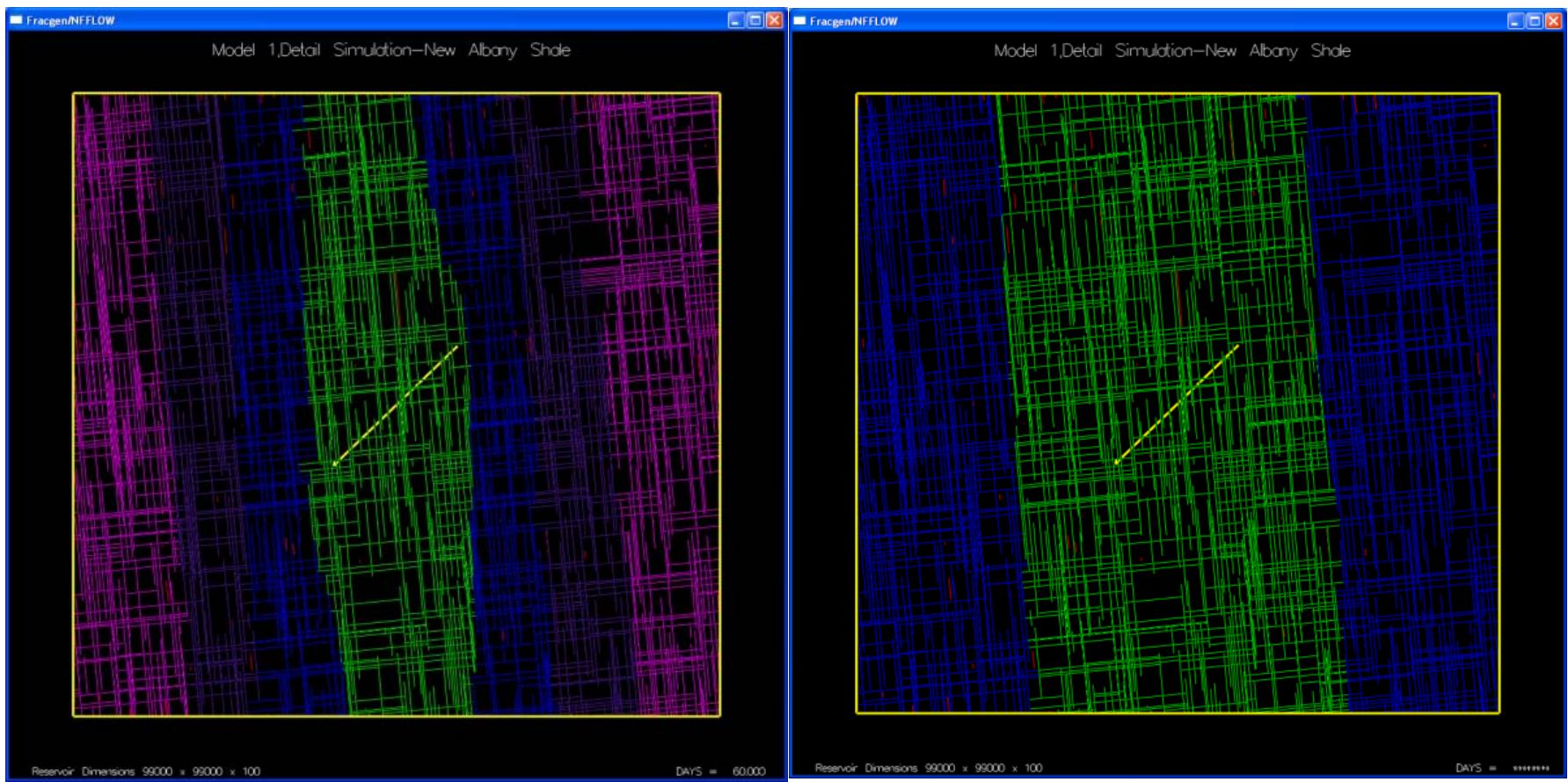

Figure 30.Pressure distribution in the reservoir as a function of time (2nd month and 30th years of production-from left to right) (Green represent the lower pressure and red shows max reservoir pressure)( 5 mile lateral length)

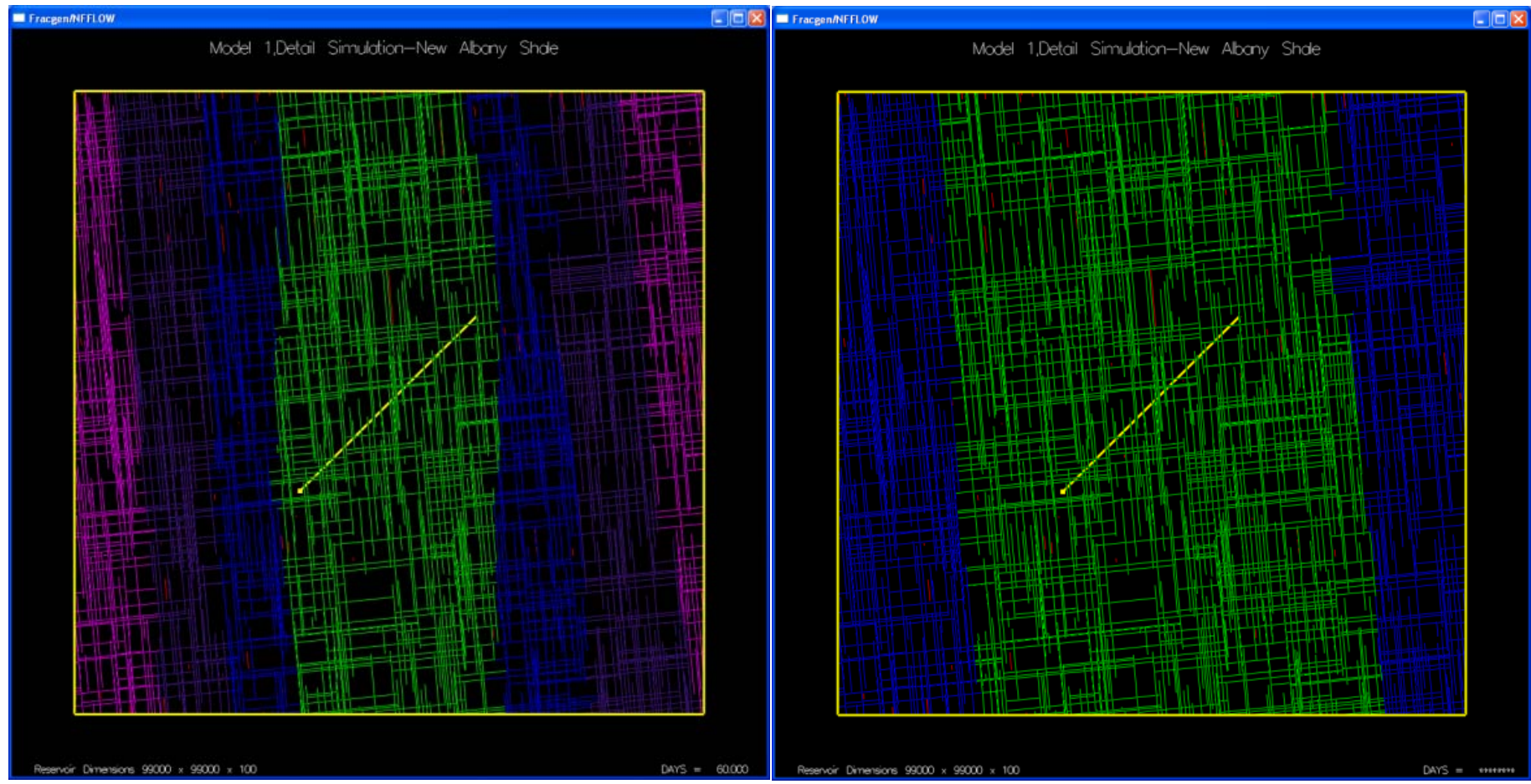

Figure 31.Pressure distribution in the reservoir as a function of time (2nd month and 30th years of production-from left to right) (Green represent the lower pressure and red shows max reservoir pressure)( 7.5 mile lateral length) 

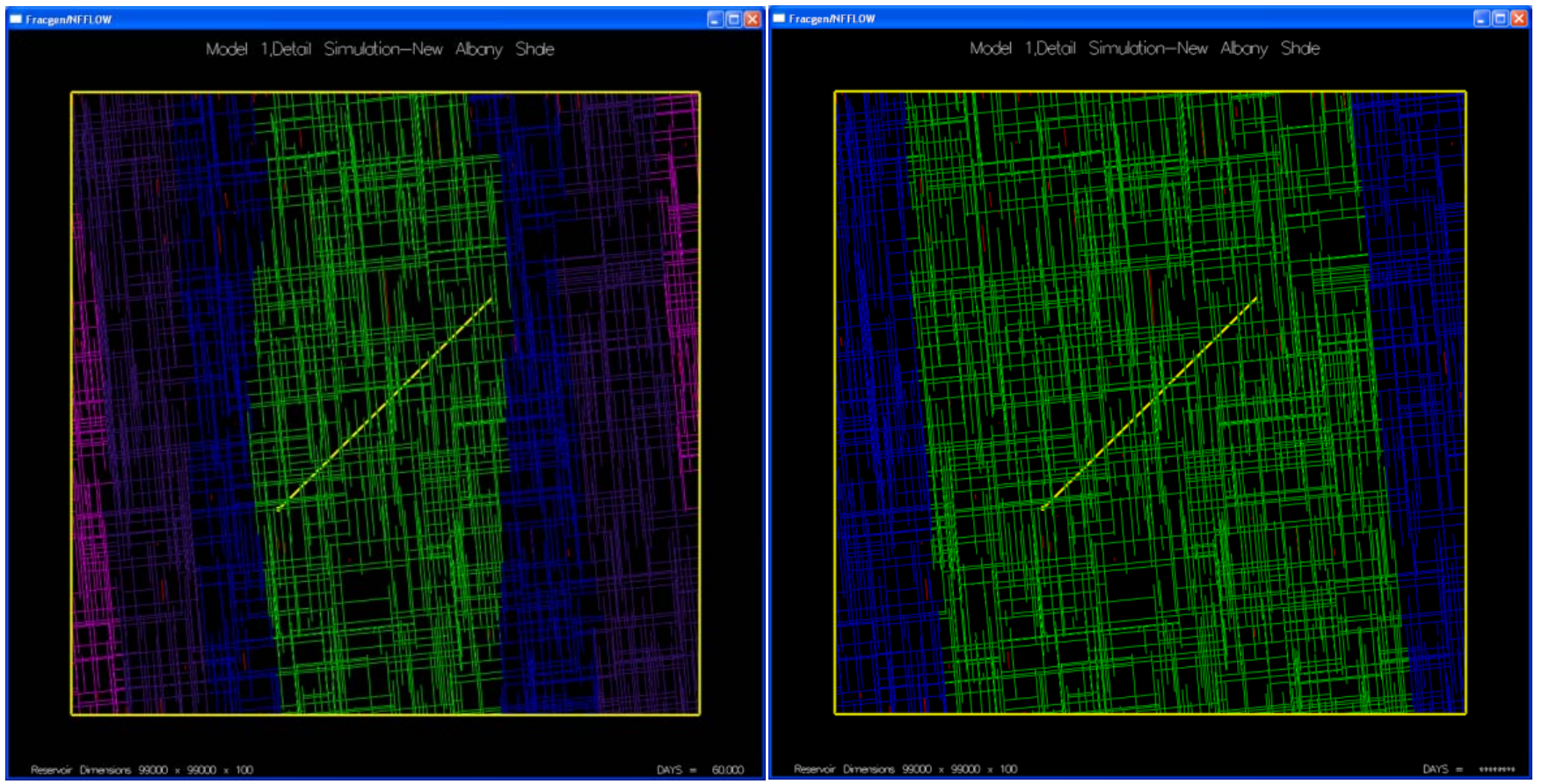

Figure 32.Pressure distribution in the reservoir as a function of time (2nd month and 30th years of production-from left to right) (Green represent the lower pressure and red shows max reservoir pressure) (9 mile lateral length)
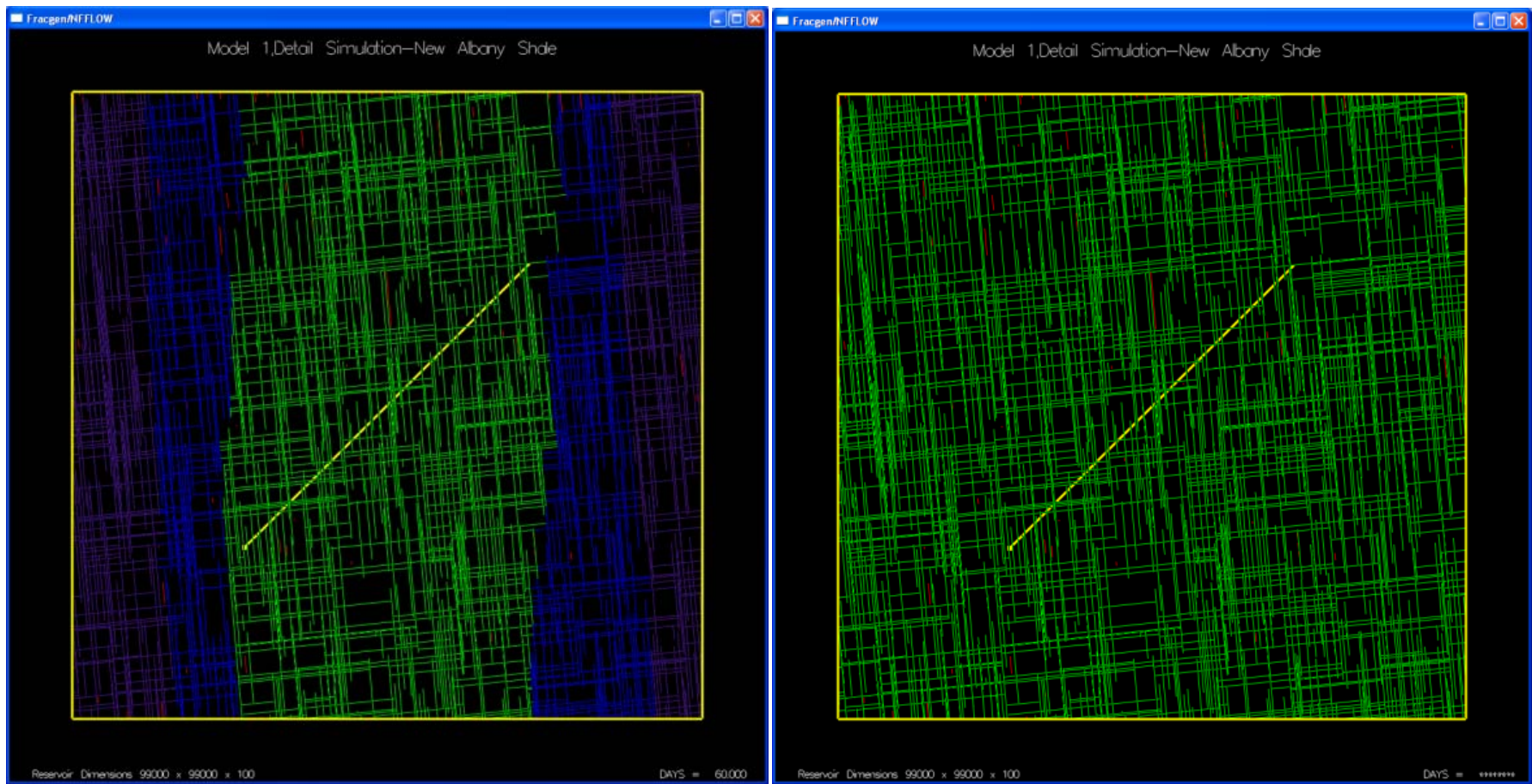

Figure 33.Pressure distribution in the reservoir as a function of time (2nd month and 30th years of production-from left to right) (Green represent the lower pressure and red shows max reservoir pressure) (12 mile lateral length) 


\subsection{Economic Analysis}

Figure 34 summarizes the results of the sensitivity analysis simulation runs. In this Figure, initial flow rate of the well is plotted against normalized reservoir and fracture properties. This figure demonstrates that initial flow rate is most impacted by initial reservoir pressure followed by horizontal lateral length, net pay thickness, and aperture reduction factor (ARF). The parameters that are not related to the natural fracture network in the New Albany Shale such as matrix permeability and matrix porosity have the least impact on the initial flow rate among the parameters that were investigated in this study.

Economic analyses has been performed to investigate the influence of the parameters such as initial reservoir pressure, fracture aperture reduction factor, and horizontal lateral length that have most contribution in flow on the Net Present Value of benefits from producing gas wells in New Albany Shale.

The initial reservoir pressure has been changed to have values of 410,440,470 and 500 psi. Figure 35 reflects the net present values (NPV) based on \$4 gas price and \$0.5 operation cost per MCF and discount rate of $10 \%$ for this case. Figure 35 shows NPV values for different fracture aperture reduction factor. (0.01, 0.03, 0.05, and 0.07)

The same analysis has been performed on different horizontal lateral length $(800,1000,1200$, and $1400 \mathrm{ft}$ ) to show that the drilling horizontal wells are more favorable than drilling vertical well in New Albany Shale gas formation so horizontal wells are considered to be effective in naturally fractured reservoirs that are characterized by permeability anisotropy. (Figure 37)

As illustrated in Figure 37, the initial pressure has the higher NPV and lateral length has an NPV profile like the initial reservoir pressure.

The NPV profile for 5 years for each abovementioned case has been generated based on different discount rates. (Figure 39 through Figure 41) 


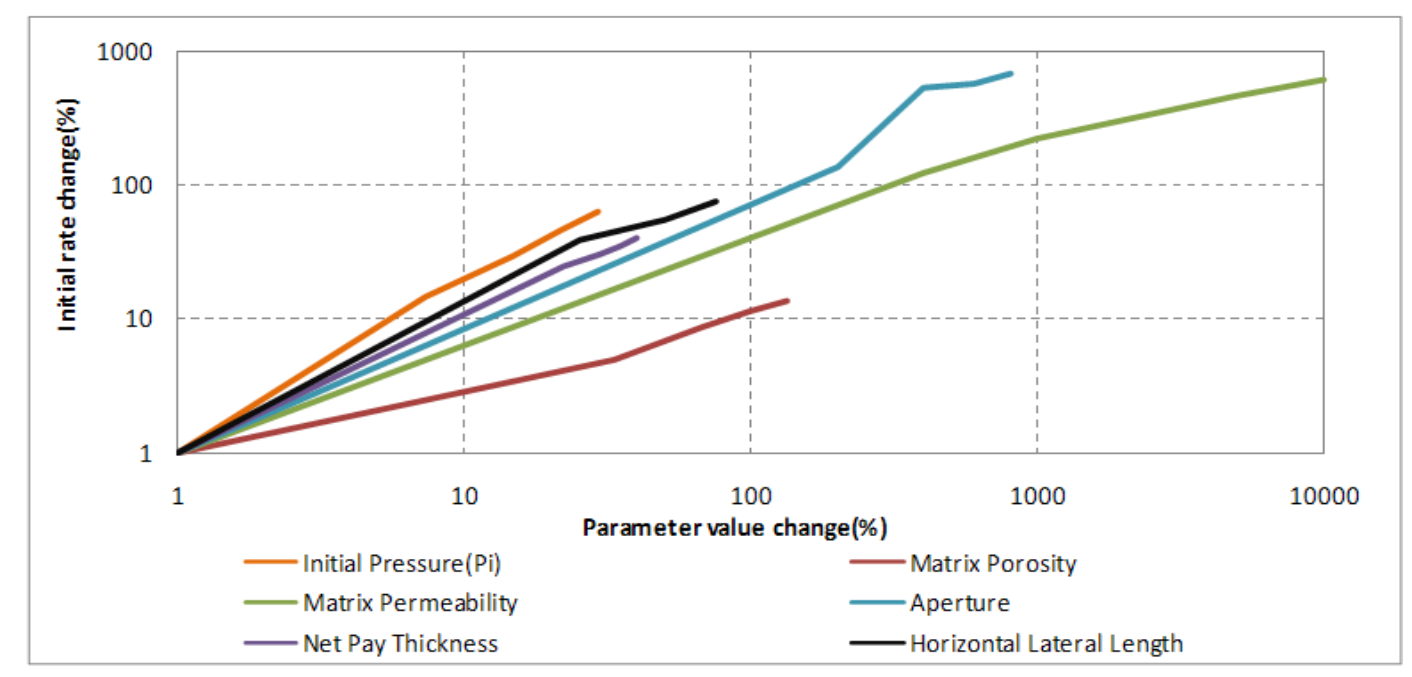

Figure 34. Sensitivity analysis on effect of normalized reservoir and fracture properties on normalized initial gas rate

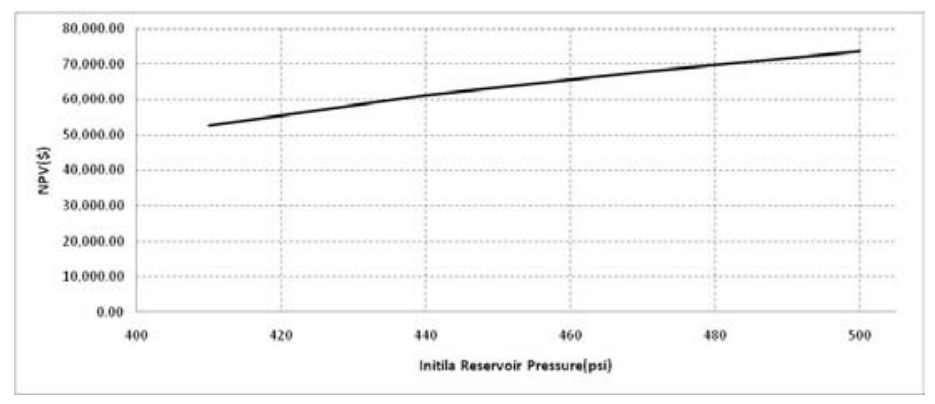

Figure 35.Effect of initial reservoir pressure on NPV factor on NPV

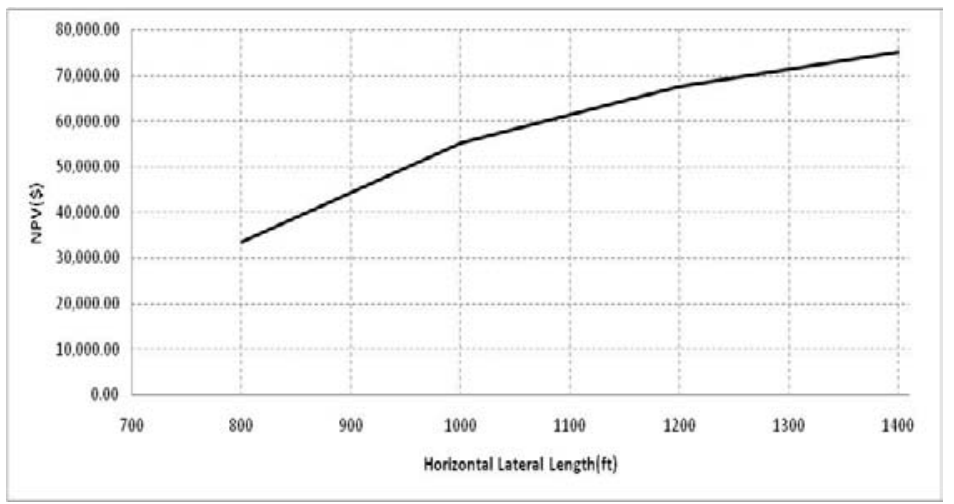

Figure 37.Effect of horizontal lateral length on NPV

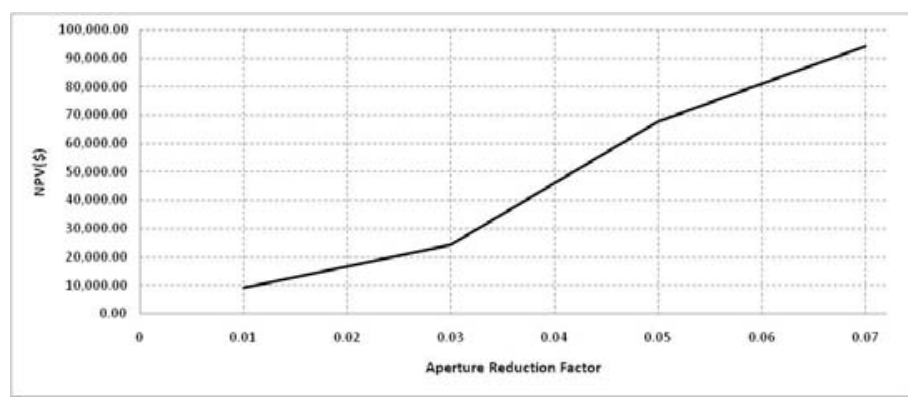

Figure 36.Effect of fracture aperture reduction

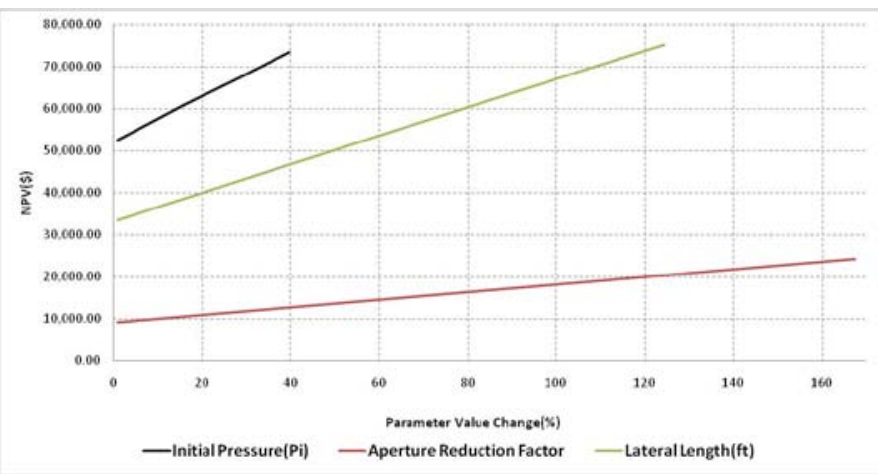

Figure 38.Comparison the effect of different parameters on NPV 


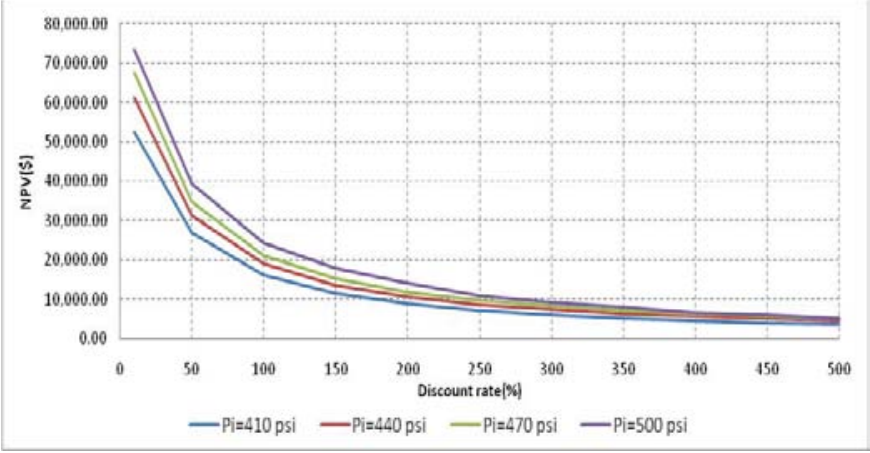

Figure 39.NPV profile for different initial reservoir pressure values Figure 40.NPV profile for different fracture aperture reduction factor values

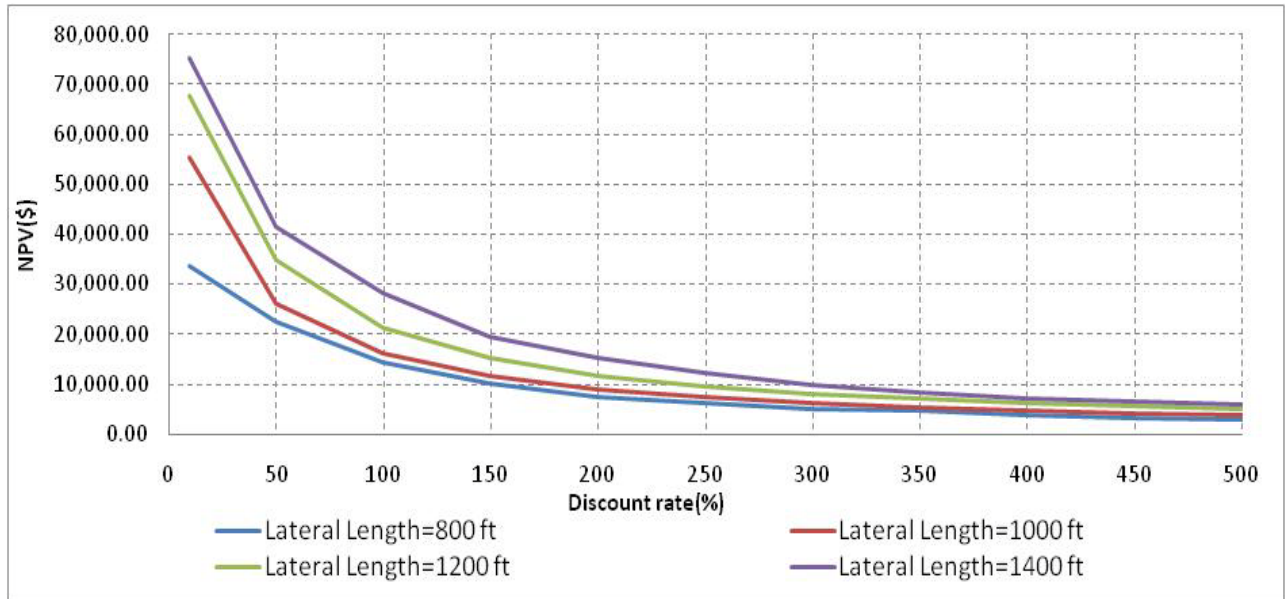

Figure 41.NPV profile for different horizontal lateral length values

\subsection{Data Preparation Procedure for Top-down Modeling}

Location and monthly production rate data for all wells and well logs (not necessary for all wells) are the minimum data requirement for the Top-Down modeling. Although gas has been produced from the New Albany Shale in the Illinois Basin for more than a century, available gas production data are sparse. Production data for the older wells were either never recorded or have not been preserved. Moreover, information about recent production is difficult to obtain. The New Albany shale data for 87 wells in Western Kentucky region was extracted from Kentucky geological survey and prepared for the analysis.

Because only last 6-9 years of production history was available for the wells mentioned above, a unique natural fracture network modeling and simulation (FracGen/NFFlow) was performed in order 
to generate (through history matching) a relatively complete production profile for each of the 87 wells. The complete production profiles were generated using FracGen/NFFlow for the 87 wells. These production profiles were used to perform Top-Down Intelligent Reservoir Modeling for the New Albany Shale gas reservoir. Figure 42 illustrates an example of generating the complete production profile for two of the NAS wells. In this figure, the green and black dots represent the actual production rates and cumulative production data collected from the Kentucky Geological Survey while the red and blue lines represent the history matched production rate and cumulative production profiles.

In this study, FracGen/NFFlow numerical simulator has been used to model natural fracture network and simulate a single gas well in New Albany shale.

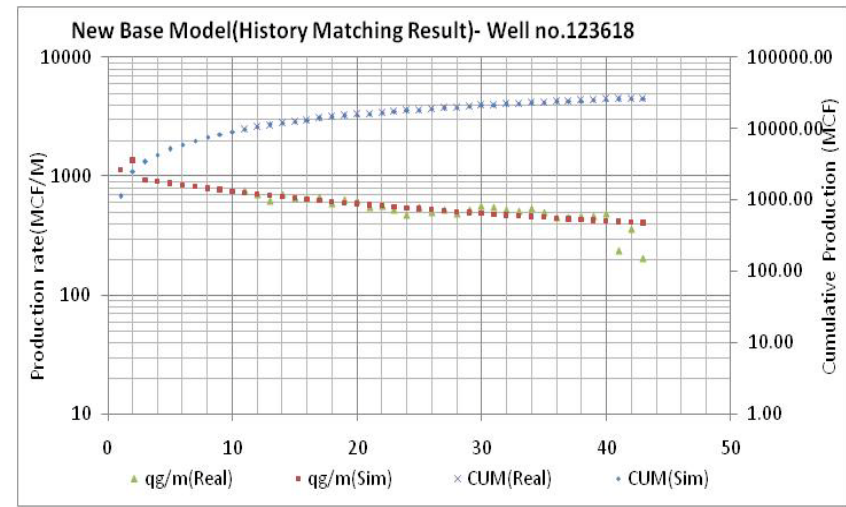

(A)

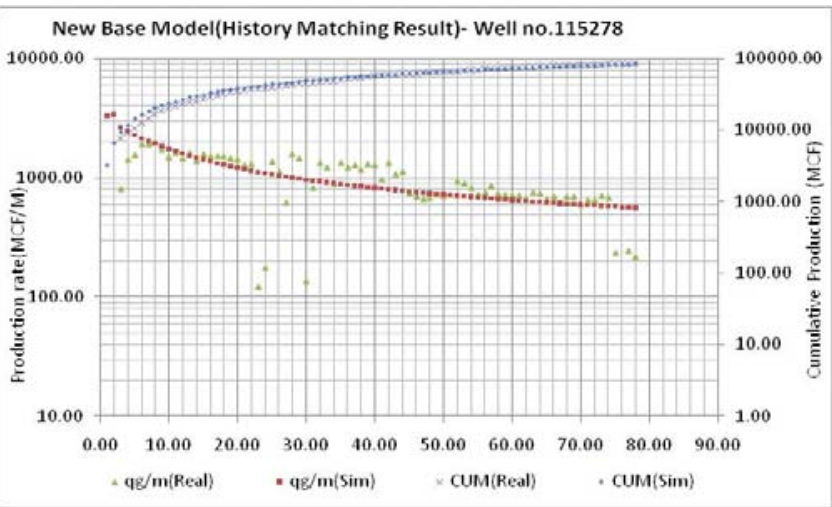

(B)

Figure 42. Simulation result examples for two history-matched New Albany Shale Gas wells (Out of 87 wells)

Figure 44 represent the location of wells being studies in Western Kentucky. To enhance the resolution of the study area, the wells being analyzed were divided into 2 clusters of 55(Case1) and 32(Case 2) wells. Both cases were analyzed during this study. 


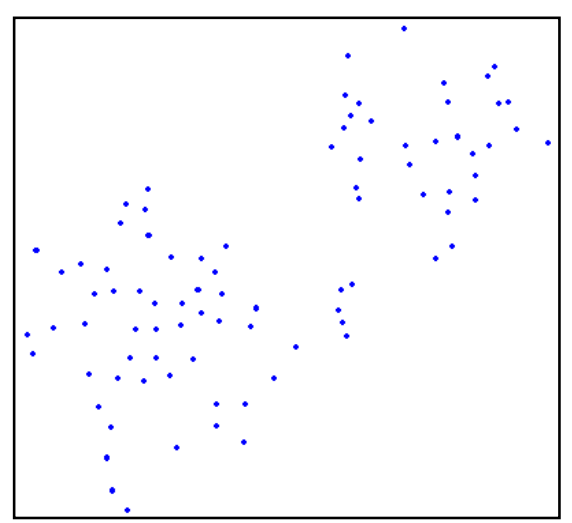

Figure 43. Location of under-study NAS gas wells

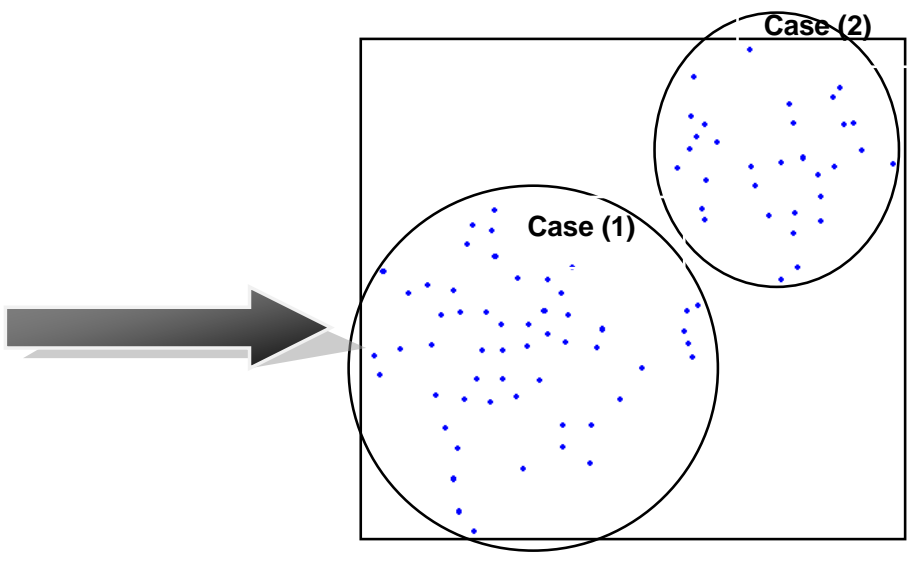

Figure 44.Two clusters of NAS wells for analysis (Case 1\&2)

Case 1-The Top-Down Intelligent Reservoir Modeling begins by plotting production rate and cumulative production versus time on a semi-log scale. An automatic optimization routine based on genetic algorithms identifies the best decline curve for the given well, as both the rate versus time and the cumulative production versus time are simultaneously matched. This is demonstrated in Figure 45 for one of the NAS gas wells. Initial production rate Qi, initial decline rate $\mathrm{Di}$, and hyperbolic exponent b are automatically identified. Additionally, the 30-year EUR is calculated. The information that results from the decline curve analysis is then passed to a type curve matching (TCM) procedure.

The appropriate type curves for the reservoir and fluid that is being investigated are selected. The type curves developed by Cox et al. (1995) have been used for the analysis of low-permeability shale gas reservoirs assuming constant bottom-hole pressure.

The type curve matching (TCM) has been performed by plotting the production profile using decline curve analysis results rather than the actual production data in order to minimize the subjectivity of the type curve matching. Performing decline curve and type curve analyses is an iterative process. 


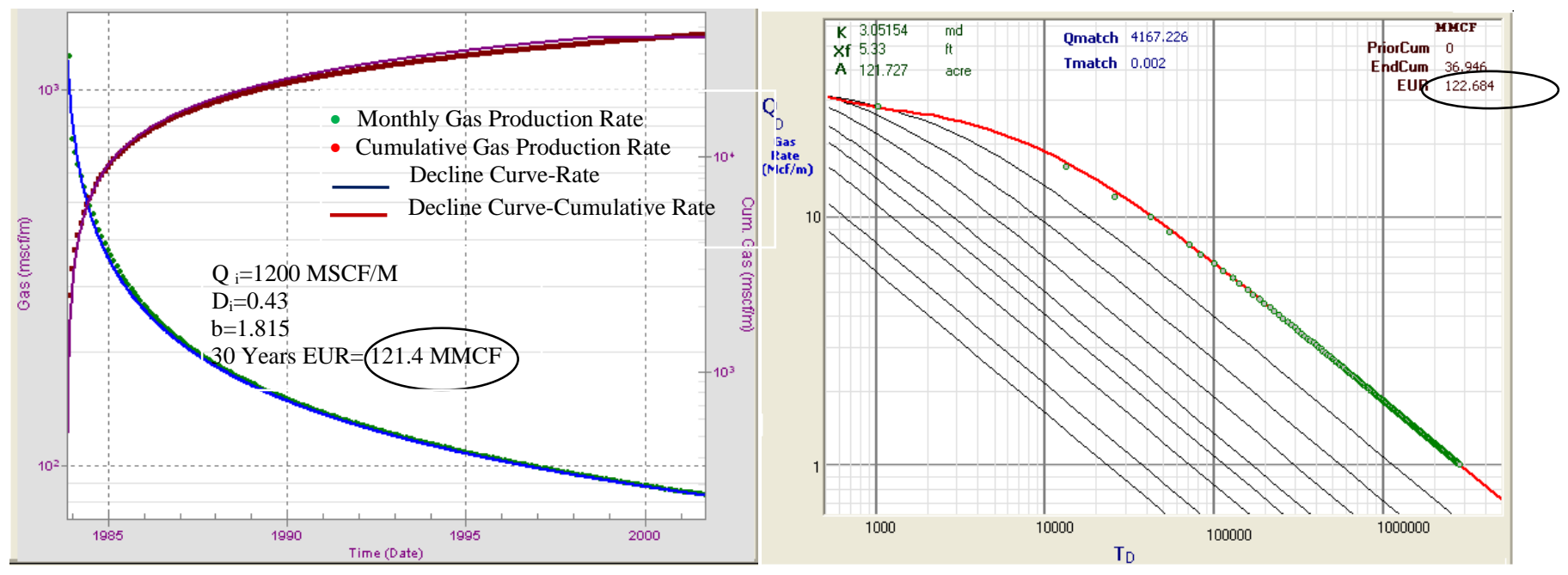

Figure 45. Decline curve analysis sample for one of NAS Figure 46.Type curve matching sample for one of Gas wells NAS Gas wells

While following this procedure, we should always keep an eye on the 30 years EUR value calculated by these two methods as a controlling yardstick. These values should be reasonably close.

The third step of Top-down Modeling is numerical reservoir simulation using a single-well, radial numerical simulator. During history matching the production data, all of the information generated from the DCA and TCM is used to achieve an acceptable match. Decline curve analysis, type curve matching, and single well history matching are an iterative process. Figure 47 represent the qualitative comparison between the result of history matching process and decline curve analysis.

Once the individual analysis for all of the wells in the field is completed, the following information for all the wells in the field is available: initial flow rate (Qi), initial decline rate (Di), hyperbolic exponent (b), permeability (k), drainage area (A), fracture half length (Xf ), and 30 Year EUR.

Figure 47 shows the well locations, followed by identification of boundary and the Voronoi grids for all the wells in the analysis for case 1.

Using the results of Decline Curve analysis and Volumetric Reserve Estimation, a well-based Recovery Factor is calculated for all wells, individually. A field-wide Recovery Factor is also calculated. Figure 49illustrates the calculate recovery factory of $17.47 \%$ for one of the wells and Field recovery factor of $23.58 \%$. 


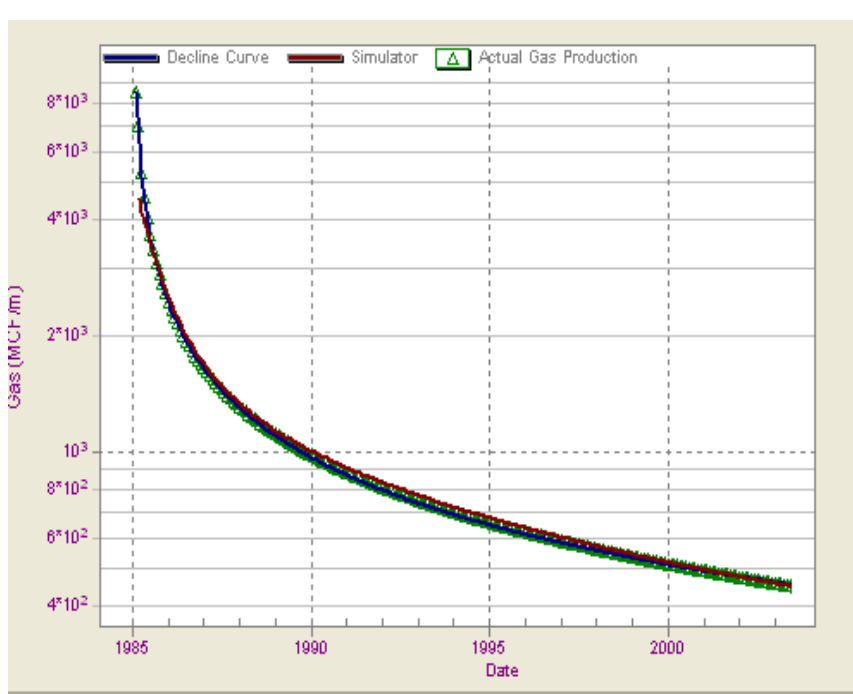

Figure 47.History matching results in comparison with DCA for one of the wells

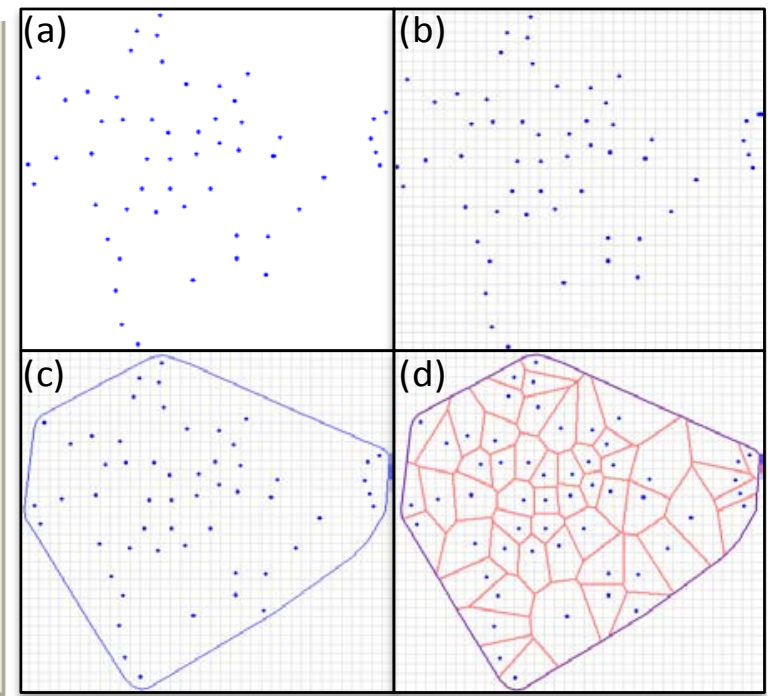

Figure 48.Generating the Voronoi cells for 55 NAS wells (Case 1)

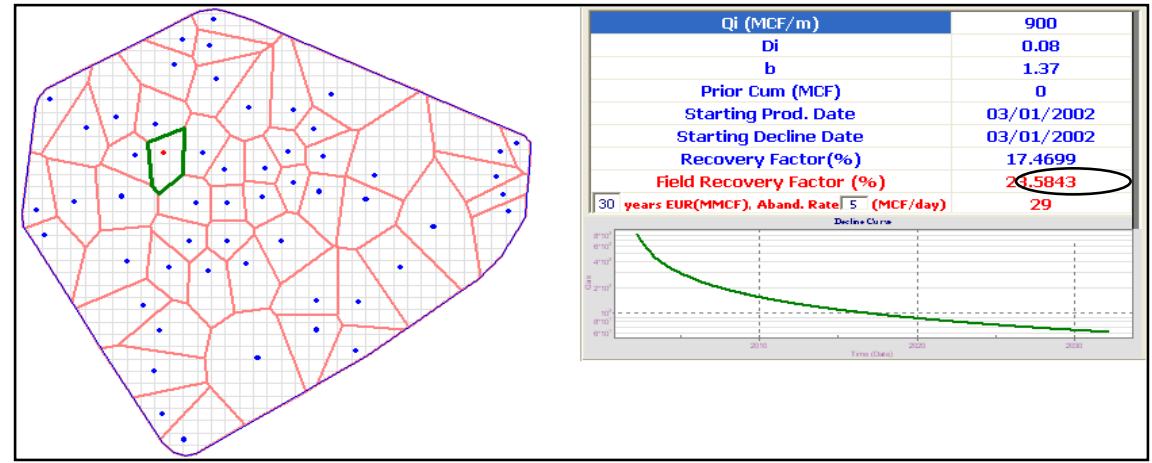

Figure 49. Calculated recovery factor for individual wells as well as field recovery factor

Once the Decline Curve Analysis and other steps mentioned above were completed, discrete, intelligent, predictive models are developed for the reservoir (production) attributes such as, first 3, 6, 9 month and 1, 3, 5, 10 years of cumulative production, decline curve information (Qi, Di and b), EUR, Fracture half length, matrix and total porosity, matrix and total permeability, net pay thickness, Initial gas in place, and well recovery factor. These sets of discrete, intelligent models are then integrated using continuous fuzzy pattern recognition in order to arrive at a cohesive model of the reservoir as a whole.

Using geostatistics a high level earth model is built. As part of the out comes of the high level earth model some of the two dimentsional maps of characteristics of the field such as porosity, permeability, and Initial Gas In Place distribution are shown in (Figure 50 and Figure 51). Another 
part of Top-Down, Intelligent Reservoir Modeling includes analysis of flow and production pattern characteristics usin fuzzy pattern recognition as shown in Figure 52 and Figure 53.

Upon completion of these analyses a rather complete spatio-temporal picture of the fluid flow in the reservoir emerges. The maps that are generated through these processes develop a sereis of visual guidelines that can help engineers and geo-scientist analyze reservoir behavior as a function of time and make decisions on field development strategies. Furthermore, optimum infill locations, examininig different infill scenarios and identifying potential remaining reserves based on each scenario and identifying underperformer wells are among tangible results that can be concluded from such analyses.

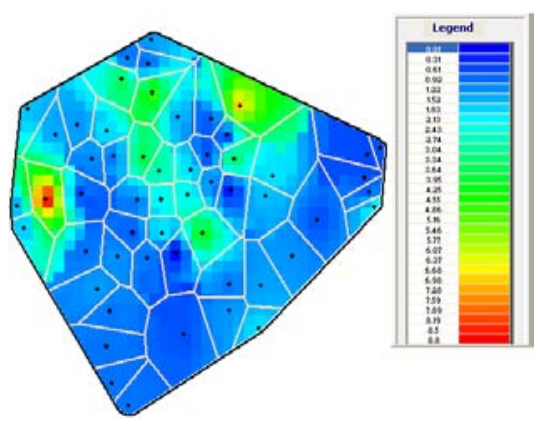

Matrix porosity (From simulation)
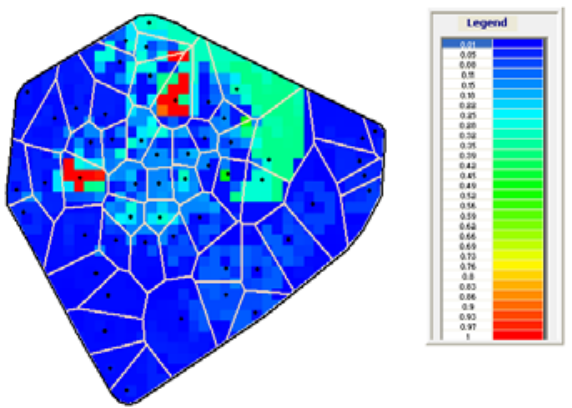
simulation)

Figure 50. Results of discrete predictive modeling showing the distribution of matrix porosity, and matrix permeability for the entire field (From left to right)

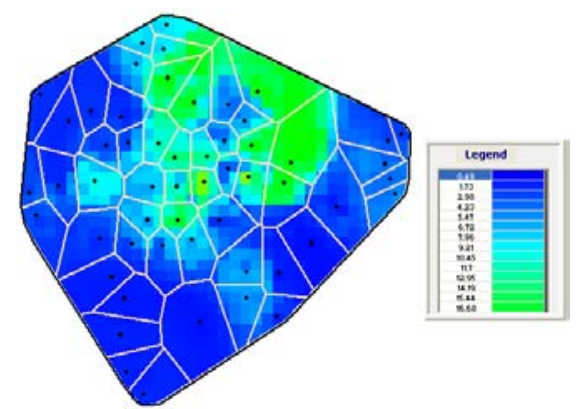

Total Permeability (From type curve)

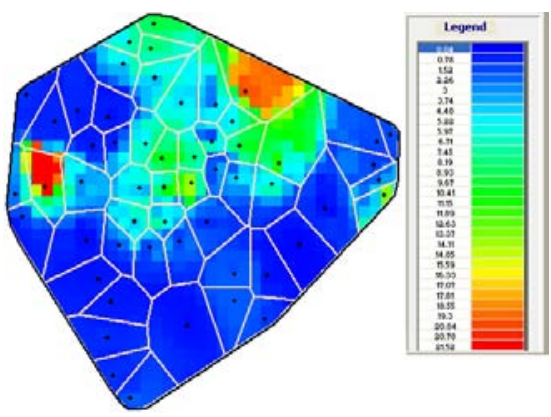

Initial gas in place (IGIP)

Figure 51. Results of discrete predictive modeling showing the distribution of total permeability from type curve and initial gas in place for the entire field (From left to right) 


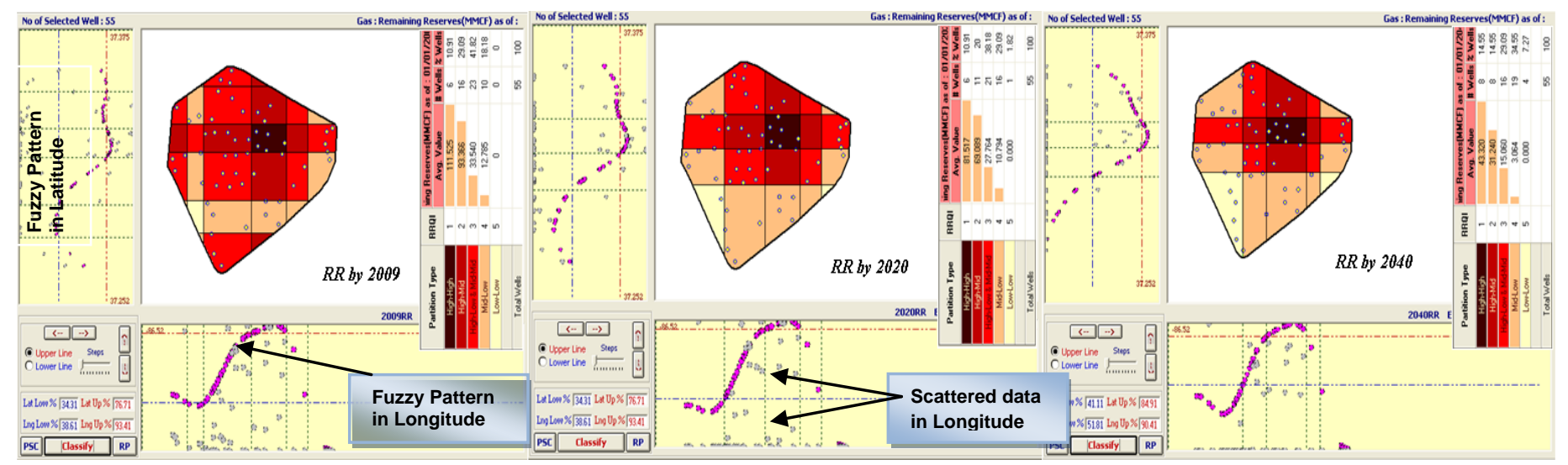

Figure 52. Results of Fuzzy Pattern Recognition showing the sweet spots in the field for the remaining reserve (MMCF) as of 2009, 2020 and 2040

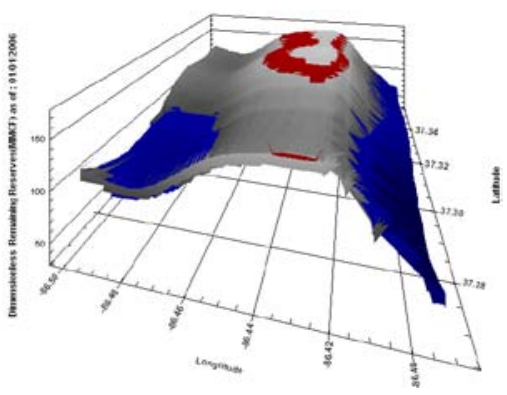

Remaining Reserve, by 2009
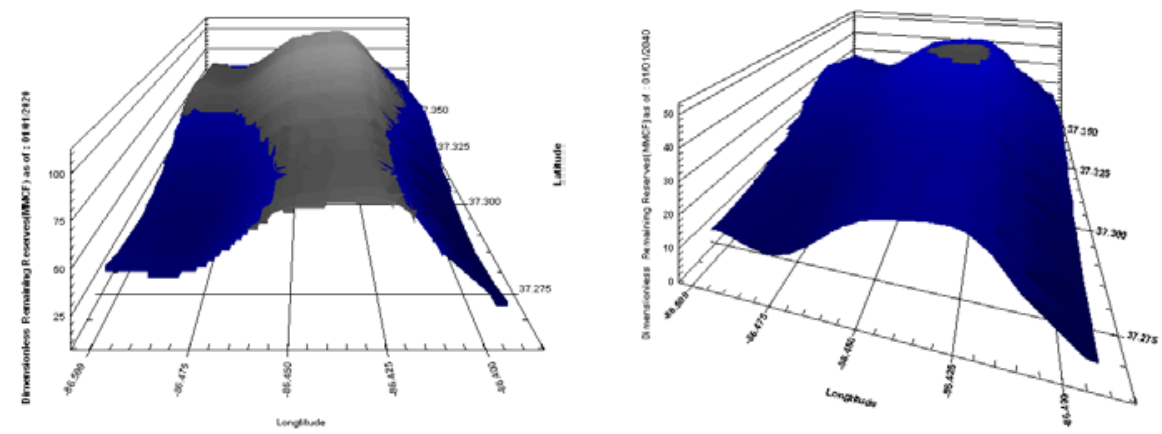

Remaining Reserve, by 2040

Figure 53. Remaining reserve as a function of time

The remaining reserve as of year 2006,2020 and 2040 has been shown in Figure 52 and Figure 53. In the two dimensional maps (Figure 52) reservoir is delineated with Relative Reservori Quality Index (RRQI) being the Remaining Reserves. The delineation shown in this figure are indicated by colors. Higher quality regions (regions with high values of Remaining Reserves) are shown in darker colors and as the average value of Remaining Reserves reduces in each region, the color becomes increasing ly lighter. The difference between these three figures shows the depletion in the reservoir and identifies the parts of the field that still have potential for more recovery.

Based on the results of predictive modeling and fuzzy pattern recognition, the best spots for drilling new wells were decided. The permeability is a key parameter that plays an important role in fluid production from the reservoir. Thereby having high initial production rate in the locations which have high permeability makes sense. Another important factor while making decision about the infill drilling locations is remaining reserves. It defines the amount of the stored fluid in the reservoir. 
Having both the remaining reserves and permeability, results in high storage and flow capacity. Thus, the potential spots for infill drilling can be selected, based on these parameters. Although these two parameters have considerable effect on deciding the new well locations, other parameters such as forcasted EUR for 30 years, matrix porosity,initial gas in place and also fracture half length have been taken into account.

According to these analyses, six new wells were proposed to be drilled in the reservoir. Locations of these new wells are shown in Figure 54. This figure also illustrates the change of drainage area ofter placement of new wells.
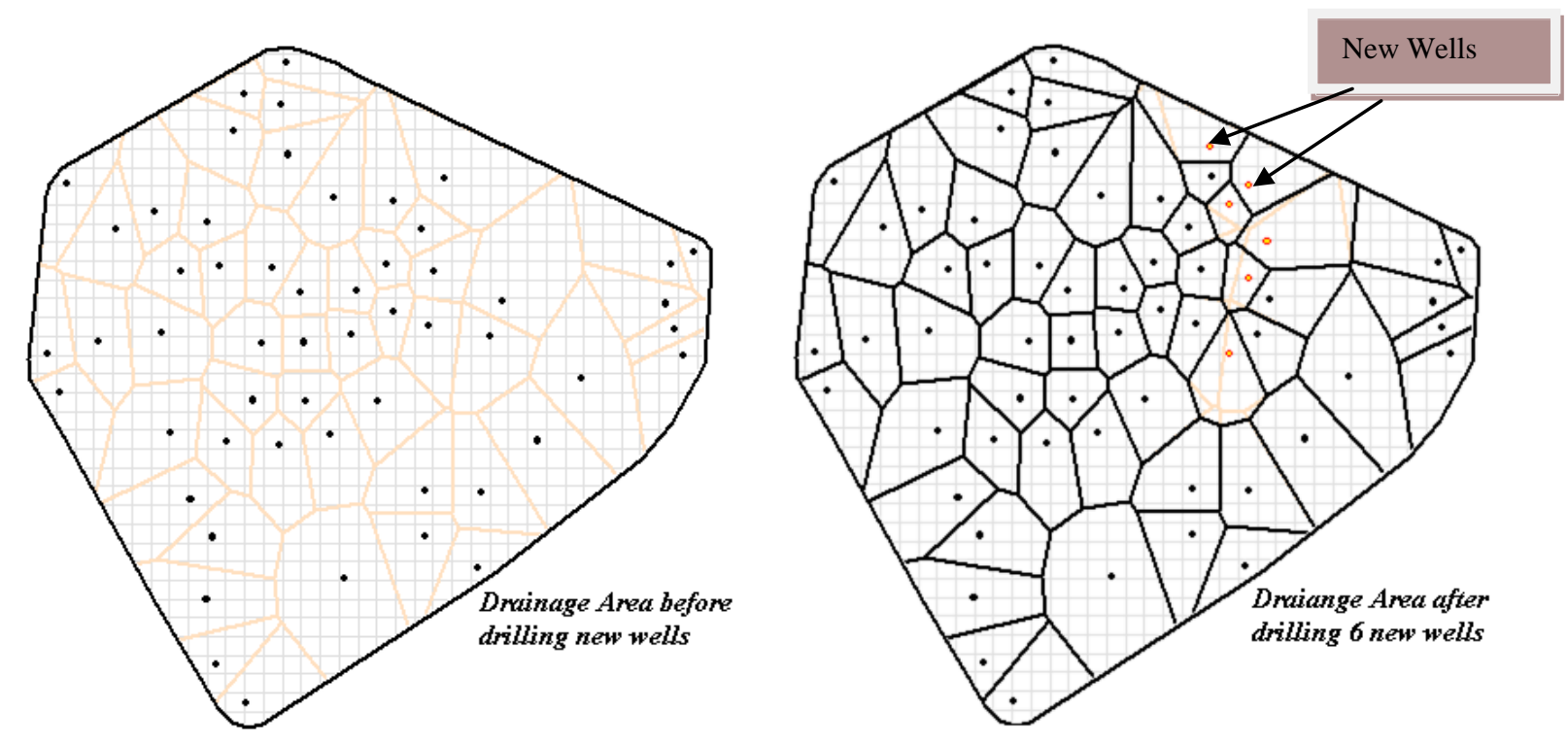

Figure 54. Proposed infill drilling locations and drainage area before and after placement of new wells (From left to right)

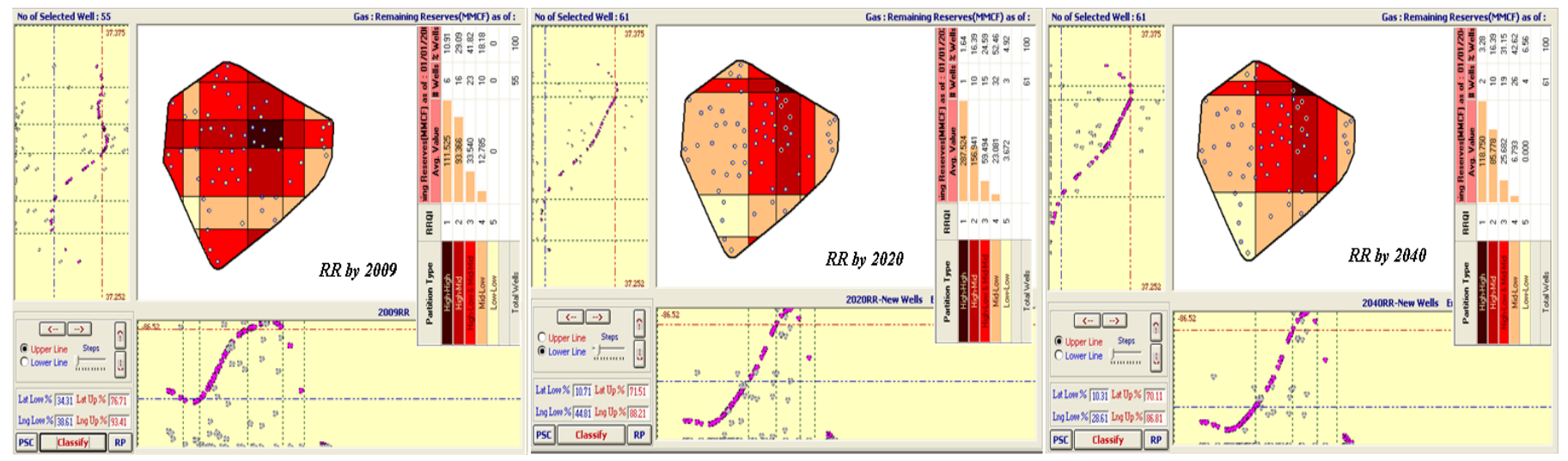

Figure 55. Results of Fuzzy Pattern Recognition showing the sweet spots in the field for the remaining reserve (MMCF) as of 2009, 2020 and 2040 (After drilling 6 extra wells) 

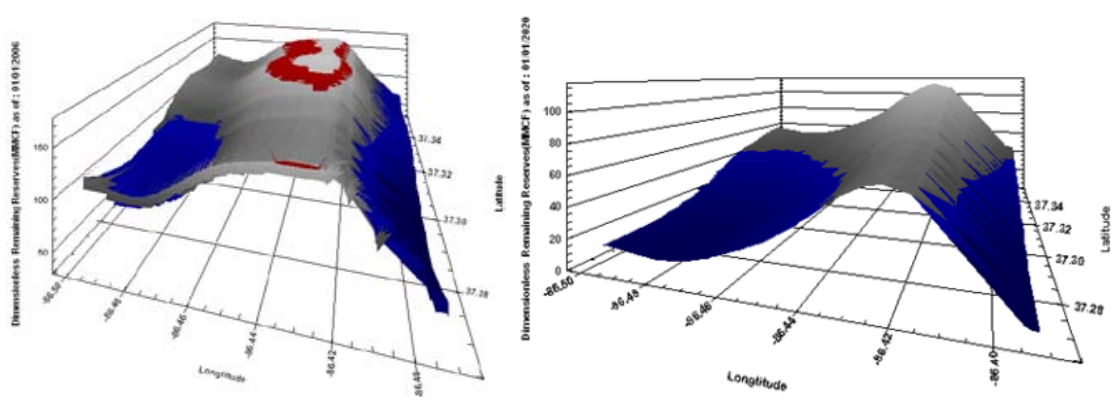

Remaining Reserve, by 2009

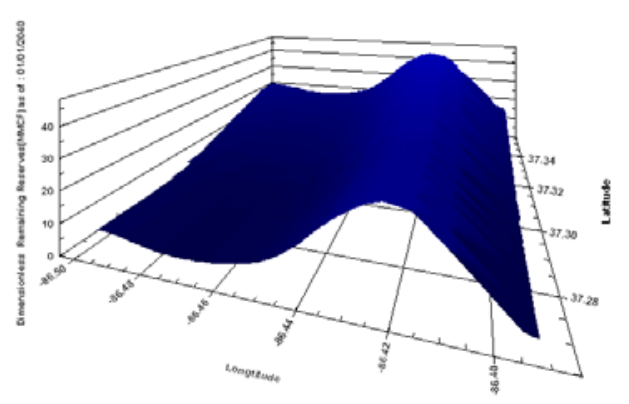

Remaining Reserve, by 2040

Figure 56. Remaining reserve as a function of time (After drilling 6 extra wells)

Figure 55 and Figure 56 illustrates remaining reserve as of year 2006,2020 and 2040 when those 6 new wells are added to the model. New wells identified in the analyses are shown in Figure 54.By selecting new wells at different locations and repeating the analyses shown in Figure 56(observing reservoir depletion as a function of their decision on where to place new wells), engineers and geoscientits can identify the best locations in the field that would provide the best production profiles and that satidfies their economic objectives.

Economic Analyses- The economic analyses were carried out for new infiil drilling liocations. Figure 57 demonstrates the details of economic analysis for one of proposed infill locations.The gas price that has been used in analysis was obtained from Energy Information Administriation(25) and the the vertical well cost has been estimated around \$200,000 (26).The value of other parameters which are used in economic analysis are based on our best guess. The predicted Net Present Value (NPV) for each new well is listed in Table 10

Table 10. NPV for New infill drilling location

\begin{tabular}{|c|c|}
\hline Well ID & NPV for 5 Years(USD) \\
\hline 1 & $87,054.53$ \\
\hline 2 & $102,207.01$ \\
\hline 3 & $134,870.31$ \\
\hline 4 & $86,170.17$ \\
\hline 5 & $124,827.53$ \\
\hline 6 & $93,311.03$ \\
\hline Average & $\mathbf{1 0 4 , 7 4 0 . 1 0}$ \\
\hline
\end{tabular}




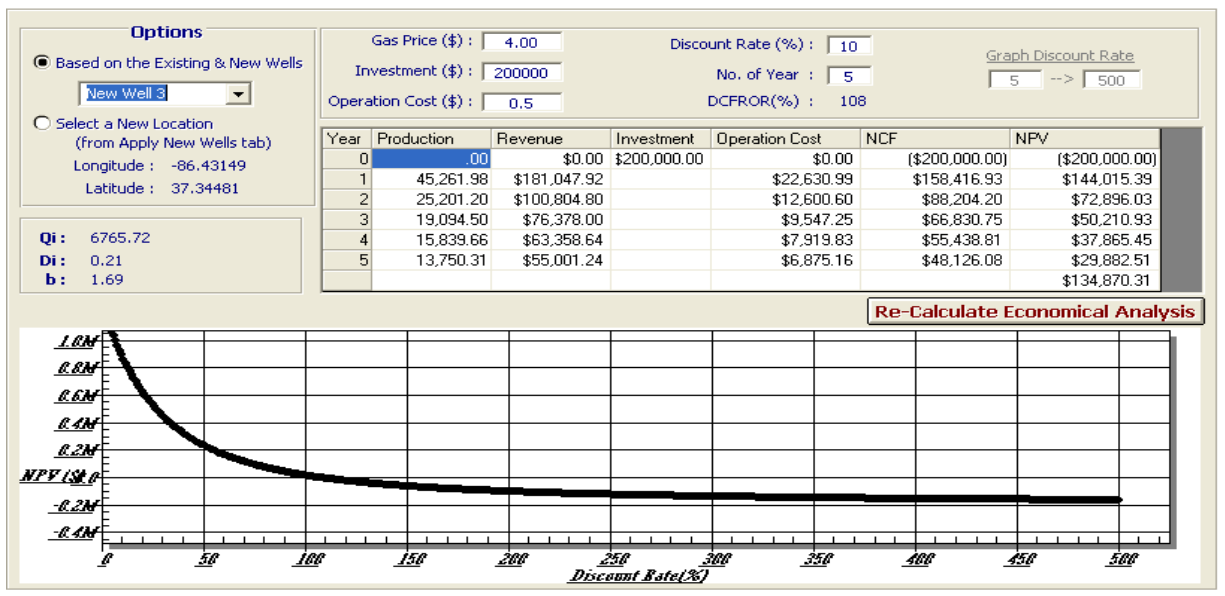

Figure 57. Economic analysis result for new well\#3.

\subsection{Model Calibration and Validation}

One of the steps that are taken upon building the Top-Down, Intelligent Reservoir Model is to calibrate and validate the model. To calibrate the Top-Down models about $10 \%$ of wells for are removed from the analyses. This constitutes removal of 6 wells from the analysis. The models are developed using the remaining 49 wells. The objective is to make sure that the Top-Down model can predict the 1 year cumulative production for these removed wells (blind data set). The results are shown in Table 11 and Figure 58.

For example in Table 11, four Relative Reservoir Quality Indices (RRQI) are shown as well as the model results that indicates the prediction for the blind/validation wells. As indicated in this table the Top-Down model predicted that the average 1 year cumulative production for wells drilled in the RRQI “1” (the darkest areas in Figure 58) will be more than 31.98 MMSCF. One well in RRQI "1" is removed and the average 1 year cumulative production for this well was 35.06 MMSCF (correct prediction).

Furthermore, the Top-Down model predicted that the average 1 year cumulative production for well in the RRQI "2" will be between 16.9 and 31.98 MMSCF. As shown in Table 11 there was 1 well drilled in RRQI "2" and the average 1 year cumulative production for this well was 26.13 MMSCF (correct prediction). 
For RRQI “3” the Top-Down model over-estimates the result slightly. It predicted that the average 1 year cumulative production for wells drilled in the RRQI "3" will be between 8.45 and 16.9 MMSCF while the 1 well drilled in RRQI "2" had an average 1 year cumulative production of 18.5 MMSCF.

The Top-Down model predicted that the average 1 year cum. for one well drilled in the RRQI " 4 " will be between 7.69 and 8.45 MMSCF and it turned out to be 8 MMSCF (correct prediction).

The same methodology has been performed for the second case.

Table 11. Results of Top-Down modeling (Case 1)

\begin{tabular}{|c|c|c|c|c|c|}
\hline \multicolumn{7}{|c|}{1 Year Cumulative Production(MSCF) } \\
\hline & \multicolumn{2}{|c|}{ Model Results } & \multicolumn{2}{c|}{ Removed Wells } \\
\hline RRQI & More Than & $\&$ & Less than & Average 1 Yr Cum & No. of Wells \\
\hline 1 & $31,980.55$ & & & $35,062.77$ & 1 \\
\hline 2 & $16,894.13$ & $\&$ & $31,980.55$ & $26,130.53$ & 2 \\
\hline 3 & $8,447.53$ & $\&$ & $16,894.13$ & $18,553.57$ & 2 \\
\hline 4 & $7,686.24$ & $\&$ & $8,447.53$ & $8,006.76$ & 1 \\
\hline & & & $7,686.24$ & Total & 6 \\
\hline
\end{tabular}

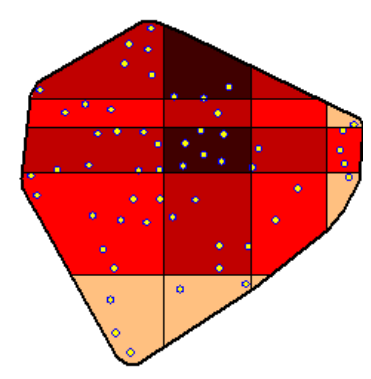

1 Year Cumulative Production (55Wells)

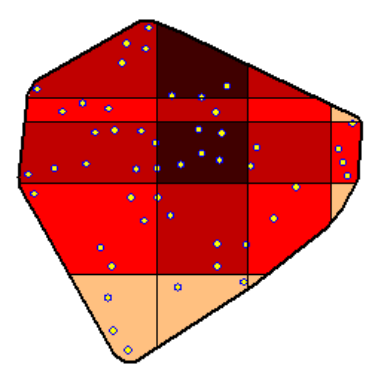

1 Year Cumulative Production (49 Wells)

Figure 58. Results of Fuzzy Pattern Recognition showing the sweet spots in the field for the 1 Year cum for 55 wells (left) and 1Year cum. Production for 49 wells (right).(Case 1) 
Case 2-The same analysis explained in the preceding section has been carried out for second case as well.

The generated field model besed on result of disceret intelligent modeling and fuzzy pattern recognition can be used to estimate the reserves, determine optimum infill drilling locations, follow fluid flow and depletion, verify remaining reserves,and detect underperforming wells. (Figure 63 through Figure 67)

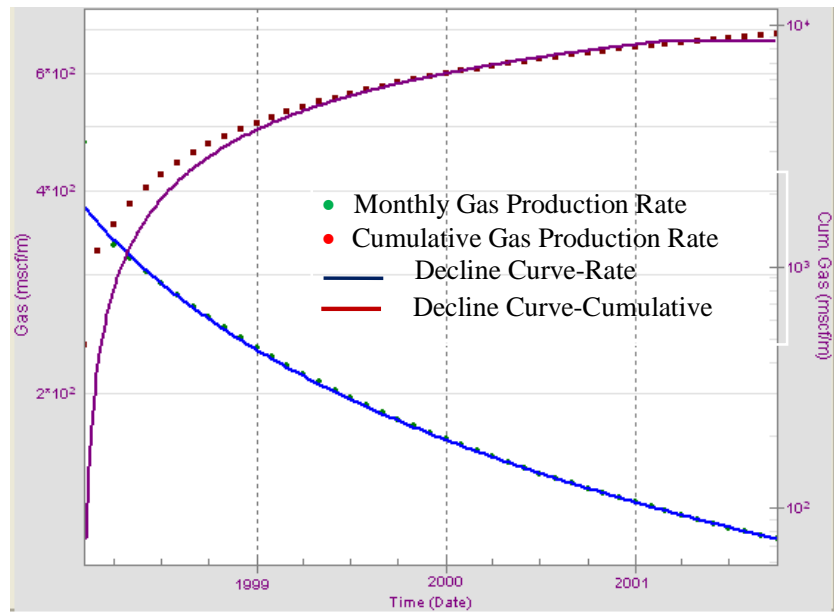

Figure 59. DCA sample for one of NAS Gas well

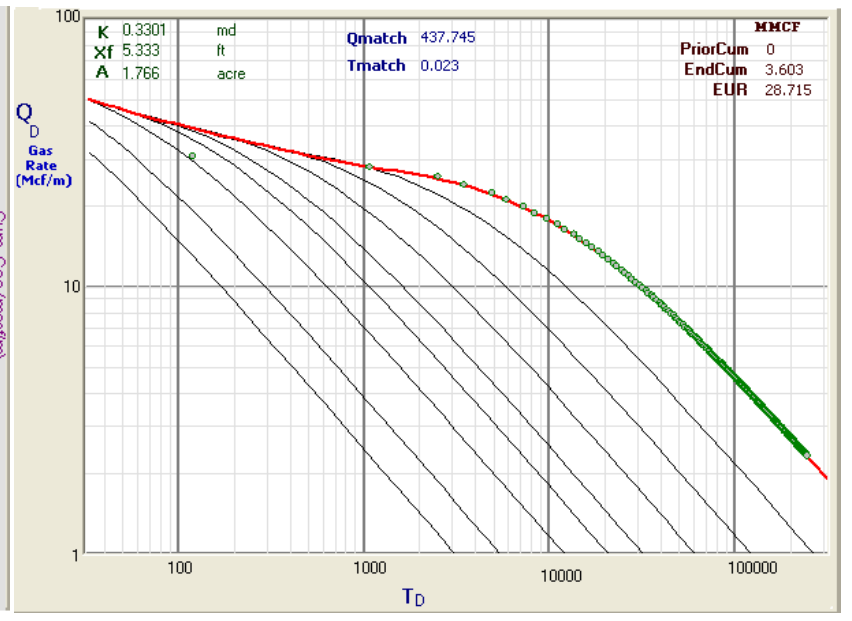

Figure 60. TCM sample for one NAS Gas wells

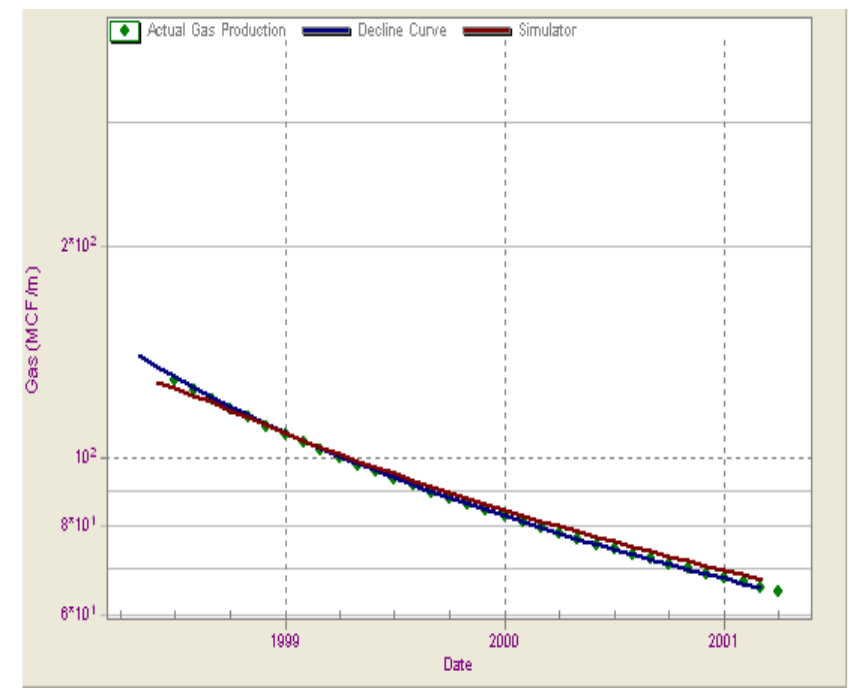

Figure 61. HM results in comparison with DCA (a)

(b)

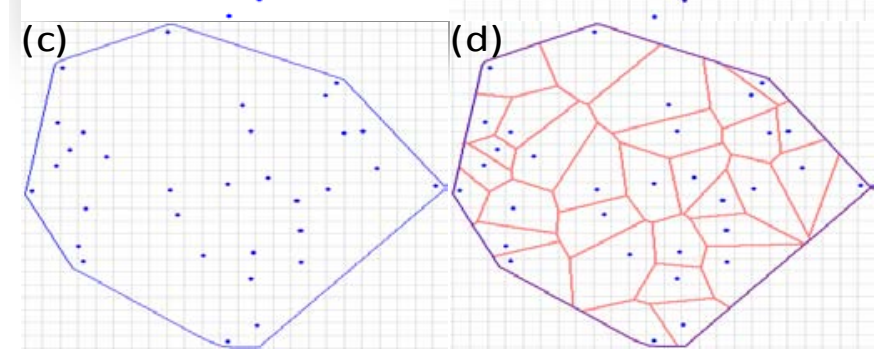

Figure 62. Generating the Voronoi cells for 32 NAS wells (Case 2) 


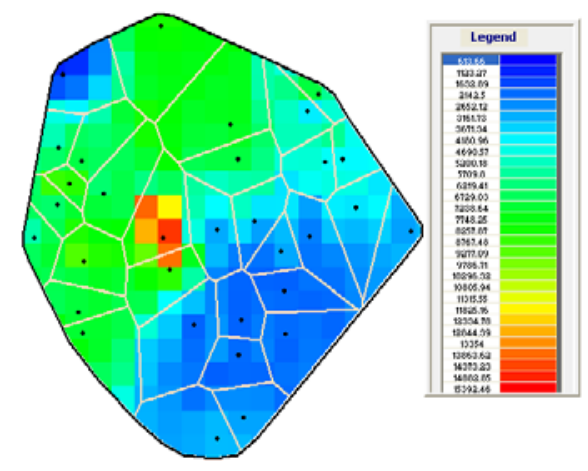

3 Month Cumulative Production

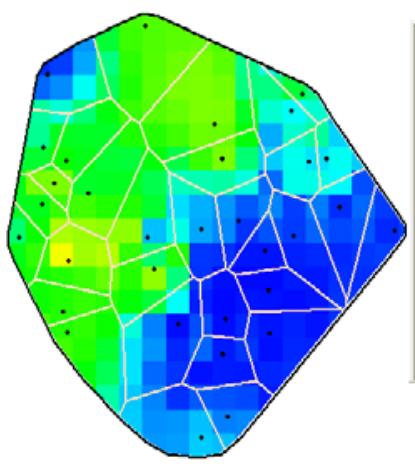

5 Years Cumulative Production

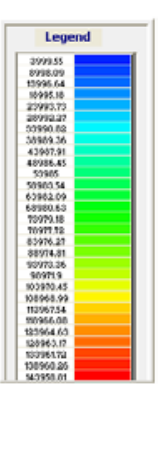

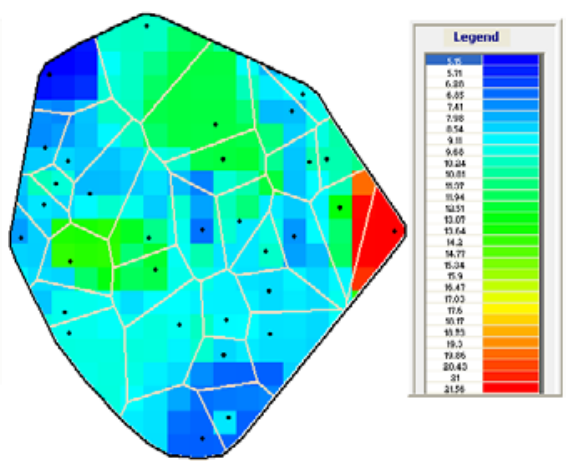

Fracture half-length

Figure 63. Results of discrete predictive modeling showing the distribution of first $\mathbf{3}$ months, $\mathbf{5}$ year cum. Production and fracture half length for the entire field (From left to right)

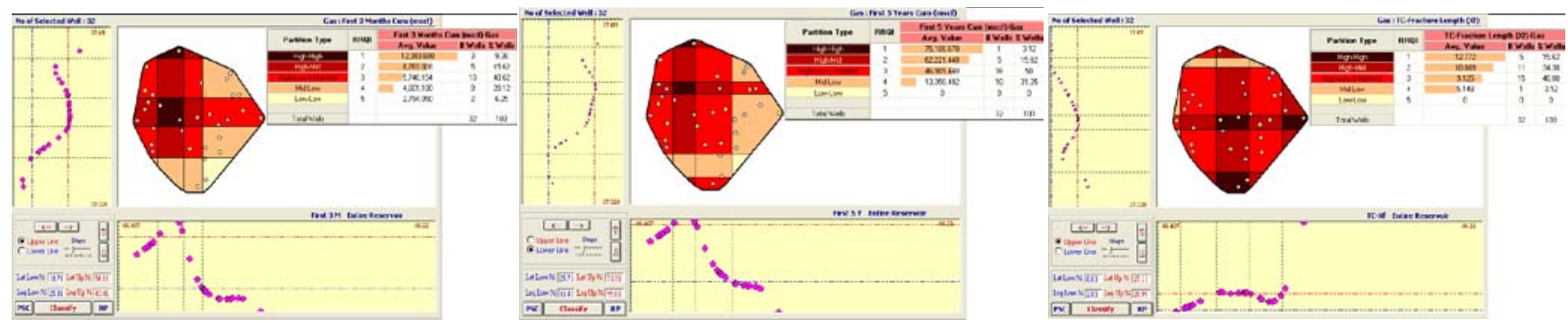

Figure 64. Results of Fuzzy Pattern Recognition showing the sweet spots in the field for the first 3 months, 5-year cum. Production, and the fracture half-length (From left to right)

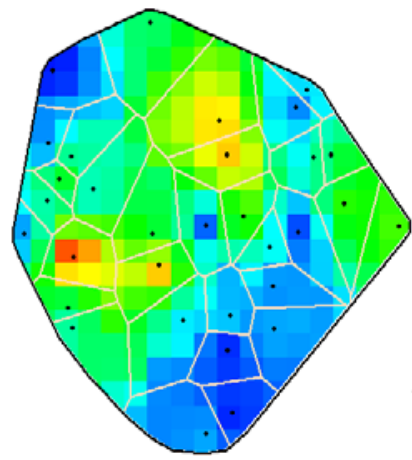

Matrix porosity
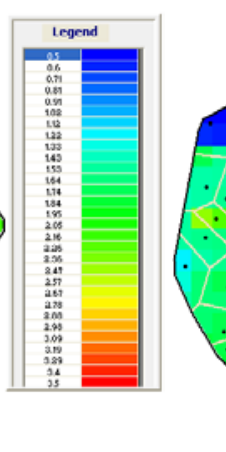

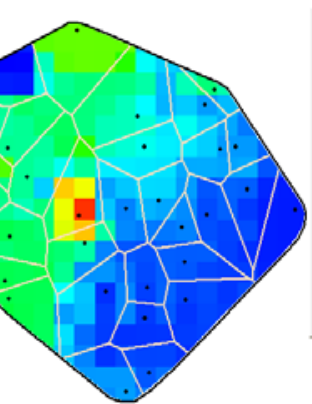

Total Permeability (TC)

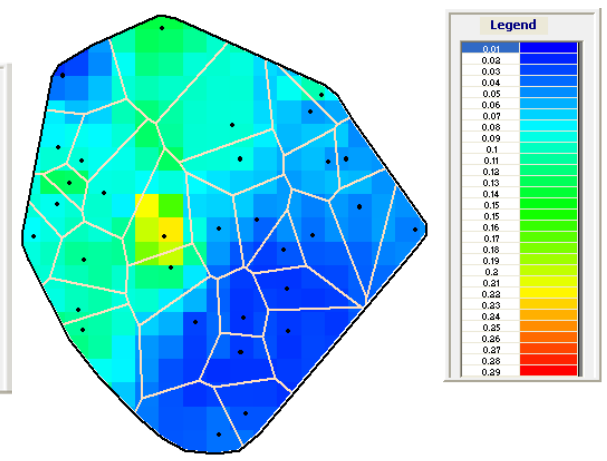

Matrix Permeability

$\left((\mathrm{md}) * 10^{\wedge}-6\right)$

Figure 65. Results of discrete predictive modeling showing the distribution of total porosity, matrix porosity, and net pay thickness for the entire field (From left to right) 

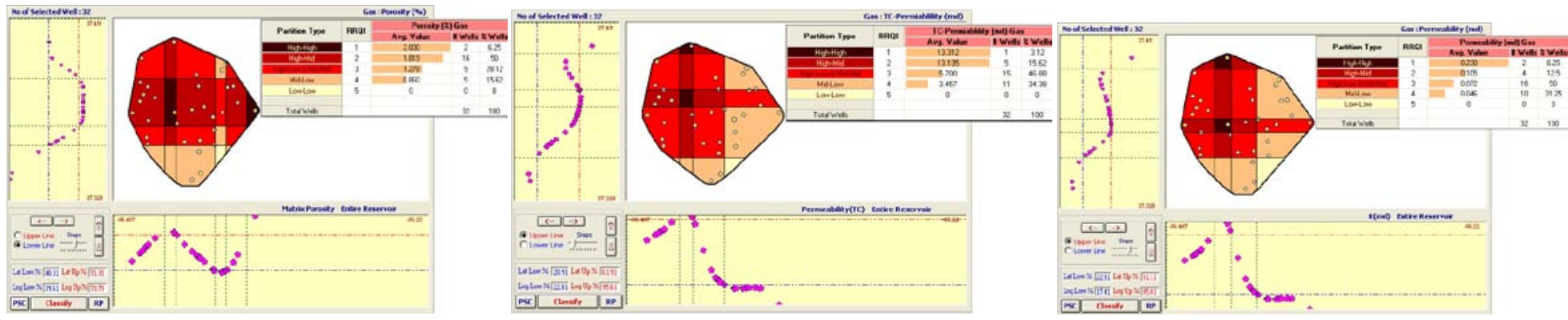

Figure 66. Results of Fuzzy Pattern Recognition showing the sweet spots in the field for the matrix porosity and total permeability from type curve and matrix permeability (From left to right)

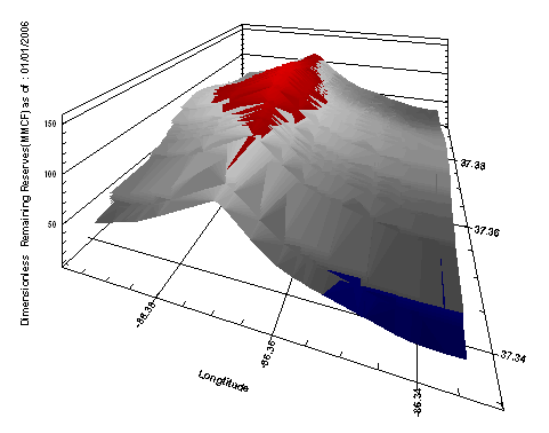

Remaining Reserve, by 2009

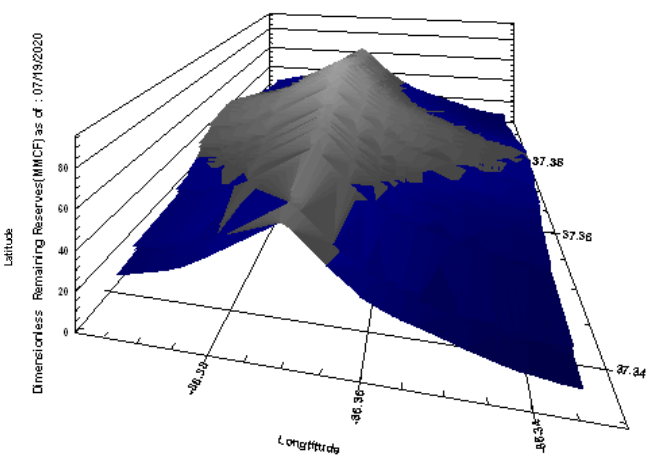

Remaining Reserve, by 2020

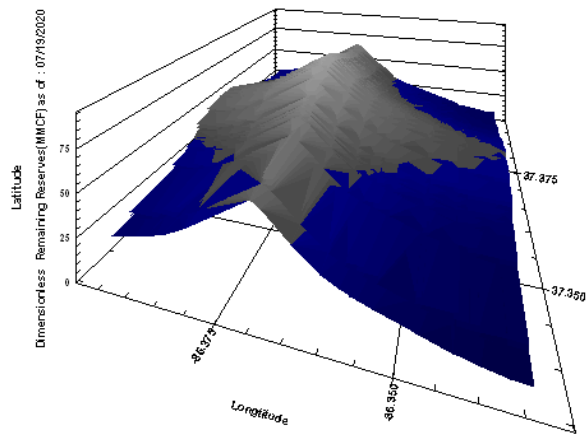

Remaining Reserve, by 2040

Figure 67. Remaining reserve as a function of time

The remaining reserve as of year 2009,2020 and 2040 has been shown in Figure 67. The difference between these three figures shows the depletion in the reservoir and identifies the parts of the field that still have potential for more recovery.

\subsection{Model Calibration and Validation}

The same methodology has been performed for the second case.(Table 12 and Figure 68)

For example in table 1 the four Relative Reservoir Quality Indices (RRQI) are shown as well as the model results that indicates the prediction for the blind/validation wells. As indicated in this table the Top-Down model predicted that the average 1 year cumulative production for wells drilled in the RRQI “1” (the darkest areas in Figure 68) will be more than 29.56 MMSCF. One well in RRQI "1" is 
removed and the average 1 year cumulative production for this well was 32.39 MMSCF. (correct prediction)

Furthermore, the Top-Down model predicted that the average 1 year cumulative production for well in the RRQI "2" will be between 18.37 and 20.93 MMSCF. As shown in Table 12 there was 1 well drilled in RRQI “2” and the average 1 year cumulative production for this well was 22.33 MMSCF .(correct prediction)

For RRQI "3" the Top-Down model predicted that the average 1 year cumulative production for wells drilled in the RRQI “3” will be between 12.92 and 18.37 MMSCF . The 1 well drilled in RRQI "2" had an average 1 year cumulative production of 14.49 MMSCF. (correct prediction)

The Top-Down model predicted that the average 1 year cum. for one well drilled in the RRQI "4" will be between 10.04 and 12.92 MMSCF and it turned out to be 11.5 MMSCF. (correct prediction) The same methodology has been performed for the second case.

Table 12. Results of Top-Down modeling (Case 2)

\begin{tabular}{|c|c|c|c|c|c|}
\hline \multicolumn{7}{|c|}{1 Year Cumulative Production(MSCF) } \\
\hline \multirow{2}{*}{ RRQI } & More Than & $\&$ & Less than & Average 1 Yr Cum & No. of Wells \\
\hline 1 & $29,559.87$ & & & $32,391.21$ & 1 \\
\hline 2 & $18,371.65$ & $\&$ & $20,937.61$ & $22,332.96$ & 1 \\
\hline 3 & $12,924.83$ & $\&$ & $18,371.65$ & $14,492.04$ & 1 \\
\hline 4 & $10,043.96$ & $\&$ & $12,924.83$ & $11,507.91$ & 4 \\
\hline & & & $10,043.96$ & Total & \\
\hline
\end{tabular}




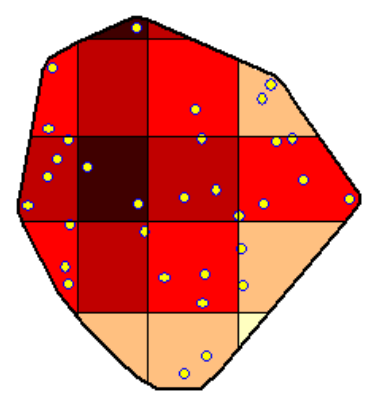

1 Year Cumulative Production (32Wells)

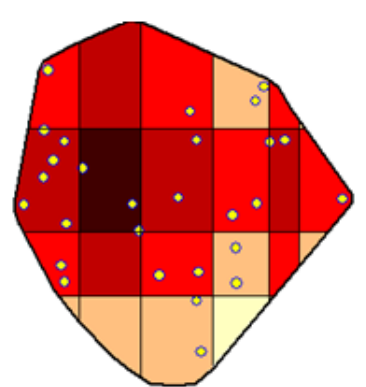

1 Year Cumulative Production (28 Wells)

Figure 68. Results of Fuzzy Pattern Recognition showing the sweet spots in the field for the 1Year cum for 32 wells (left) and 1 Year cum. Production for 28 wells (right).(Case 2)

\subsection{New Albany Shale Subsurface Modeling-Recently Completed Gas Wells}

In this part, 31 recently drilled well in Christian county Western Kentucky-Halley’s Mills quadrangle have been used to perform the geological analysis using GeoGraphix ${ }^{\circledR}{ }^{\mathrm{TM}}$ software Halliburton. The available well logs have been interpreted and the top and bottoms for New Albany Shale and the lower formation (Devonian LS) have been picked. The gas effect has been recognized using the neutron and density porosity logs. The structural maps for these formations have been created.

GeoGraphix ${ }^{\circledR}$ Discovery ${ }^{\mathrm{TM}}$ is an integrated suite of geophysical and geologic tools that increase asset understanding and provide the highest quality geologic maps available to the industry today.

The GeoGraphix Discovery suite is a Windows ${ }^{\circledR}$-based geologic and geophysical interpretation system that combines industry-leading technologies supported by a common data and project architecture.

GeoGraphix ${ }^{\circledR}$ PRIZM ${ }^{\mathrm{TM}}$ software is a sophisticated log analysis application that is designed for multi-well petrophysical projects. Designed to meet the needs of both the petrophysicist and geologist, PRIZM software technology operates in a familiar Microsoft ${ }^{\circledR}$ Windows ${ }^{\circledR}$ environment. Furthermore, PRIZM software contains customizable and interactive tools for data editing, log analysis, and curve displays in multi-well, multi-zone projects. It is an ideal tool for reservoir characterization. PRIZM has tight integration with the GeoGraphix Discovery suite of mapping, cross-section, zone analysis and geophysical applications. 
Zone manager feature of Geographix ${ }^{\circledR}$ software has been used .The available production data and other static reservoir properties have been imported as the attributes to generate related contour maps and have been are interpreted.

The project was built in the GeoGraphix, setting the datum as NAD 1927.Figure 69 shows the workflow of this process.

The next step was to import the well location map and corresponding well logs. The GR, Resistivity, Neutron porosity and Density porosity logs were available for almost all the wells.

Figure 70 lists the formation names. Since we are focusing on New Albany Shale for this study only this formation and the underlying formation (Devonian Limestone) are picked in the logs.

The Gamma ray was used to determine the shales using the "Area Fill" feature of the "Prizm” (Figure 71).

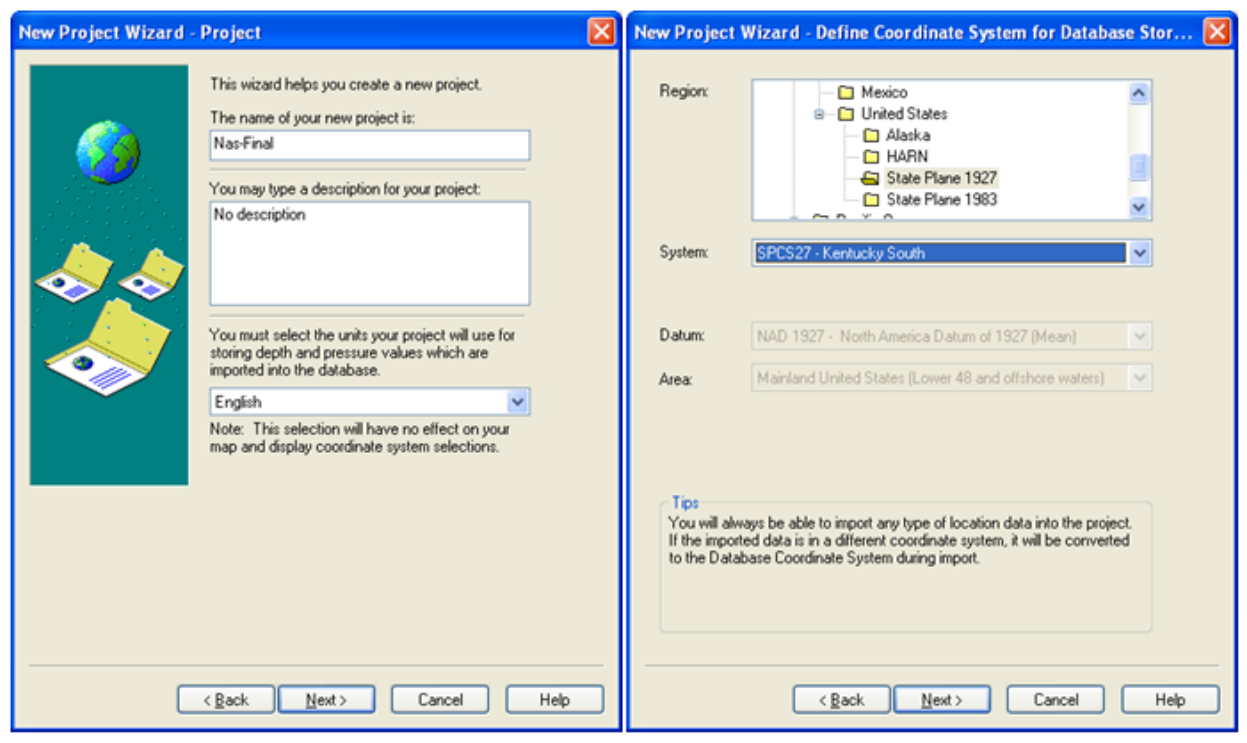

Figure 69. Making a New Project and Setting the Datum

When gas is present, the neutron log reads low porosity, and there is a big spread between the density and neutron curves. This spread is called "gas effect". The presence of sandstone also causes the two curves to spread, but not nearly so much as gas effect. This concept was used again in the "Area Fill" section of "Prizm" and by setting it to show the Gas Effect in the formations that we have the density porosity value more than the neutron porosity value we are going to have log sections as shown in Figure 71. 


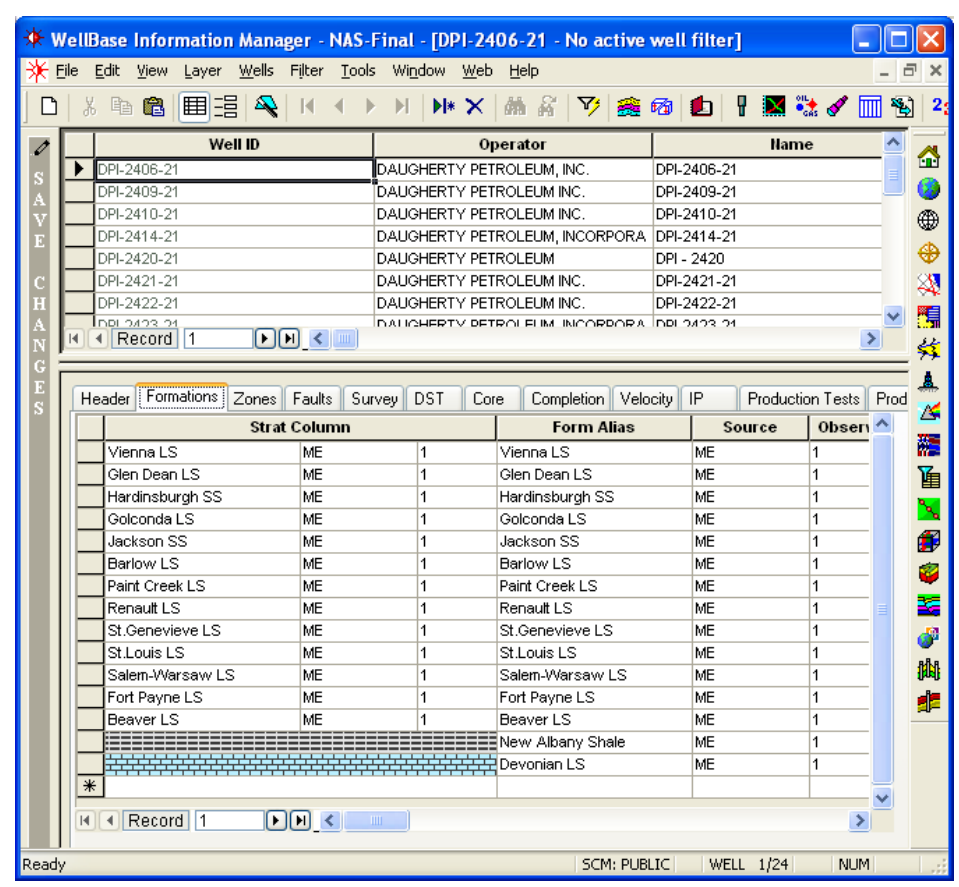

Figure 70.Well Records and Formation List.

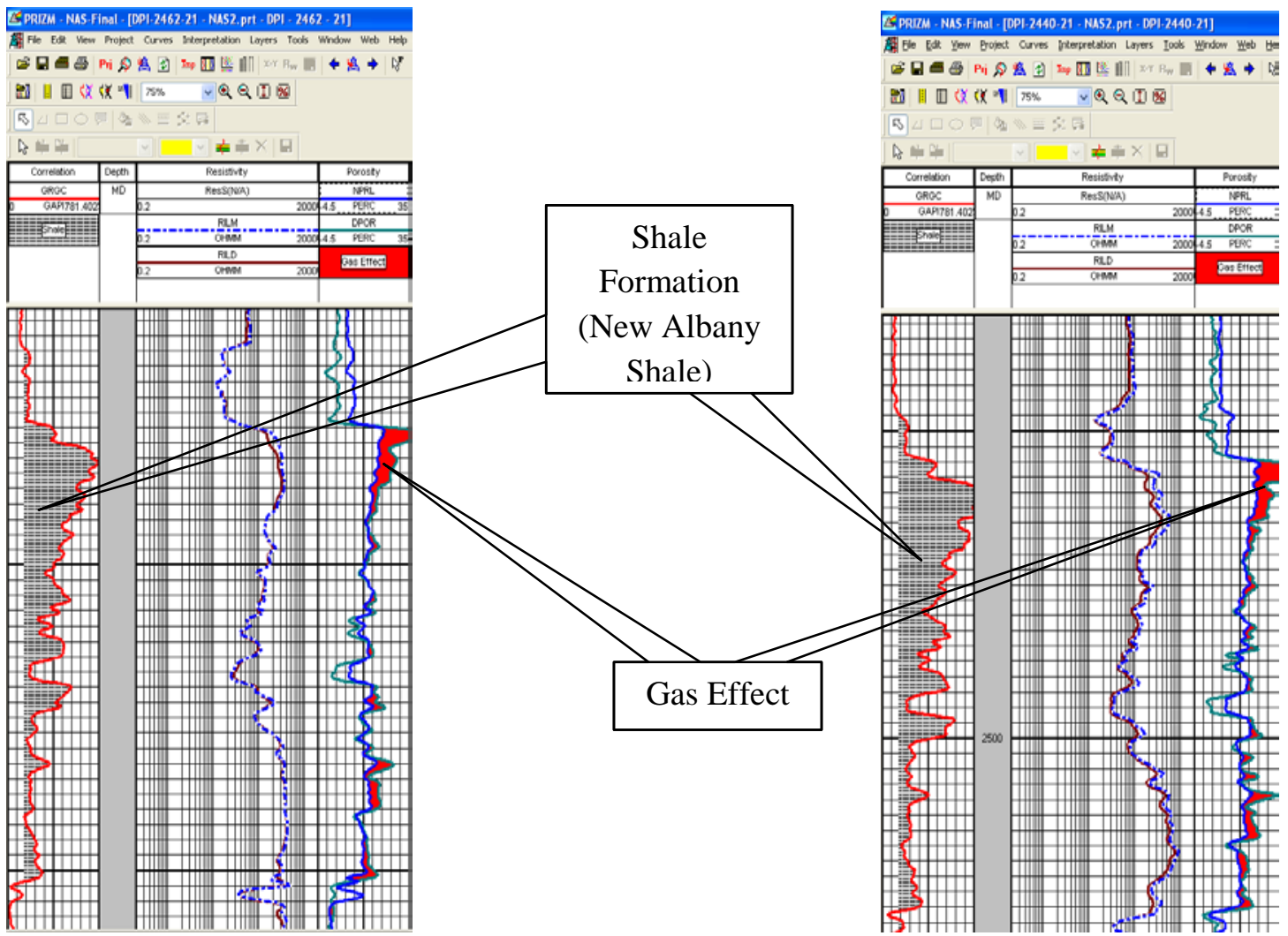

Figure 71.Interpreting the Shale Formations and Gas Effect in Prizm. 
Four cross sections were created to interpret the well logs in the "X-Section" part of GeoGraphix. (Figure 72) .The New Albany Shale and Devonian Limestone tops and bottoms were picked in the well logs (Figure 73 and Figure 74). The data obtained from this step is used to build the structural maps of these formations in "GeoAtlas".

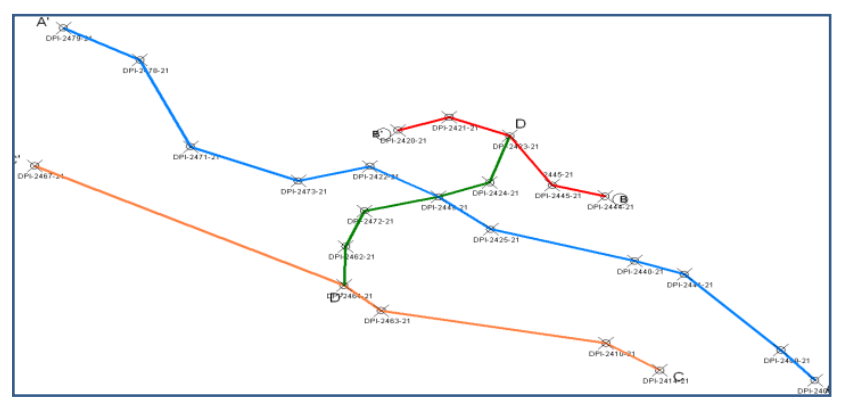

Figure 72. Four cross sections were created for analyzing the well logs.

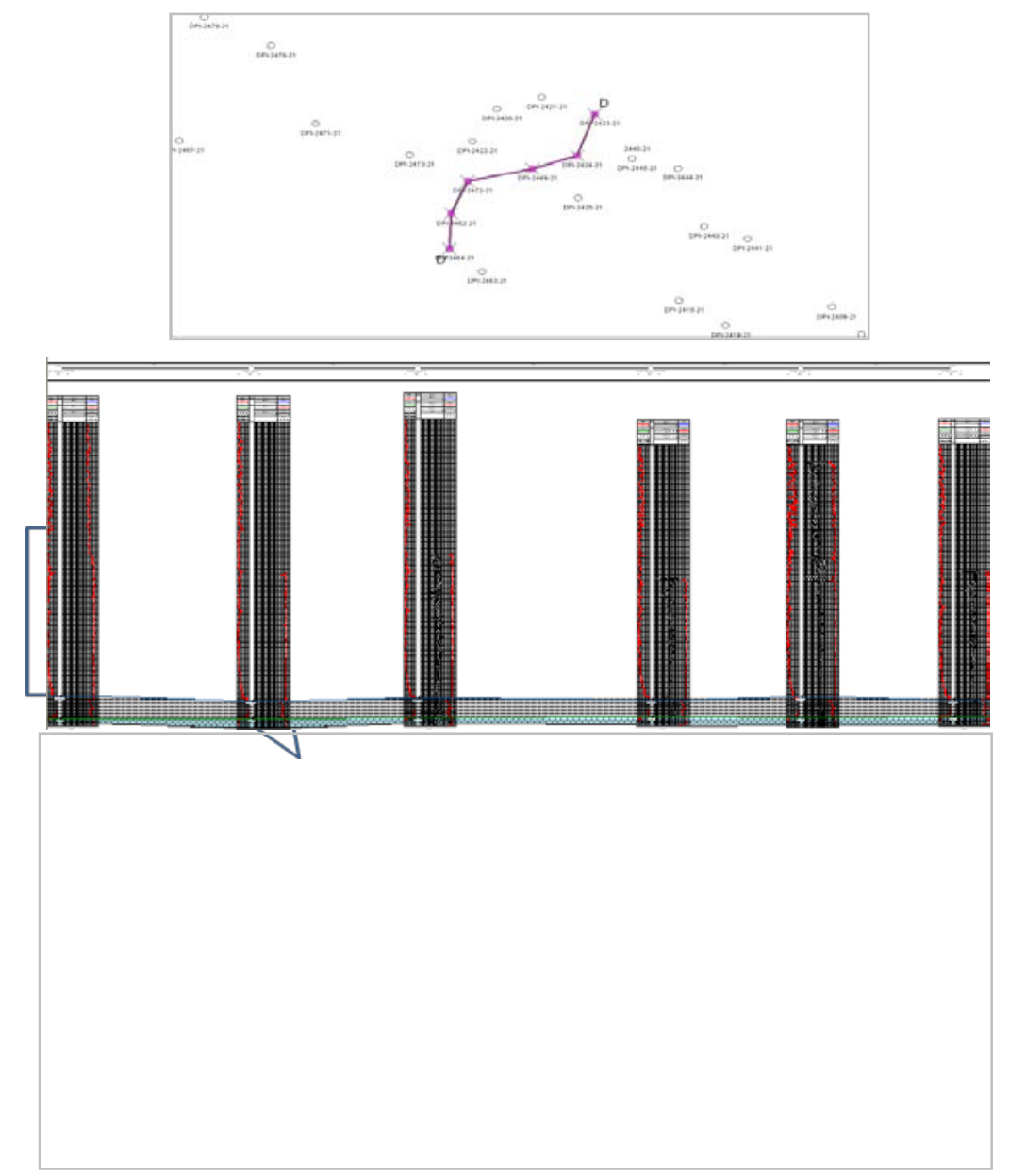

Figure 73. Picking the top and bottom of formations in Cross Section D. 


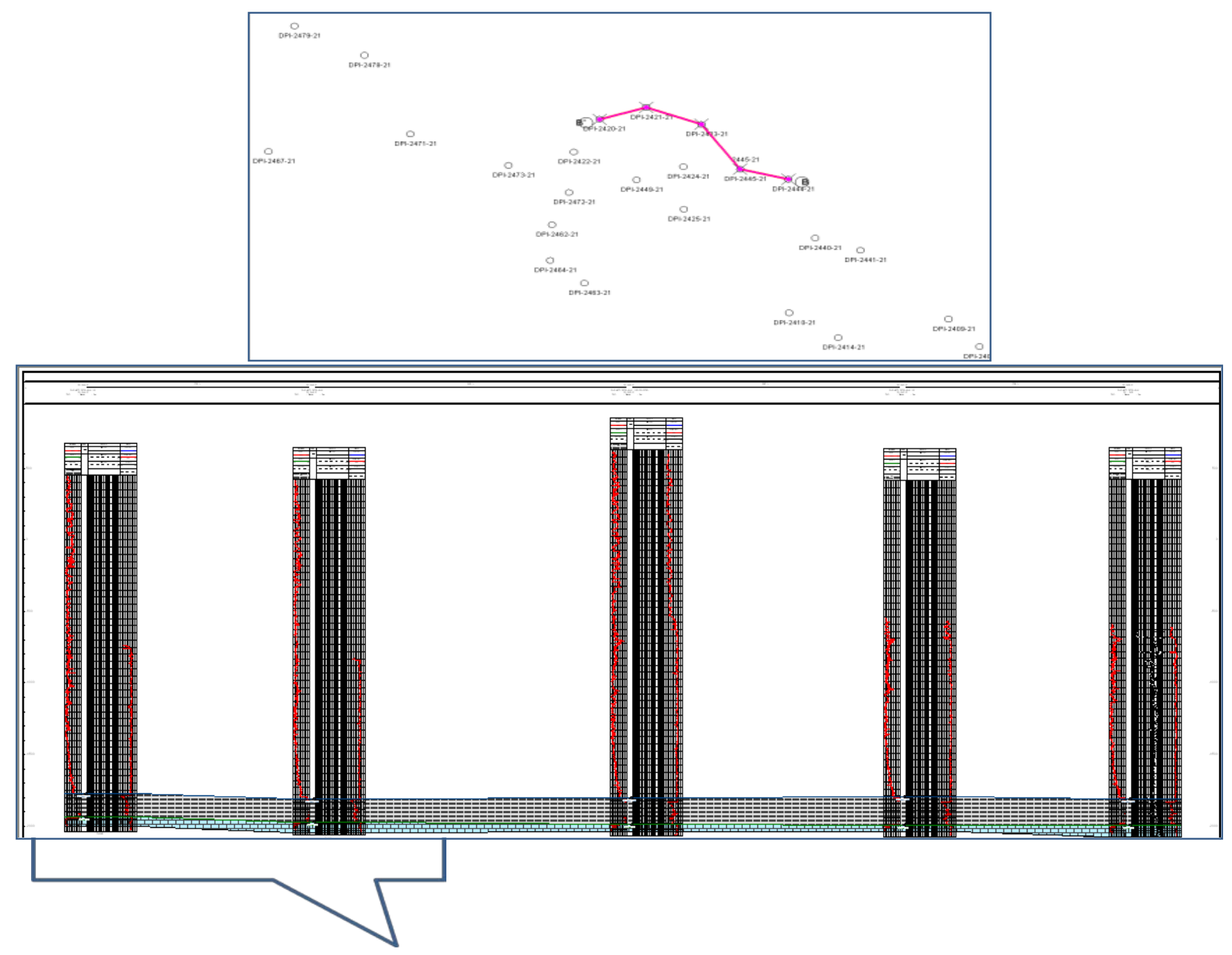

Figure 74.Picking the top and bottom of formations in Cross Section B. 
The production data for the wells were imported to "Zone Manager". Resistivity logs were used to calculate the water saturation in the target formation (using the Schlumberger charts).Since New Albany Shale is only producing dry gas; the gas saturation was calculated base on the difference between $100 \%$ and the water saturation.

The average porosity was calculated by averaging the neutron and density porosity in the New Albany formation. This porosity takes into account both the matrix and fracture porosity. Since this is a Shale formation, the matrix porosity values are not significant in comparison with the fracture porosity.

A fracture network was built for New Albany Shale formation in "FracGen" software and it was history matched using the production data from these wells in "NFFlow". The matrix porosity, permeability and initial pressure calculated results from history matching process were used as import to "Zone Manager".

The formations top and bottom were used to create the structural maps. Figure 75 shows the Top Subsea map of New Albany Shale (NAS).

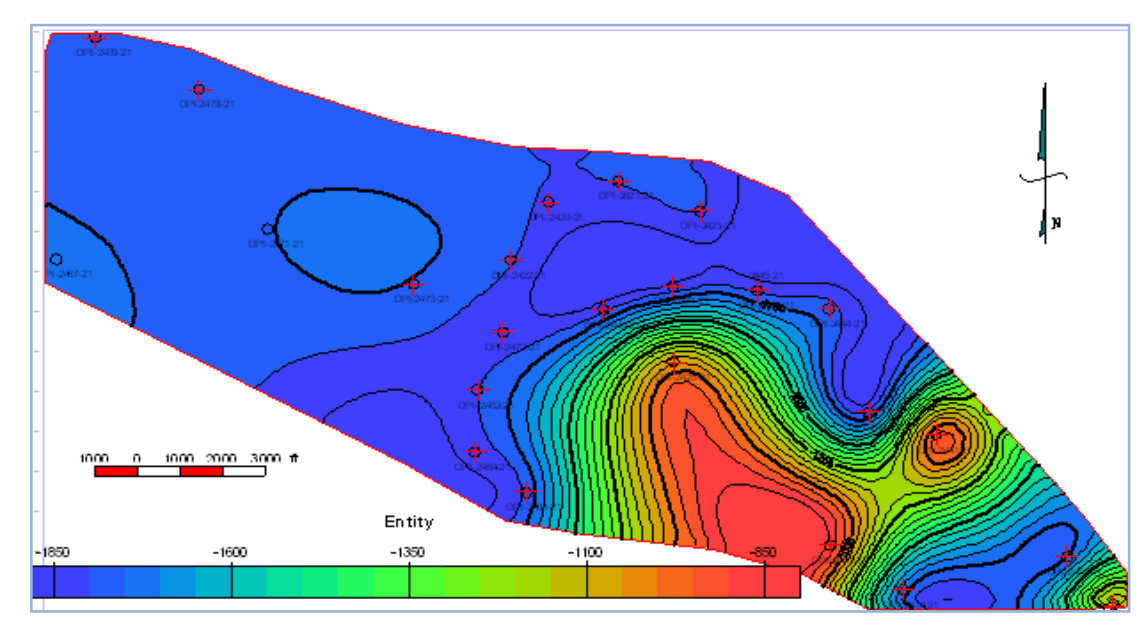

Figure 75. NAS Top Subsea

This figure shows that the formation is getting shallower in the south part, so it is dipping NorthWest. The top subsea map, which is, actually the NAS bottom map is shown below. (Figure 76) 


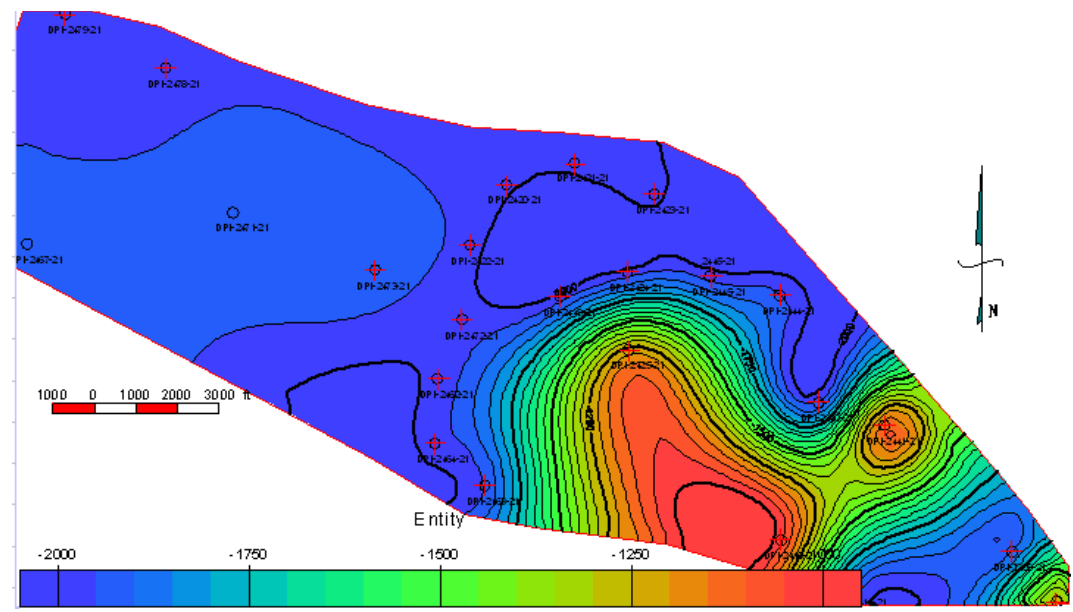

Figure 76. Devonian LS Top Subsea

According to the above figure, it can be concluded that the Devonian LS is almost following the same trend as NAS in dip.

The Gross Thickness of NAS has been mapped and shown below (Figure 77). Along with the thickness map, it is obvious that NAS formation is getting thicker in the Northern part.

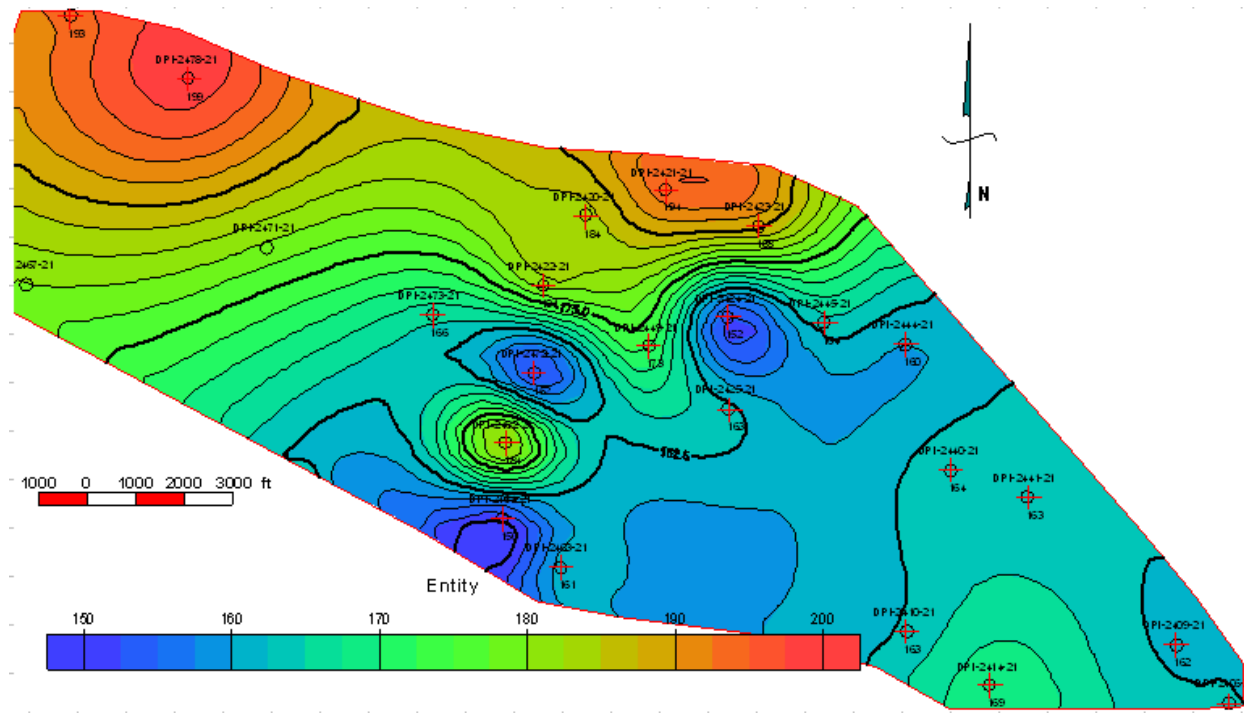

Figure 77. NAS Isochore map

The Top-Down Intelligent Reservoir Modeling workflow has been performed on recently completed wells (understudy area) 


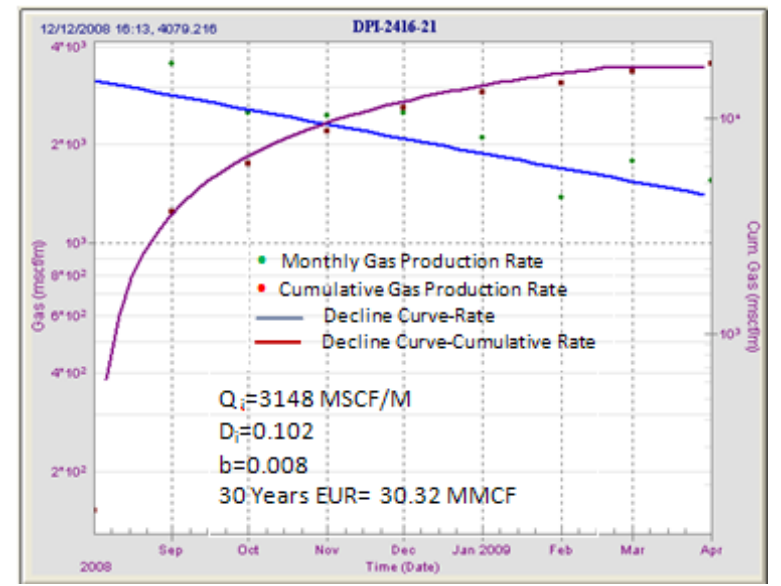

Figure 78.Decline curve analysis sample for one of NAS gas wells

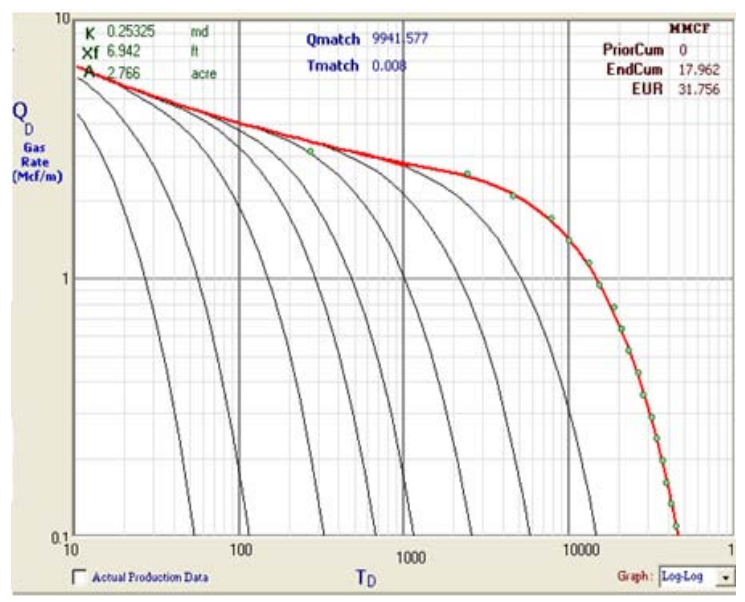

Figure 79.Type curve matching sample for one of NAS gas wells

Figure 80 represents the qualitative result of history matching process. Once the individual analysis for all of the wells in the field is completed, the following information for all the wells in the field is available: initial flow rate (Qi), initial decline rate (Di), hyperbolic exponent (b), permeability (k), drainage area $(\mathrm{A})$, fracture half length $\left(\mathrm{X}_{\mathrm{f}}\right)$, and 30 Year EUR.

Figure 80 shows the well locations, followed by identification of boundary and the Voronoi grids for all the wells in the analysis.

Using the results of Decline Curve analysis and Volumetric Reserve Estimation, a well-based Recovery Factor is calculated for all wells, individually. A field-wide Recovery Factor is also calculated. Figure 79 illustrates the calculate recovery factory of $1.0547 \%$ for one of the wells and Field recovery factor of $0.9717 \%$.

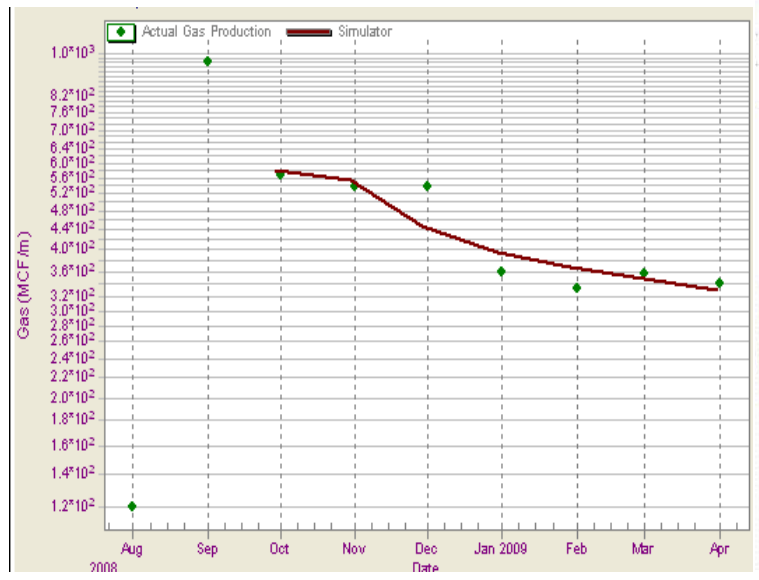

Figure 80.History matching results

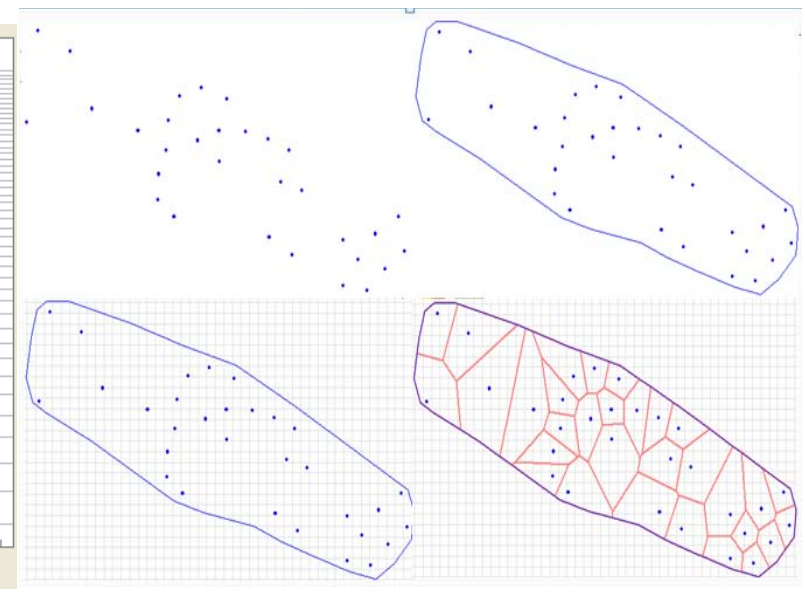

Figure 81.Generating the Voronoi cells for 31 NAS wells 


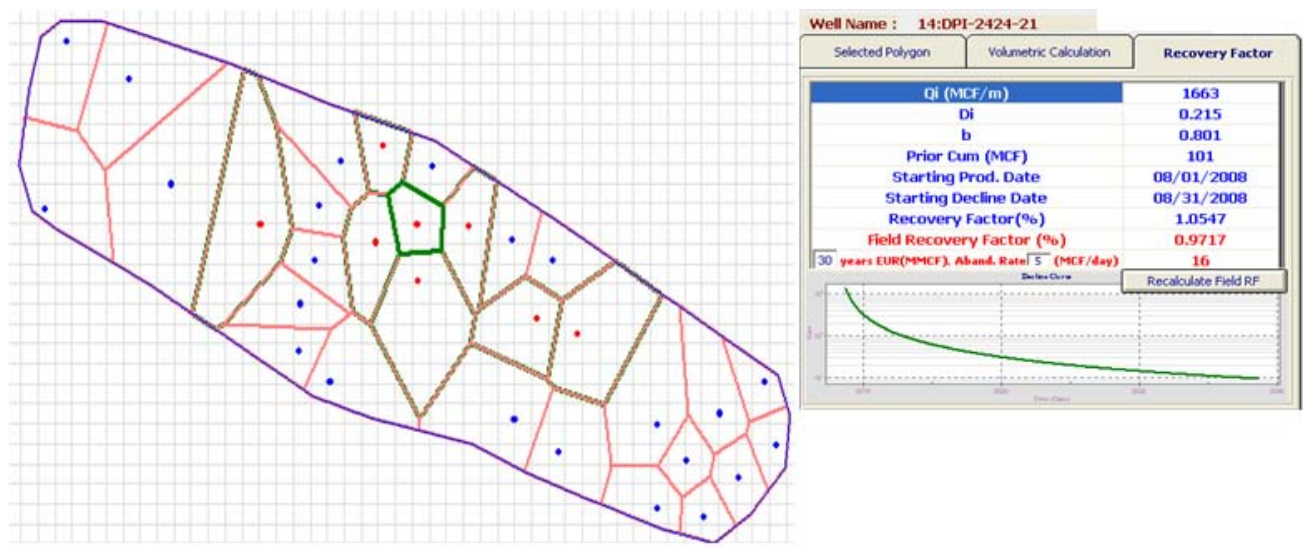

Figure 82.Calculated recovery factor for individual wells as well as field recovery factor

Once the Decline Curve Analysis and other steps mentioned above were completed, discrete, intelligent, predictive models are developed for the reservoir (production) attributes such as, first 3, 6, 9 month of cumulative production, decline curve information (Qi, Di and b), EUR, Fracture half length, matrix and total porosity, matrix and total permeability, net pay thickness, Initial gas in place, and well recovery factor. This set of discrete, intelligent models is then integrated using continuous fuzzy pattern recognition in order to arrive at a cohesive model of the reservoir as a whole.

Using geostatistics a high level earth model is built. As part of the out comes of the high level earth model some of the two dimentsional maps of characteristics of the field such as porosity, permeability, gas saturation and fracture aperture distribution are shown in Figure 83 and Figure 84

In addition the contour maps that are generated using geoghraphix software has been compared to the 2D geostatistical model of Top-Down Modeling and also fuzzy pattern recognition results.(Figure 83 and Figure 84).
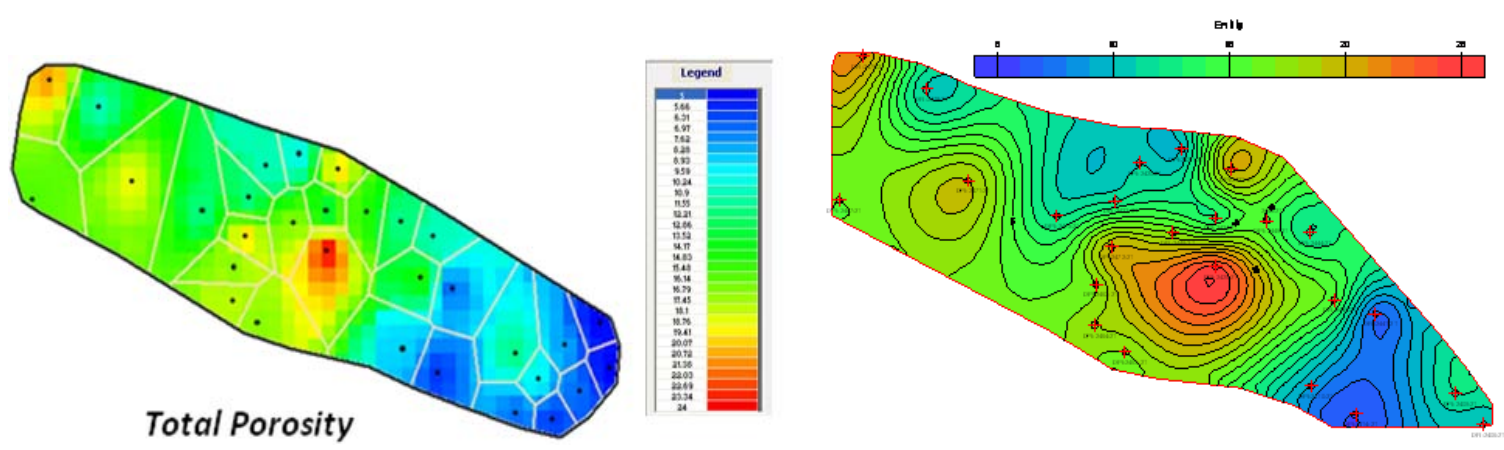

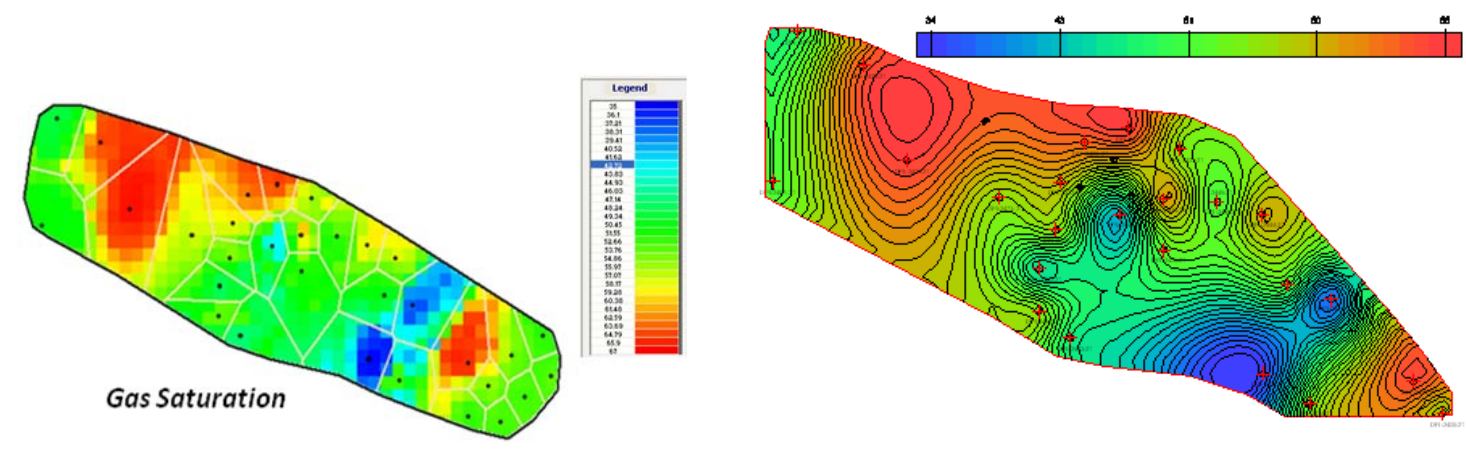

Figure 83.Results of discrete predictive modeling in comparison with contour map (Geographix result) showing the distribution of total porosity, and gas saturation for the entire field
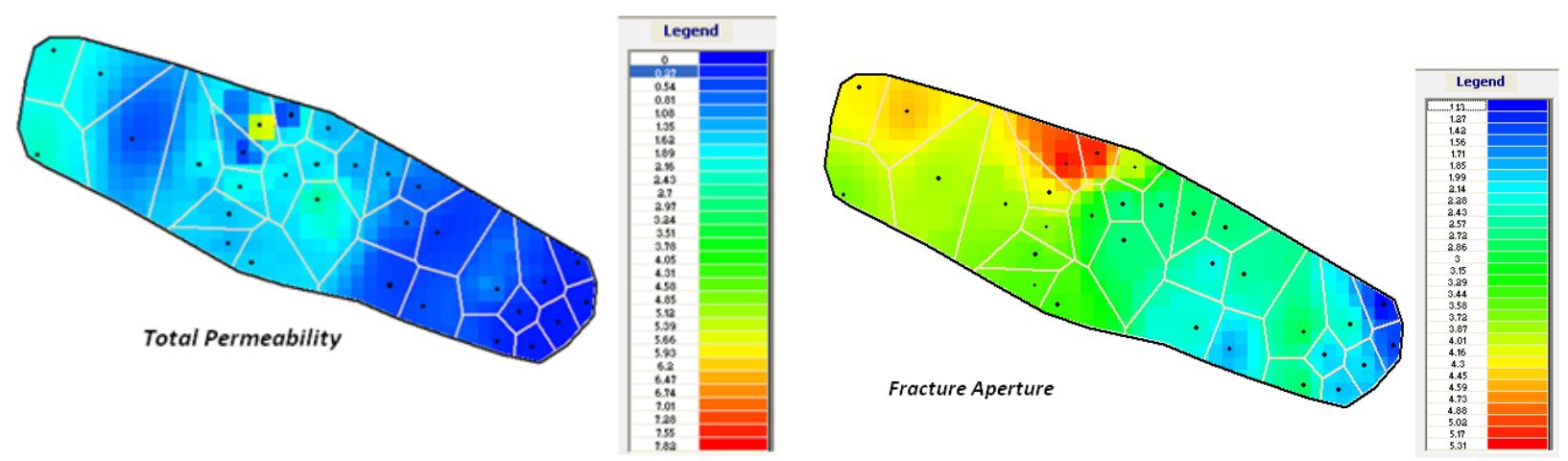

Figure 84.Results of discrete predictive modeling showing the distribution of total permeability from type curve and fracture aperture for the entire field (From left to right)

Another part of Top-down, Intelligent Reservoir Modeling includes analysis of flow and production pattern characteristics usin fuzzy pattern recognition as shown in Figure 85 through Figure 87.

Upon completion of these analyses a rather complete spatio-temporal picture of the fluid flow in the reservoir emerges. The maps that are generated through these processes develop a sereis of visual guidelines that can help engineers and geo-scientist analyze reservoir behavior as a function of time and make decisions on field development strategies. Furthermore, optimum infill locations, examininig different infill scenarios and identifying potential remaining reserves based on each scenario and identifying underperformer wells are among tangible results that can be concluded from such analyses. 

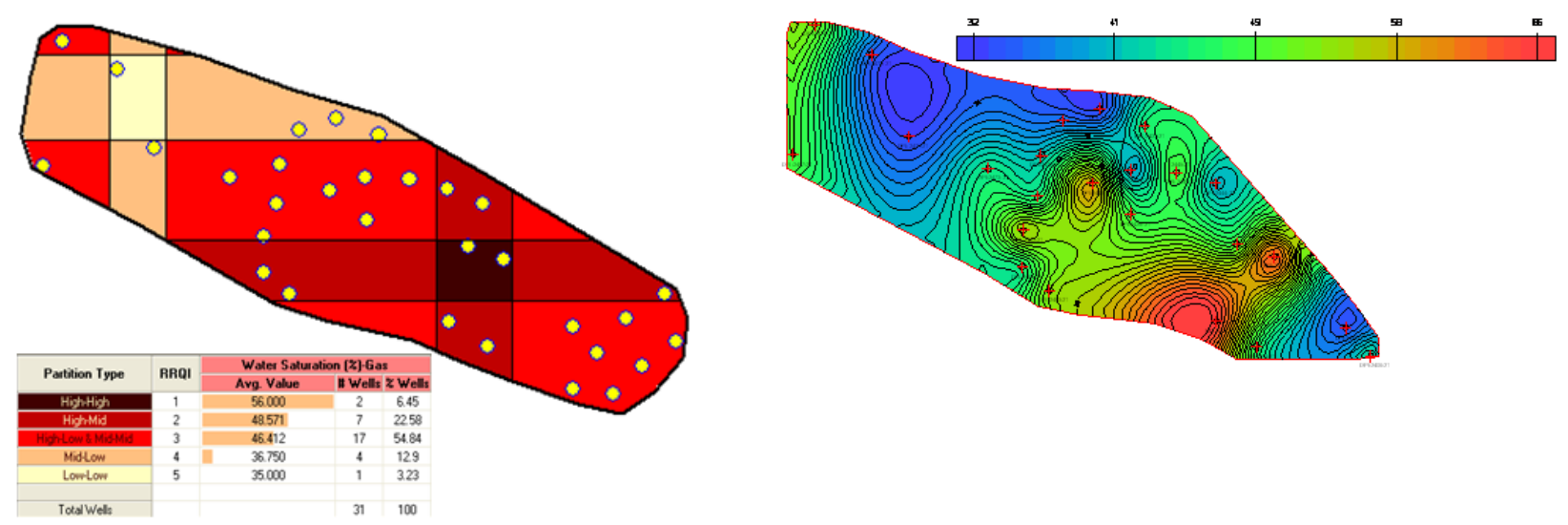

Figure 85.Results of Fuzzy Pattern Recognition showing the sweet spots in the field based on initial water saturation in comparison with the Geographix generated contour map.
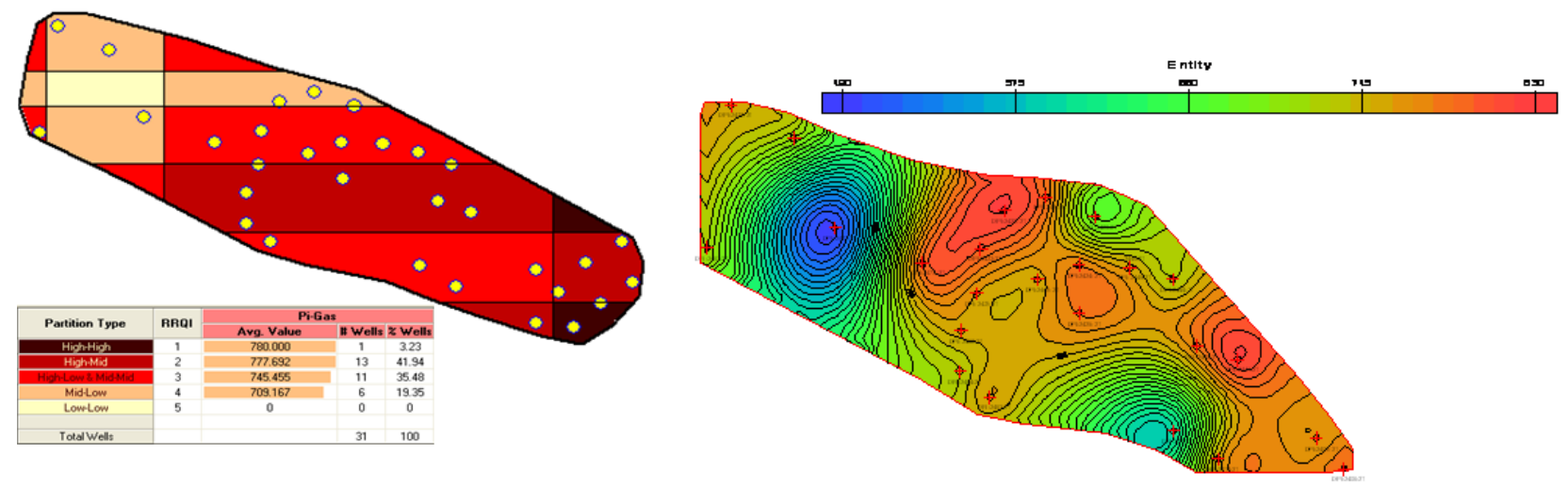

Figure 86.Results of Fuzzy Pattern Recognition showing the sweet spots in the field based on initial reservoir pressure in comparison with the Geographix generated contour map.
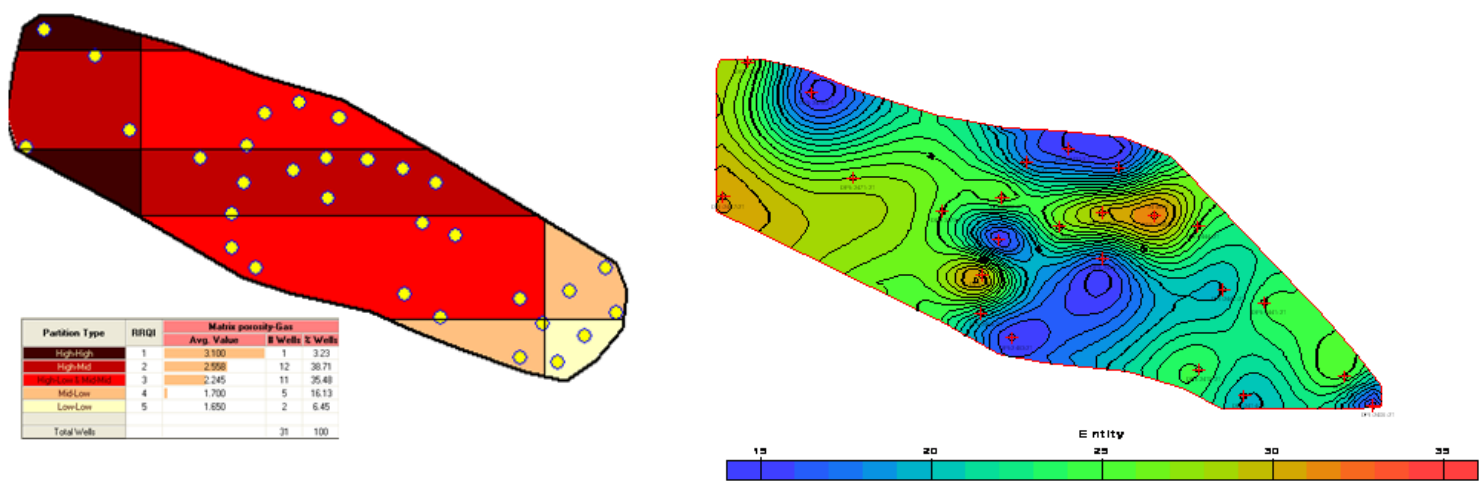

Figure 87.Results of Fuzzy Pattern Recognition showing the sweet spots in the field based on matrix porosity in comparison with the Geographix generated contour map. 
Figure 85 represent the distribution of cumulative gas production for the first 3,6 and 9 month of production and the corresponding contour maps from Geoghraphix.
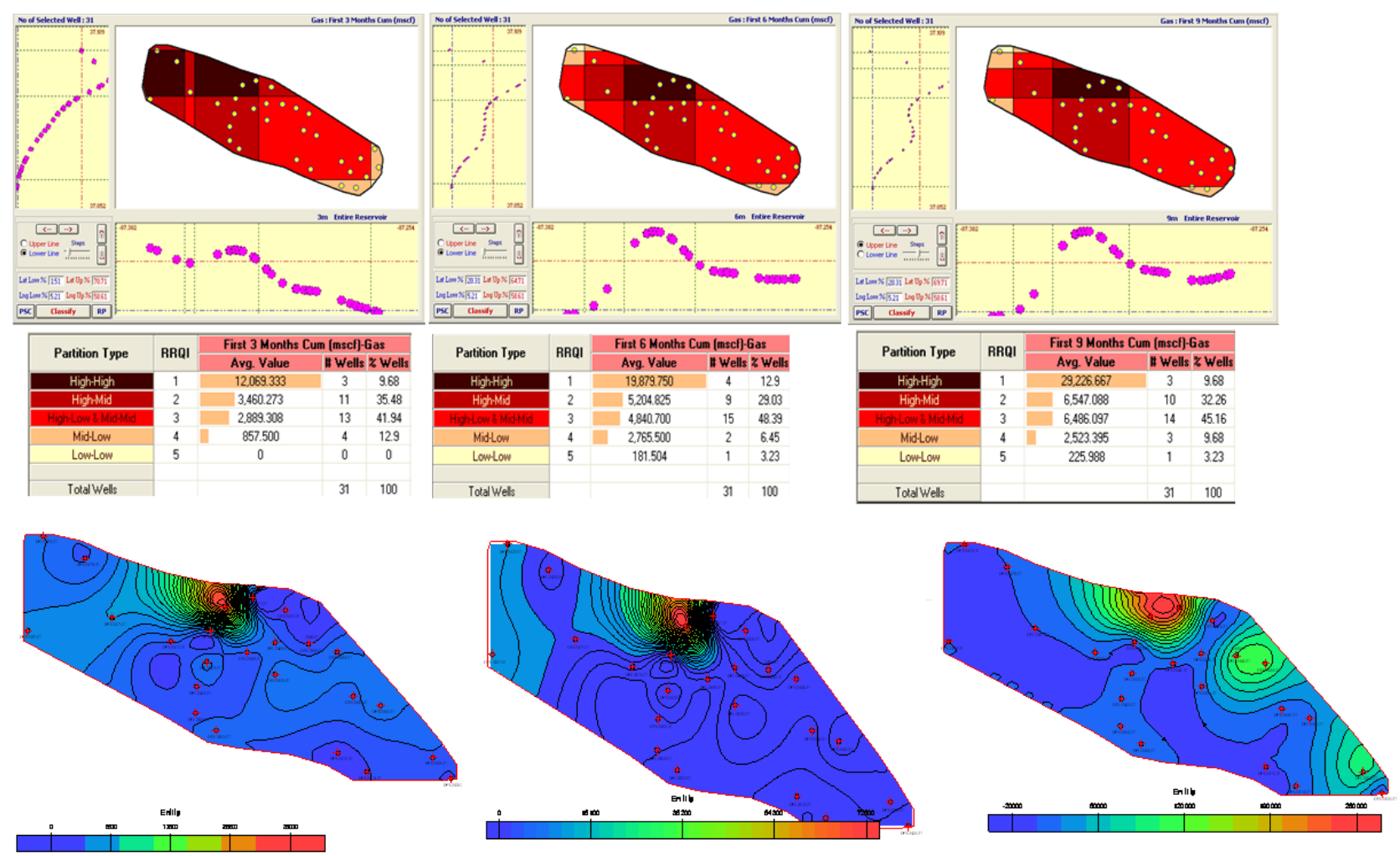

Figure 88.Results of Fuzzy Pattern Recognition showing the sweet spots in the field for the first 3, 6 and 9 month of Cum.gas production in comparison with the corresponding contour maps from geographix.

The remaining reserve as of year 2009,2020 and 2040 has been shown in Figure 89. In the two dimensional maps (Figure 89) reservoir is delineated with Relative Reservori Quality Index (RRQI) being the Remaining Reserves. The delineation shown in this figure are indicated by colors. Higher quality regions (regions with high values of Remaining Reserves) are shown in darker colors and as the average value of Remaining Reserves reduces in each region, the color becomes increasing ly lighter. The difference between these three figures shows the depletion in the reservoir and identifies the parts of the field that still have potential for more recovery.

Based on the results of predictive modeling and fuzzy pattern recognition, the best spots for drilling can be identified. So engineers and geo-scientits can identify the best locations in the field that would provide the best production profiles and that satidfies their economic objectives. 


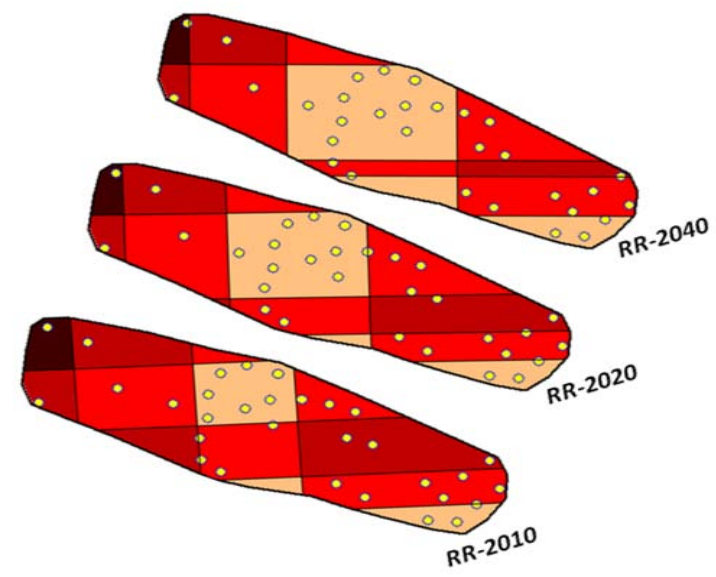

Figure 89.Results of Fuzzy Pattern Recognition showing the sweet spots in the field for the remaining reserve (MMCF) as of 2009, 2020, and 2040

The permeability is a key parameter that plays an important role in fluid production from the reservoir. Thereby having high initial production rate in the locations which have high permeability makes sense. Another important factor while making decision about the infill drilling locations is remaining reserves. It defines the amount of the stored fluid in the reservoir. Having both the remaining reserves and permeability, results in high storage and flow capacity. Thus, the potential spots for infill drilling can be selected, based on these parameters. Although these two parameters have considerable effect on deciding the new well locations, other parameters such as forcasted EUR for 30 years, matrix porosity,initial gas in place and also fracture half length have been taken into account.

\subsection{Model Calibration and Validation}

To calibrate the NAS Top-Down models about $10 \%$ of wells for are removed from the analyses. This constitutes removal of 3 wells from the analysis. The models are developed using the remaining 28 wells. The objective is to make sure that the NAS Top-Down model can predict the first 3 month cumulative production for these removed wells (blind data set). The results are shown in Table 13.Results of Top-Down modeling- Model Calibrationand Figure 90.

For example in table 1 the four Relative Reservoir Quality Indices (RRQI) are shown as well as the model results that indicates the prediction for the blind/validation wells. As indicated in this table the Top-Down model predicted that the average first 3 month cumulative production for wells drilled in the RRQI “ 1 ” (the darkest areas in Figure 1) will be more than 9.7 MMSCF. One well in RRQI “1” is 
removed and the average first 3 month cumulative production for this well was 13.48 MMSCF (correct prediction).

Furthermore, the Top-Down model predicted that the average first 3 month cumulative production for well in the RRQI "2" will be between 2.97 and 9.7 MMSCF. As shown in Table 1 there was 1 well drilled in RRQI " 2 " and the average first 3 month cumulative production for this well was 4.56 MMSCF (correct prediction).

For RRQI "3" the Top-Down model over-estimates the result. It predicted that the average first 3 month cumulative production for wells drilled in the RRQI "3" will be between 1.8 and 2.97 MMSCF while the 1 well drilled in RRQI "2" had an average first 3 month cumulative production of 3.9 MMSCF.

Table 13.Results of Top-Down modeling- Model Calibration

\begin{tabular}{|c|c|c|c|c|c|}
\hline \multicolumn{7}{|c|}{ First 3 Month Cumulative Production(MSCF) } \\
\hline & \multicolumn{2}{|c|}{ Model Results } & \multicolumn{2}{c|}{ Removed Wells } \\
\hline RRQI & More Than & $\&$ & Less than & Average 1 Yr Cum & $\begin{array}{c}\text { No. of } \\
\text { Wells }\end{array}$ \\
\hline 1 & $9,707.85$ & & & $13,488.00$ & 1 \\
\hline 2 & $2,968.89$ & $\&$ & $9,707.85$ & $4,566.00$ & 1 \\
\hline 3 & $1,803.29$ & $\&$ & $2,968.89$ & $3,906.00$ & 1 \\
\hline 4 & 857.00 & $\&$ & $1,803.29$ & & 0 \\
\hline & & & $7,908.59$ & Total no. of Wells & 3 \\
\hline
\end{tabular}




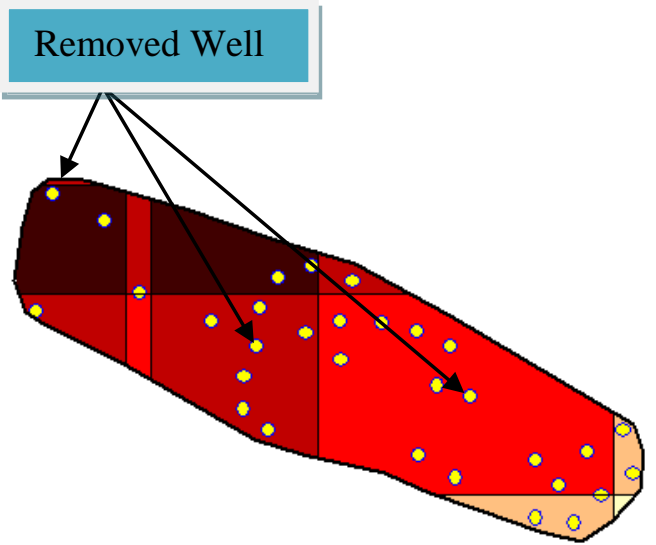

First 3 Month Cumulative Production (31Wells)

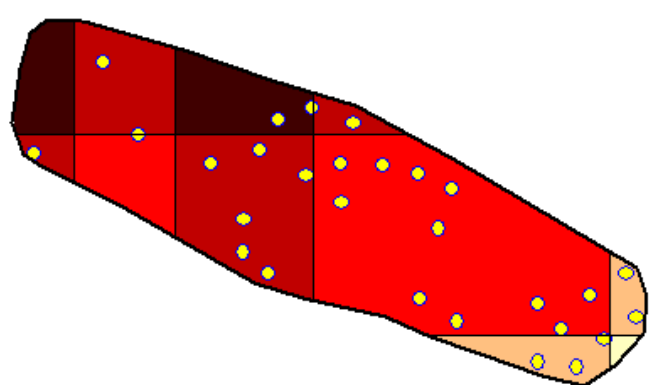

First 3 Month Cumulative Production (28 Wells)

Figure 90. Results of Fuzzy Pattern Recognition showing the sweet spots in the field for the first 3-month cum. production for 31 wells (left) and first 3-month cum. Production for 28 wells (right). 


\section{Chapter 4}

\section{Concluding Remarks}

In this study, natural fractures in the New Albany Shale were characterized by a comprehensive review of literature. Sensitivity analysis was performed on key reservoir and fracture parameters such as matrix porosity, matrix permeability, initial reservoir pressure, fracture aperture, fracture density, fracture length and well's lateral length .The orientation of natural fractures in New Albany Shale wells are EW and NNW-SSE and a minor ENE-SWS. Majority of natural fractures are vertical through there appears a minor set that dip between 55 to 75 degree.

A fracture network based on best available information and data was developed in FracGen. NFflow was used for fluid flow modeling based on the FracGen model. Reservoir characteristics and fracture properties were modified systematically until a reasonable history match was achieved for all the wells being studied.

The fracture model like any other geological model has a degree of uncertainty and can be updated by using additional information from fracture detection log, seismic and core analysis and any other tools that help to characterize fracture properties in order to building the more accurate model that represents the fracture network distribution of New Albany Shale.

A novel reservoir modeling technology has been applied to New Albany Shale. This relatively new modeling technology, Top-Down, Intelligent Reservoir modeling, incorporates Artificial Intelligent and Data Mining techniques such as data driven Neural network modeling and fuzzy pattern recognition in conjunction with solid reservoir engineering analyses in order to combine single well analyses into a cohesive full field model.

Top-Down intelligent reservoir modeling allows the reservoir engineer to plan and evaluate future development options for the reservoir and continuously updated the model that has been developed as new wells are drilled and more production data and well logs become available.

One of the most important advantages of Top-Down intelligent reservoir modeling is its ease of development. It is designed so that an engineer or a geologist will be able to comfortably develop a Top-Down model in a relatively short period of time with minimum amount of data (only monthly production data and some well logs are enough to start modeling). This new technique can be performed on the other types of shale and tight gas sand (Unconventional resources) as well as conventional reservoirs. (Oil and Gas)

Our Studies have shown that Intelligent Top-Down Reservoir Modeling holds much promise and can open new door for developing reservoir models using field measurement data.

This new workflow can be performed on the other types of Unconventional resources such as other shale plays and tight gas reservoirs. 


\section{References}

1. Some Predictions of Possible Unconventional Hydrocarbon Availability. Kawata Y, Fujita K. Jakarta : SPE, 2001. SPE68755.

2. Tight Gas Sands. SA, Holditch. s.l. : SPE, 2006. SPE103356.

3. Shale Gas Opportunities and Challenges. Search and Discovery Articles. Bustin, M. R., Bustin, A., Ross, D., Chalmers, G., Murthy, V., Laxmi, C., Cui, X. San Antonio, Texas, : AAPG Annual Convention,, 2008.

4. Browing, I.B. Relation of Structure to Shale Gas Accumulation. In: Devonian Shales. Charleston,WV : Appalachian Geol.Society, 1935.

5. Gas Occurrence in the Devonian Shale. Smith, E.C. Denver: SPE Symposium on LowPermeability Gas Reservoirs, 1979. SPE 7921.

6. A 'New' Gas Supply - The Devonian Shales. Foster, J.M. Charleston : SPE, 1975. 5451.

7. The Barnett Shale Play; Phoenix of the Fort Worth Basin, A History. Steward, D.B., and Paniszczyn, F. s.l. : The Fort Worth Geologic Society and the North Texas Geologic Society, 1977.

8. Guidry, F.K., Luffel, D.L., and Curtis, J.B. Development of Laboratory and Petrophysical Techniques for Evaluating Shale Reservoirs. 1995. GRI-95/0496..

9. Importance of Fabric on Production of Gas Shale. Bustin, A.M.M., Bustin, R.M, and Cui, X. Keystone,CO : Unconventional Reservoirs Conference, 2008. SPE 114167.

10. Nanoscale Gas Flow in Shale Gas Sediments. Javadpour, F., Fiser, D., and Unsworth, M. 10, s.l. : J. Canadian Pet. Tech., 2007, Vol. 46.

11. Nanopores and Apparent Permeability of Gas Flow. In Mudrocks (Shales and Siltstone). Javadpour, F. s.l. : JCPT Distinguished, 2009.

12. Petrophysical Considerations in Evaluating and Producing Shale Gas Resources. C.H. Sondergeld, SPE, University of Oklahoma and K.E. Newsham, SPE, J.T. Comisky, SPE, and M.C. Rice,. Pittsburgh : SPE, 2010. 131768.

13. Joseph H.Frantz, Jr. Shale Gas. s.l. : Schlumberger, 2005.

14. New Albany Shale Project. Salehi, Iraj. s.l. : Gas Technology Institute, 2009.

15. Consortium, Illinois Basin. Gas Potential of the New Albany Shale (Devonian and Mississippian) in the Illinois Basin. s.l. : Gas Research Institute, 1994. 
16. Frost, J. K., Zierath, D. L., and Shimp, N. F. Chemical composition and geochemistry of the New Albany Shale Group (Devonian-Mississippian)in Illinois. s.l. : U.S. Department of Energy, 1985. DE-AC21-76ET12142.

17. Kalyoncu, R. S., Boyer, J. P., and Snyder, M. J. Characterization and analysis of Devonian shales as related to release of gaseous hydrocarbons, well P-1 Sullivan County, Indiana. Ohio : s.n., 1979.

18. McKoy, Mark L,W. Neal Sams. Tight Gas Reservoir Simulation:Modeling Discrete Irregular Strata-Bound Fracture Networks and Network Flow, Including Dynamic Recharge from the Matrix. . Morgantown : DOE, 2006.

19. ASA, Roxar. http://www.roxar.com/category.php?categoryID=1081. [Online]

20. Virtual Intelligence Applications in Petroleum Engineering: Part 1; Artificial Neural Networks. D.Mohaghegh, Shahab. s.l. : Journal of Petroleum Technology, 2000.

21. Virtual Intelligence Applications in Petroleum Engineering: Part 2; Evolutionary Computing. D.Mohaghegh, Shahab. s.l. : Journal of Petroleum Technology, 2000.

22. Virtual Intelligence Applications in Petroleum Engineering: Part 3; Fuzzy Logic. D.Mohaghegh, Shahab. s.l. : Journal of Petroleum Technology, 2000.

23. A comprehensive Reservoir Evaluation of a Shale Reservoir. Michael D.Zober, Jeron R.Williamson,David G.Hill. s.l. : SPE, 2002. SPE 77469.

24. Ault, C.H. Directions and characteristics of jointing in the New Albany Shale (DevonianMississippian) of southeastern Indiana. Kentucky: Center for Applied Energy Research, 1990. IMMR89/201.

25. Energy Information Administration(Official Eneregy Statistics From the US. Government). [Online] http://tonto.eia.doe.gov/oog/info/ngw/ngupdate.asp.

26. David Wagman, Contributing Editor. Shale Plays Show Growth Prospects. [Online] Hart Energy Publishing. http://www.redorbit.com/news/science/357066/shale_plays_show_growth_prospects/. 


\section{Appendix A}

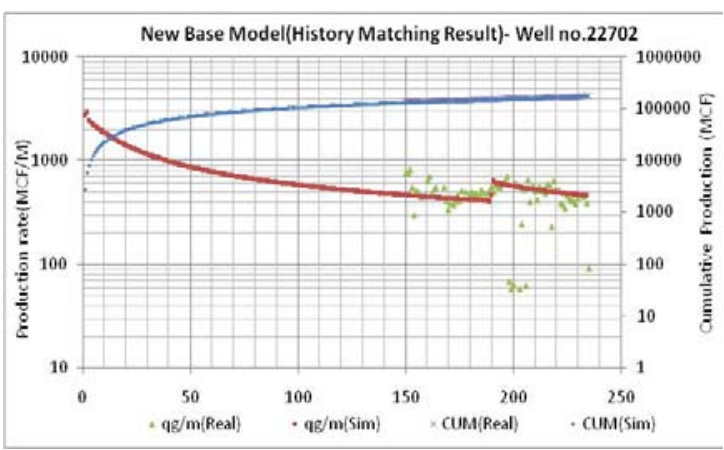

Figure A-1.History matching result - well\#22702

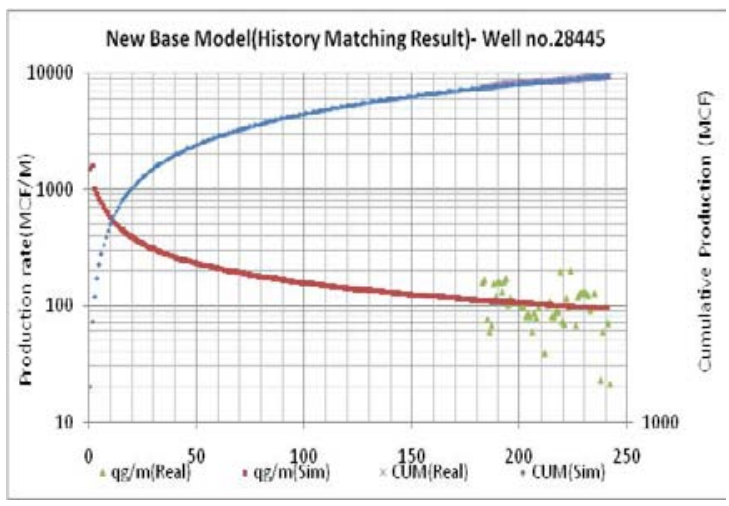

Figure A-3.History matching result-well\#28445

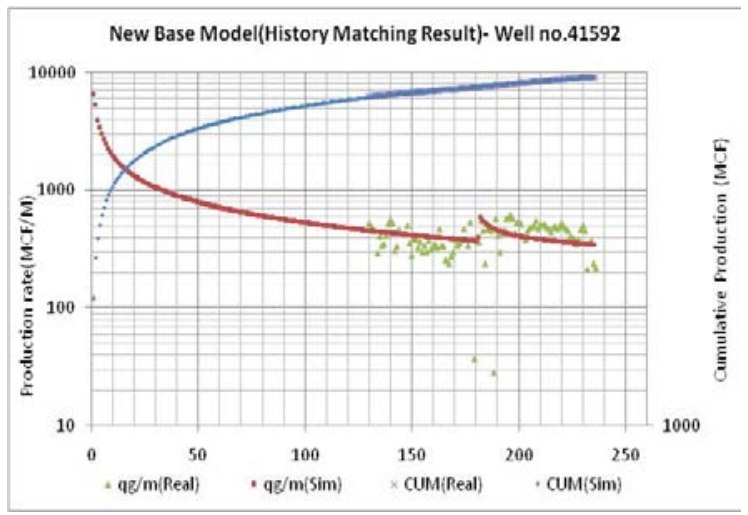

Figure A-5.History matching result well\#41592

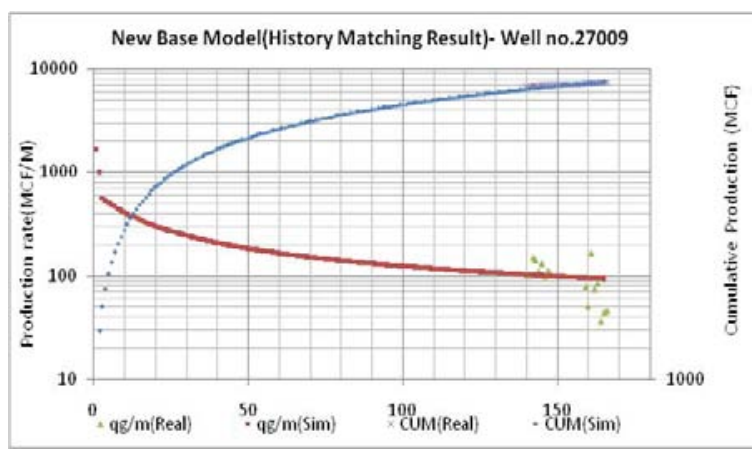

Figure A-2.History matching result-well\#27009

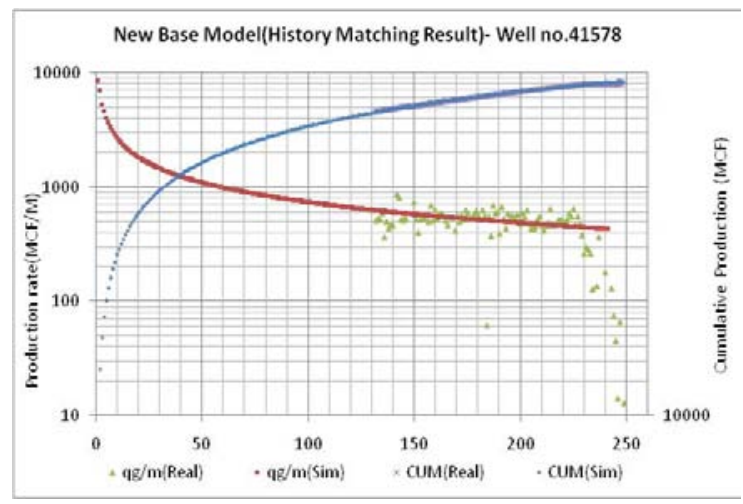

Figure A-4.History matching result well\#41578

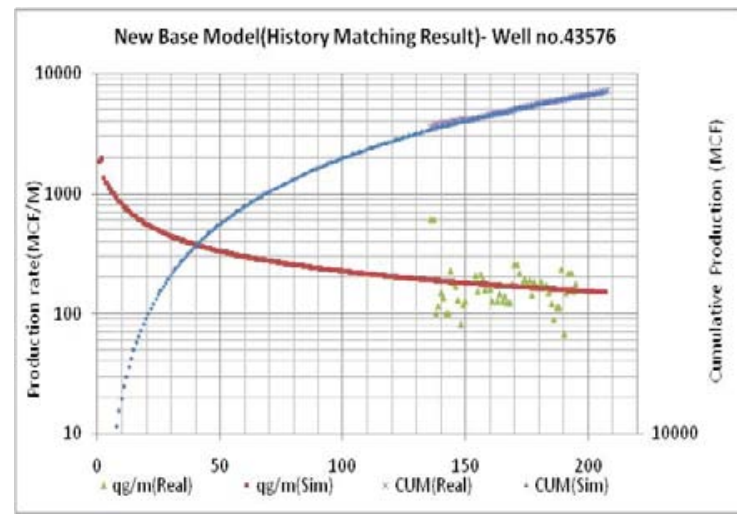

Figure A-6.History matching result well\#43576 

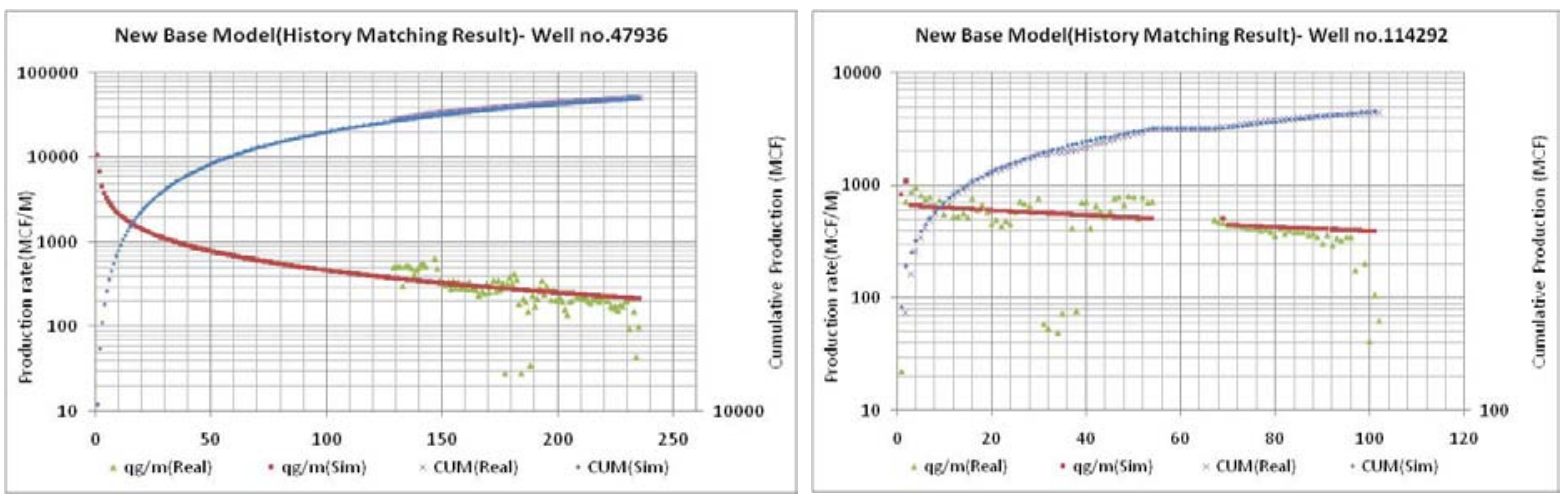

Figure A-7.History matching result well\#47936

Figure A-8.History matching result well\#114292
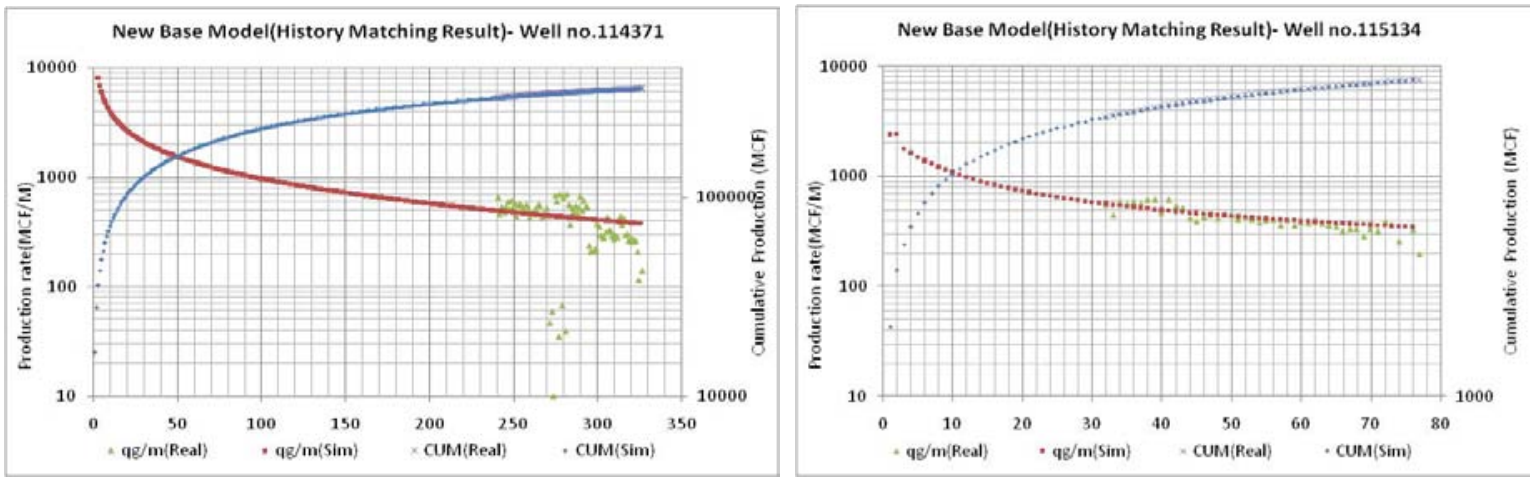

Figure A-9.History matching result well\#114371

Figure A-10.History matching result well\#115134
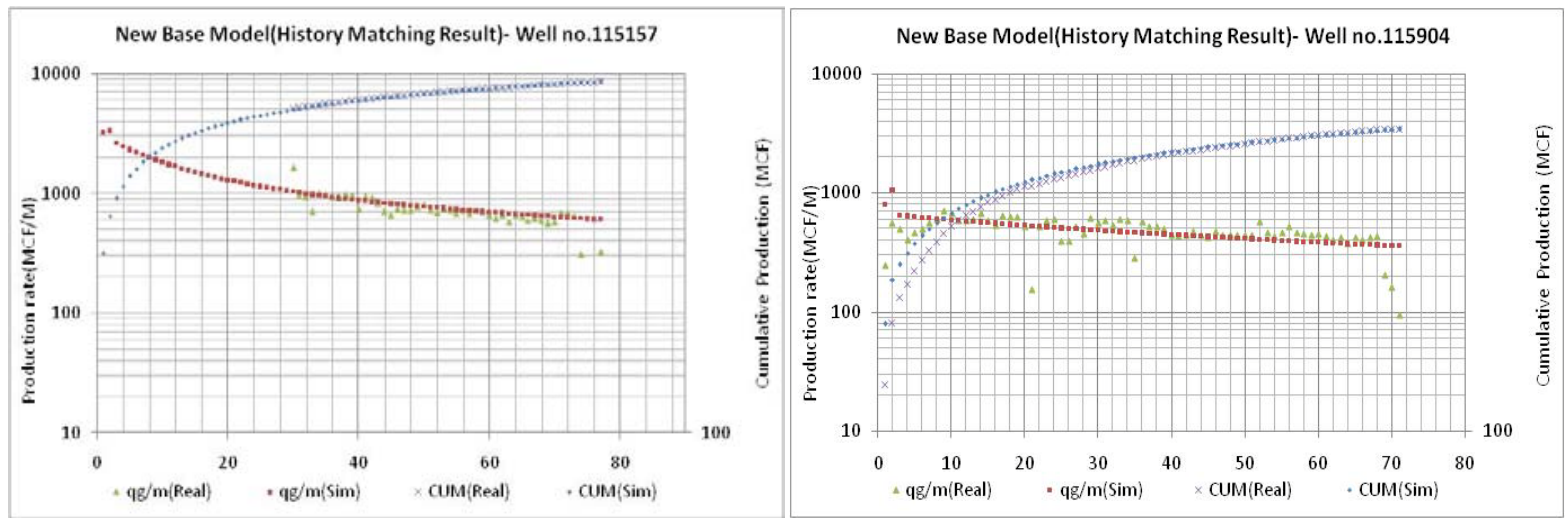

Figure A-11.History matching result well\#115157 Figure A-12.History matching result well\#115904 

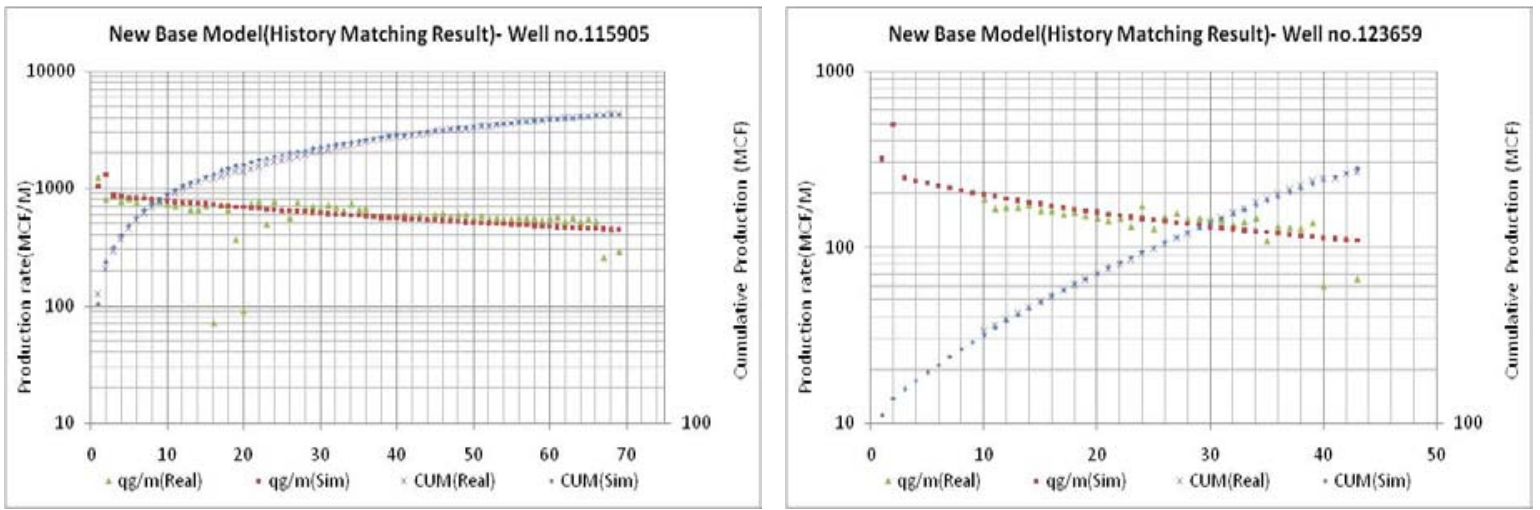

Figure A-13.History matching result well\#115905 Figure A-14.History matching result well\#123659
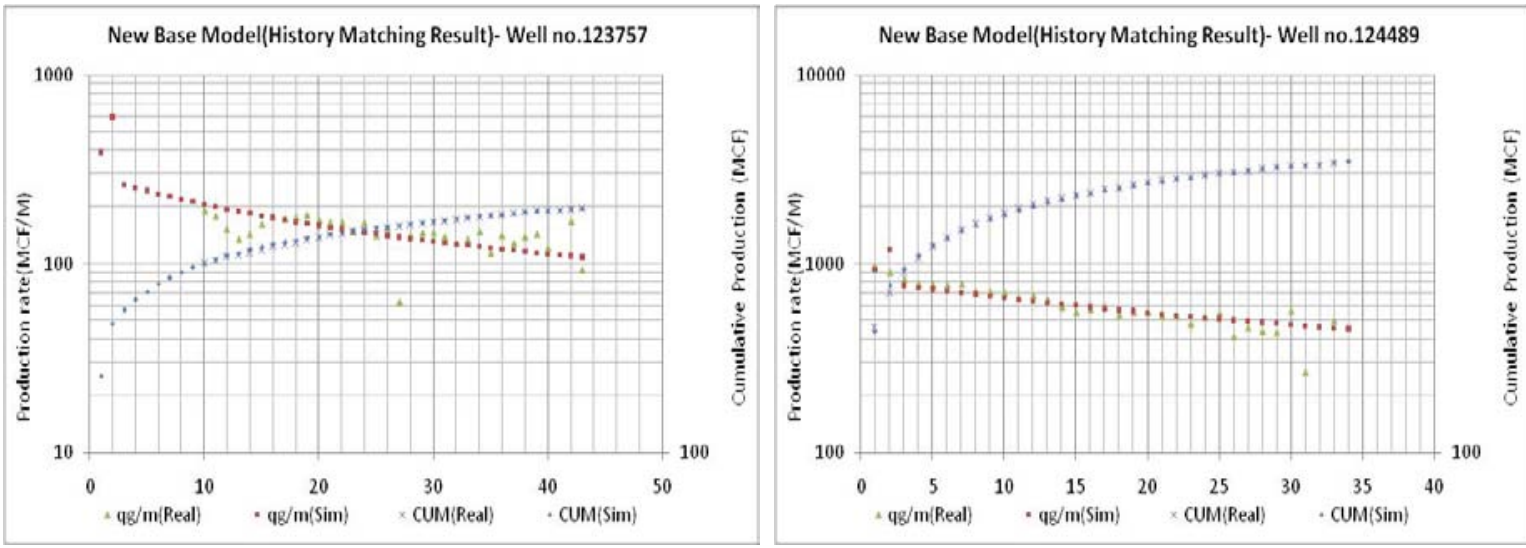

Figure A-15.History matching result well\#123757 Figure A-16.History matching result well\#124489
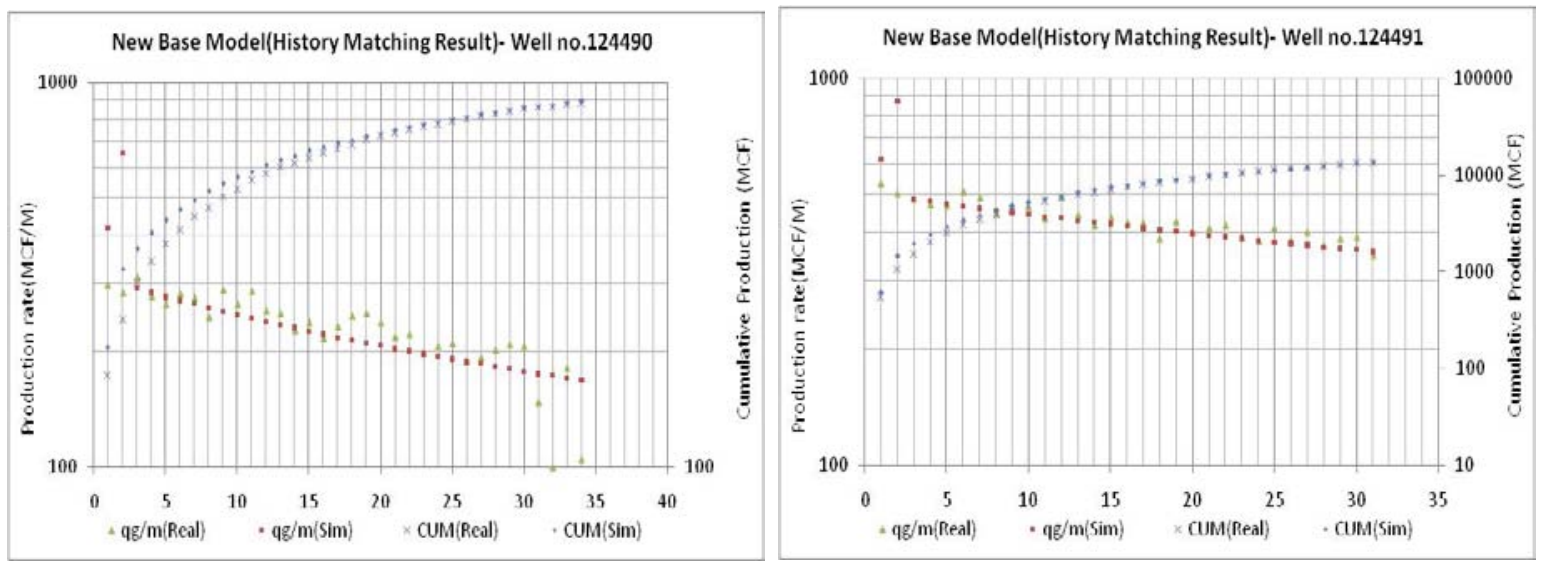

Figure A-17.History matching result well\#124490 Figure A-18.History matching result well\#124491 

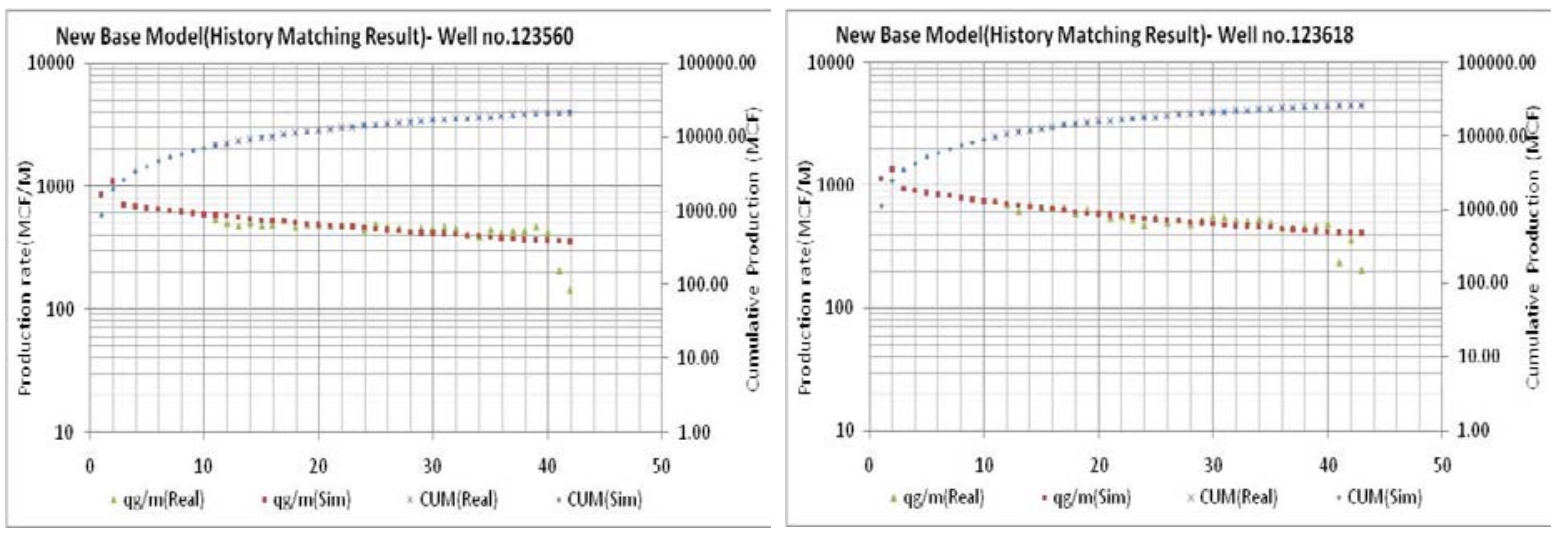

Figure A-19.History matching result well\#123560 Figure A-20.History matching result well\#123618
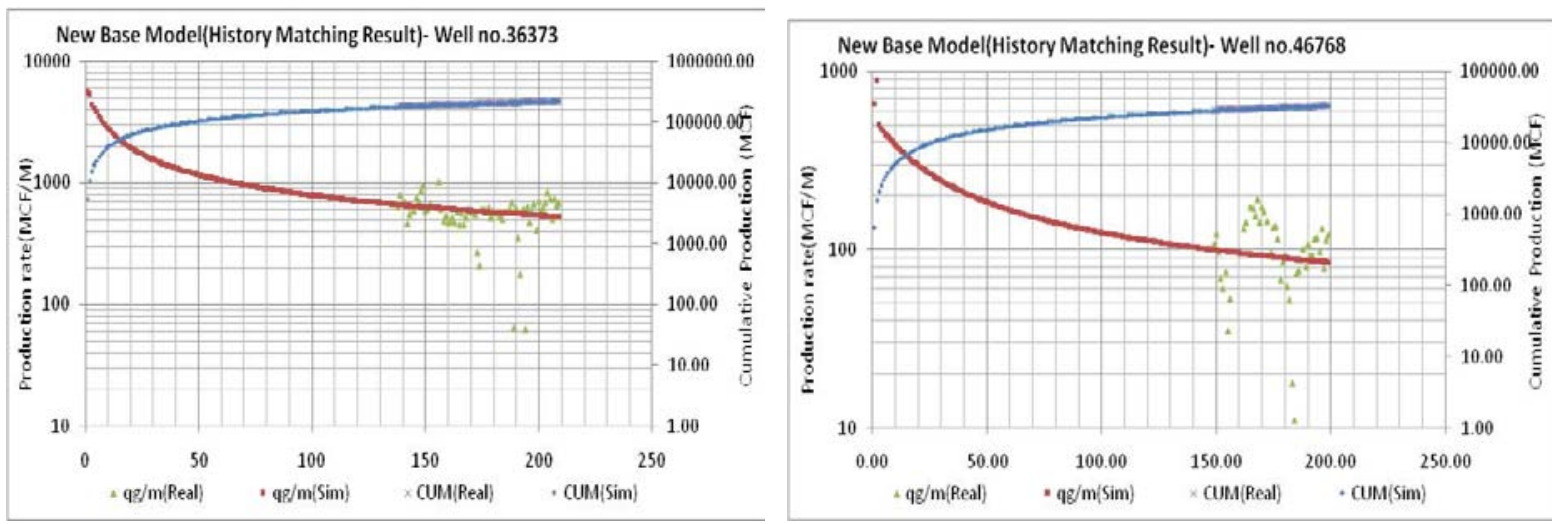

Figure A-21.History matching result well\#36373
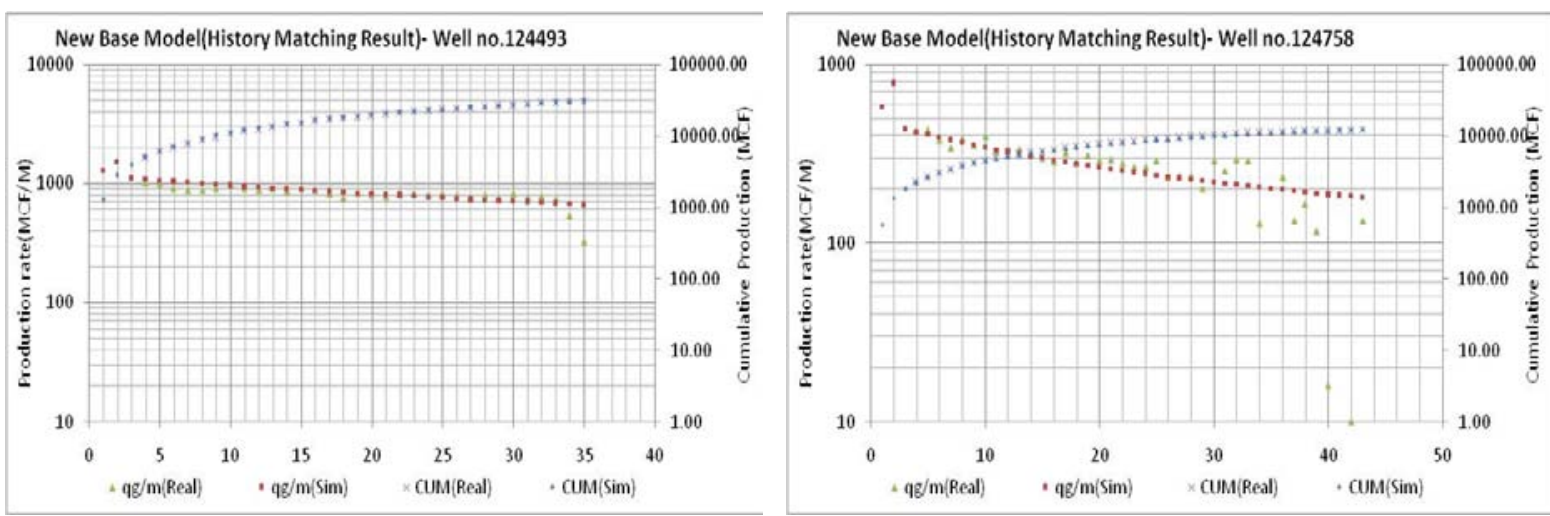

Figure A-23.History matching result well\#124493 Figure A-24.History matching result well\#124758 


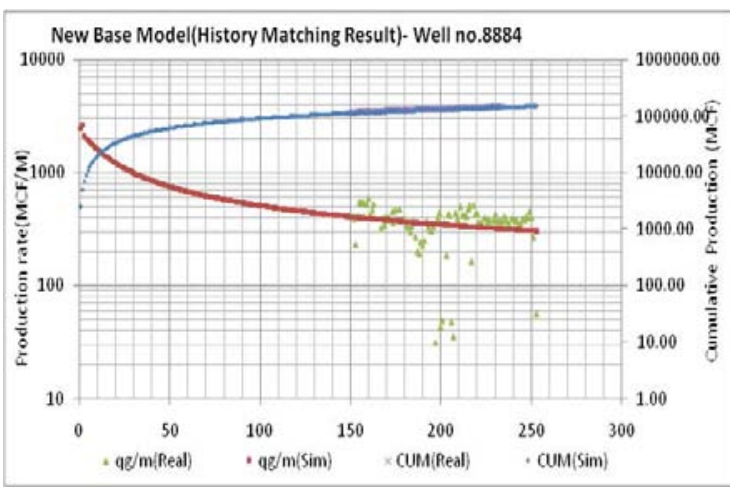

Figure A-25.History matching result well\#8884

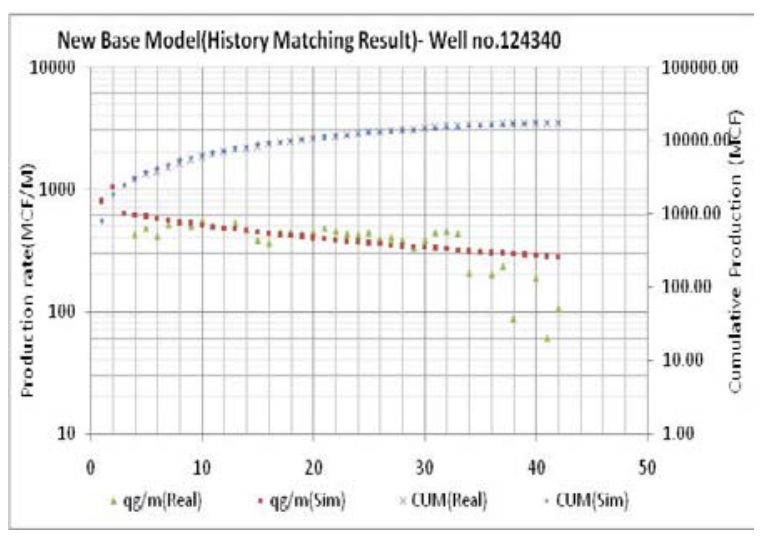

Figure A-27.History matching result well\#124340 Figure A-28.History matching result well\#124638

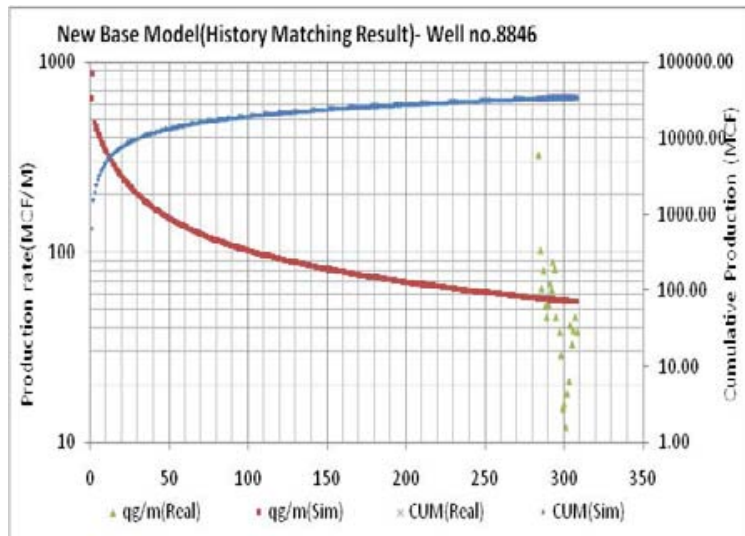

Figure A-29.History matching result well\#8846

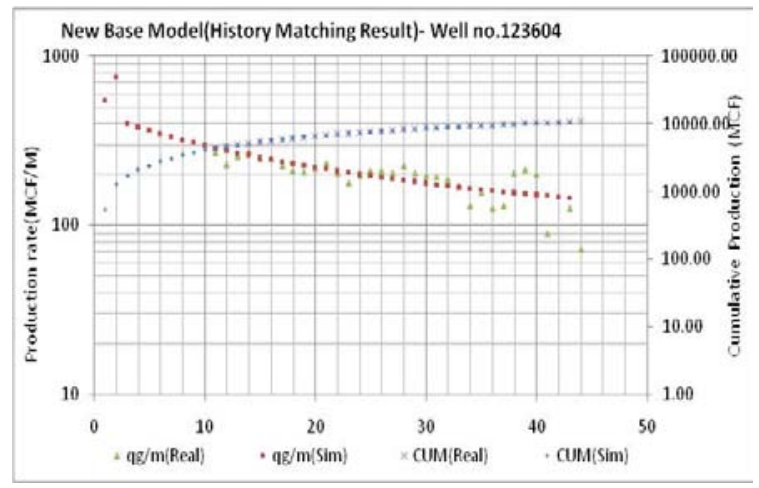

Figure A-26.History matching result well\#123604
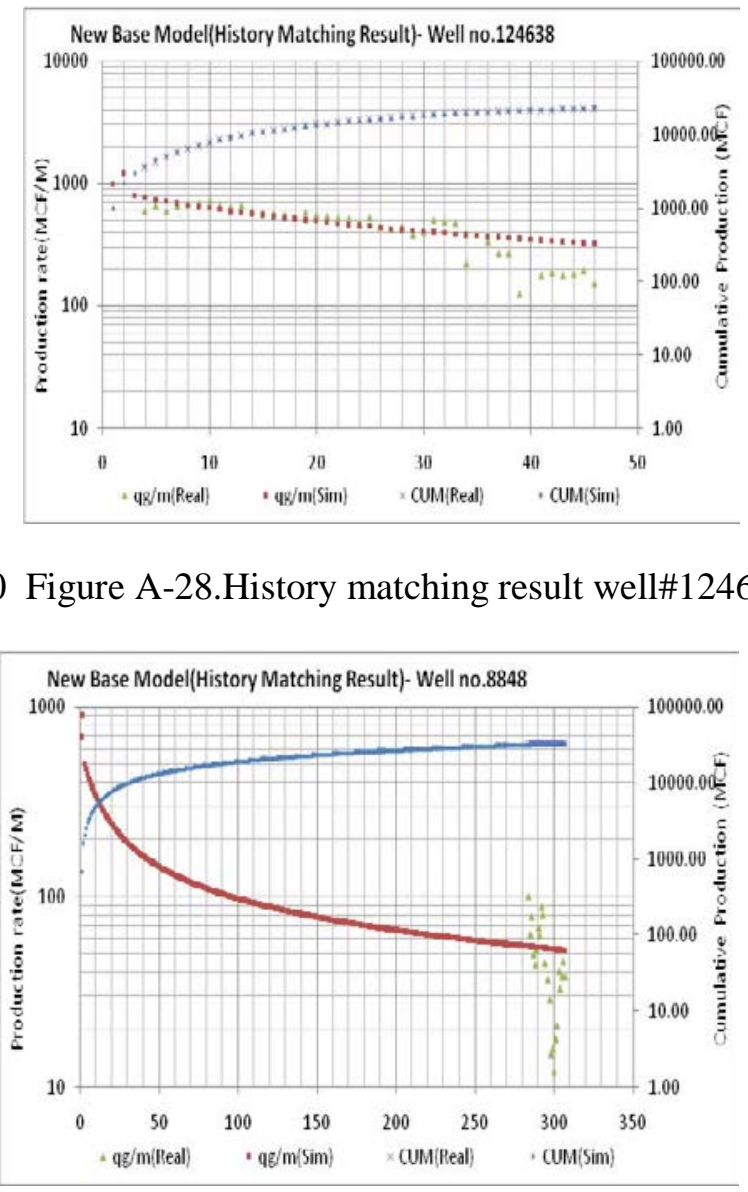

Figure A-30.History matching result well\#8848 


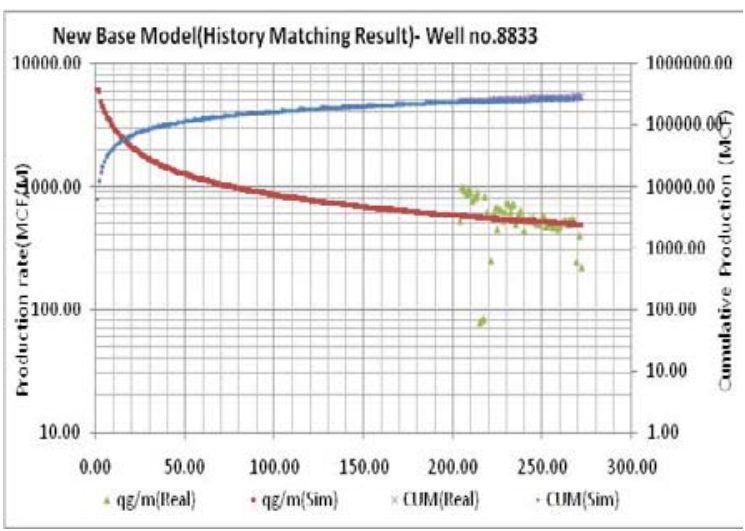

Figure A-31.History matching result well\#8833

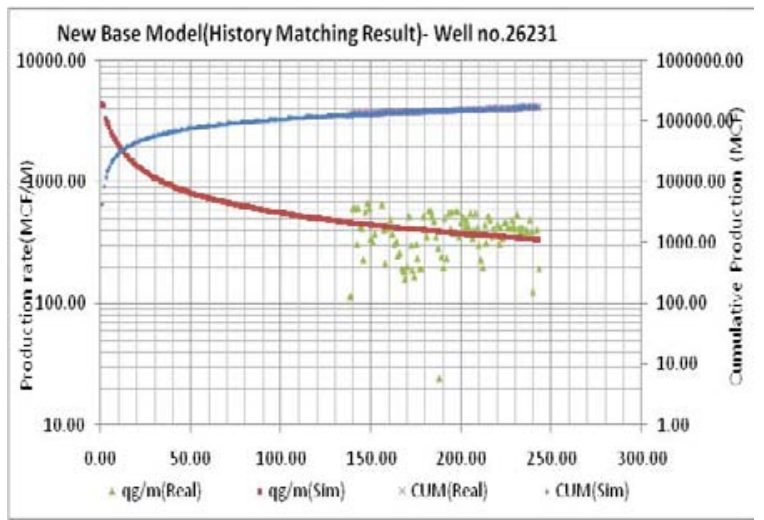

Figure A-33.History matching result well\#26231

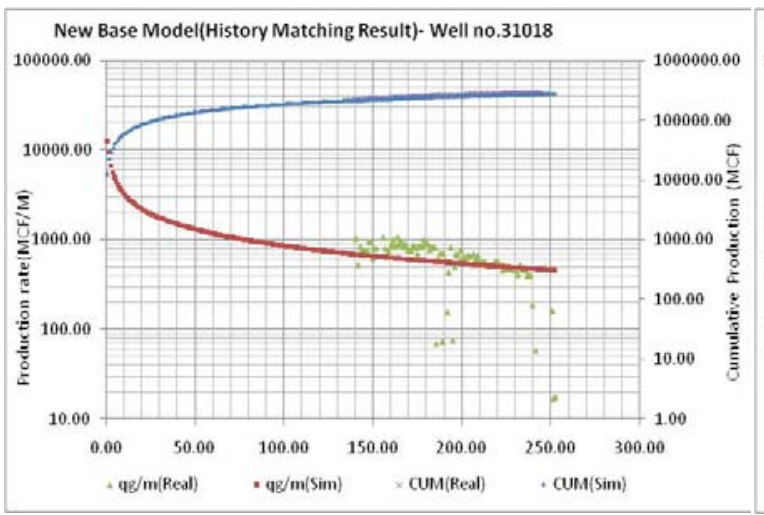

Figure A-35.History matching result well\#31018

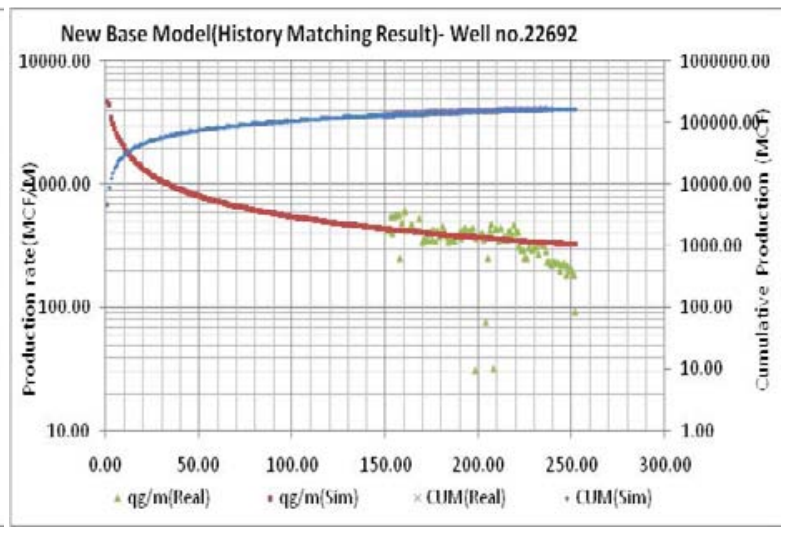

Figure A-32.History matching result well\#22692

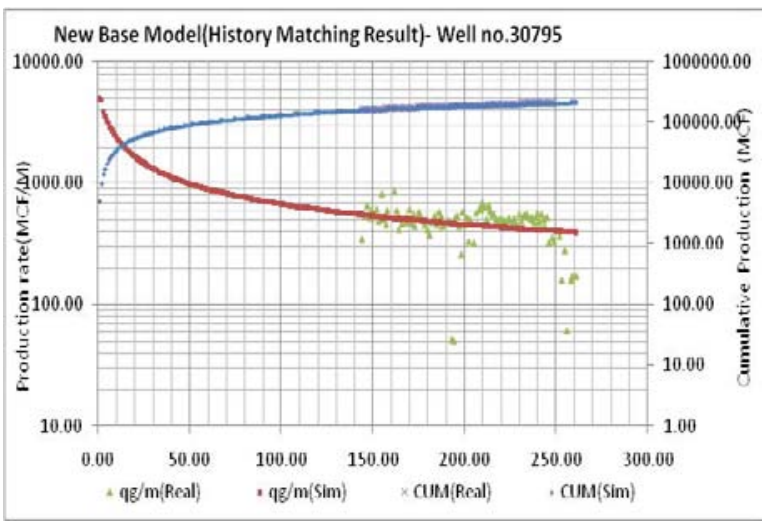

Figure A-34.History matching result well\#30795

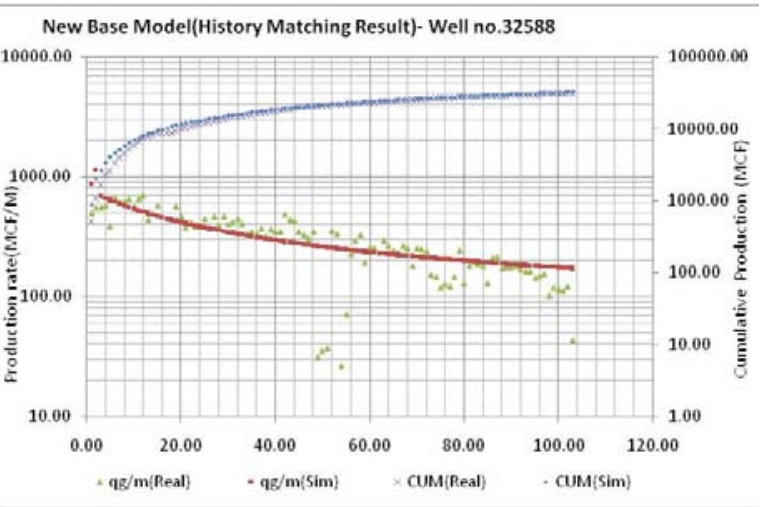

Figure A-36.History matching result well\#32588 

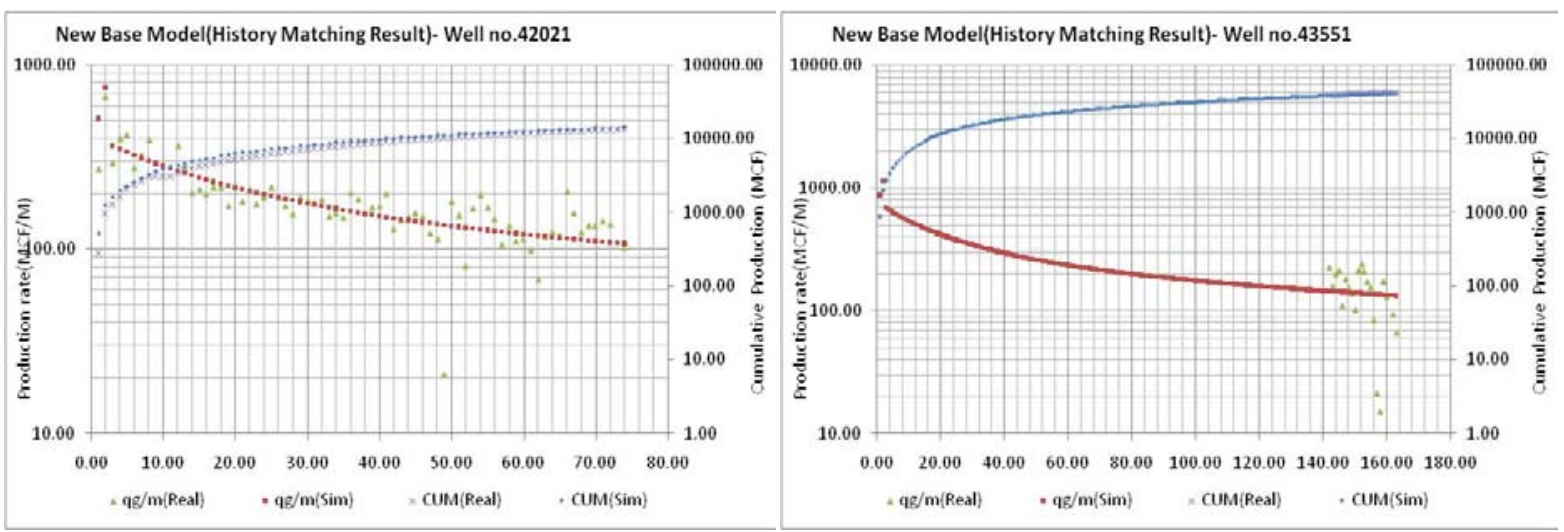

Figure A-37.History matching result well\#42021
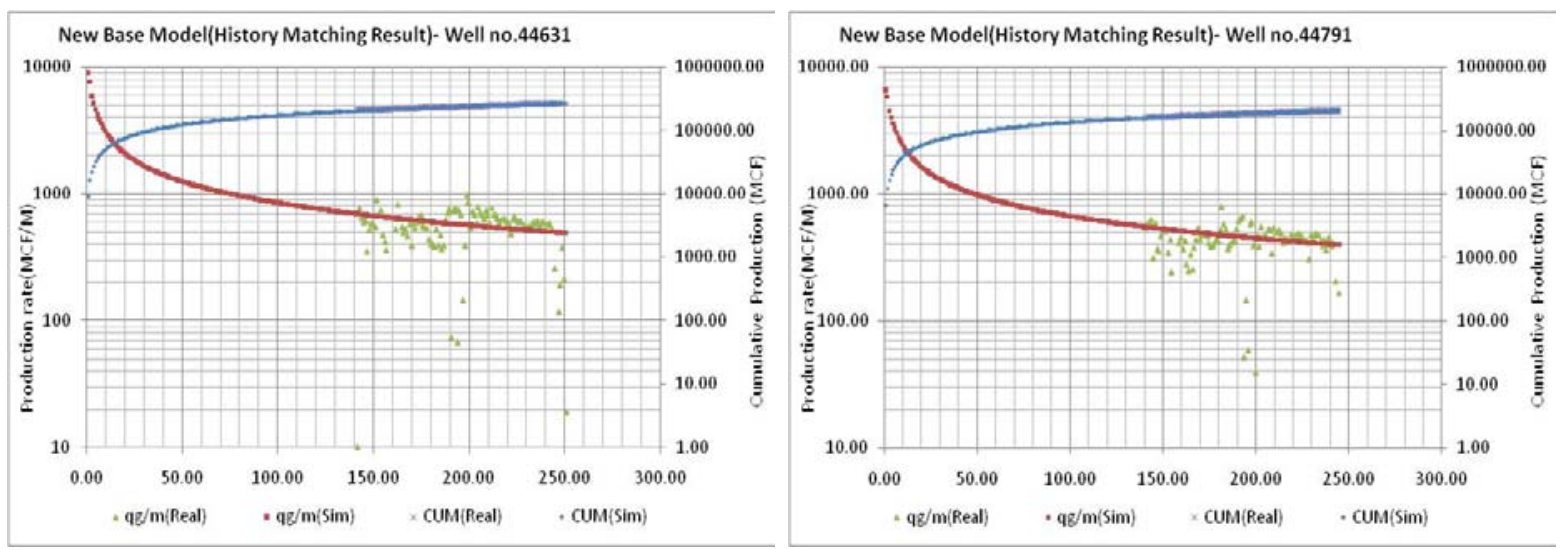

Figure A-39.History matching result well\#44631
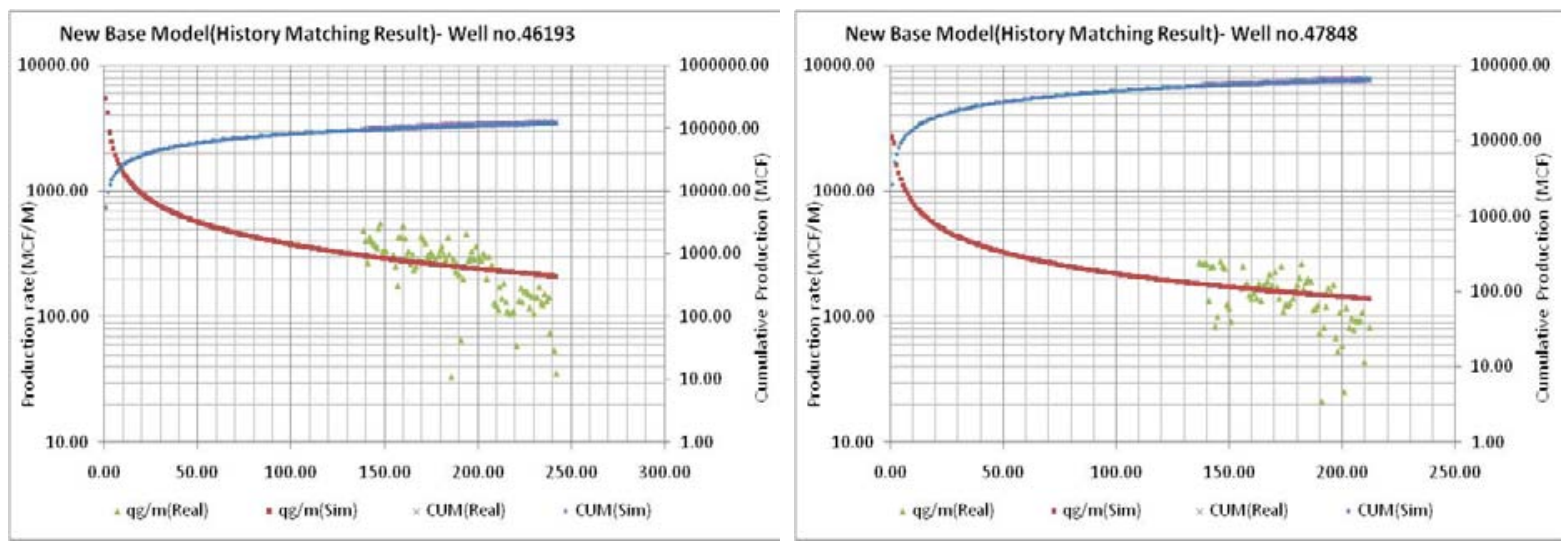

Figure A-41.History matching result well\#46193 Figure A-42.History matching result well\#47848 

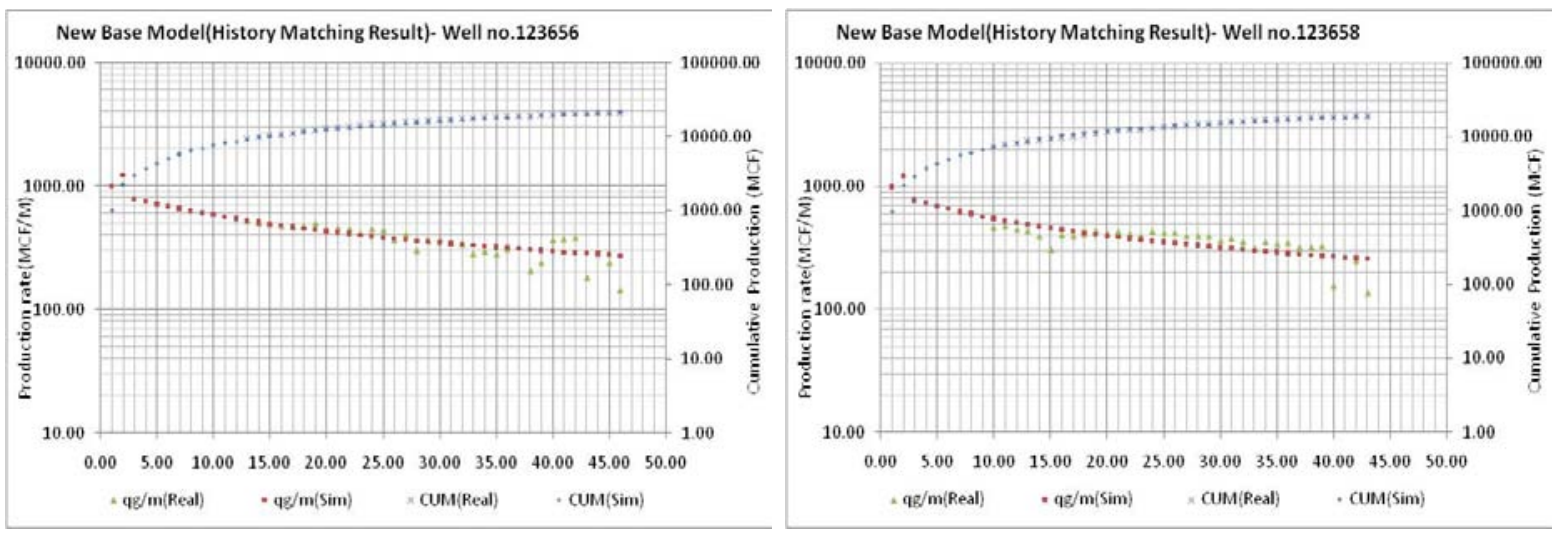

Figure A-43.History matching result well\#123656 Figure A-44.History matching result well\#123658
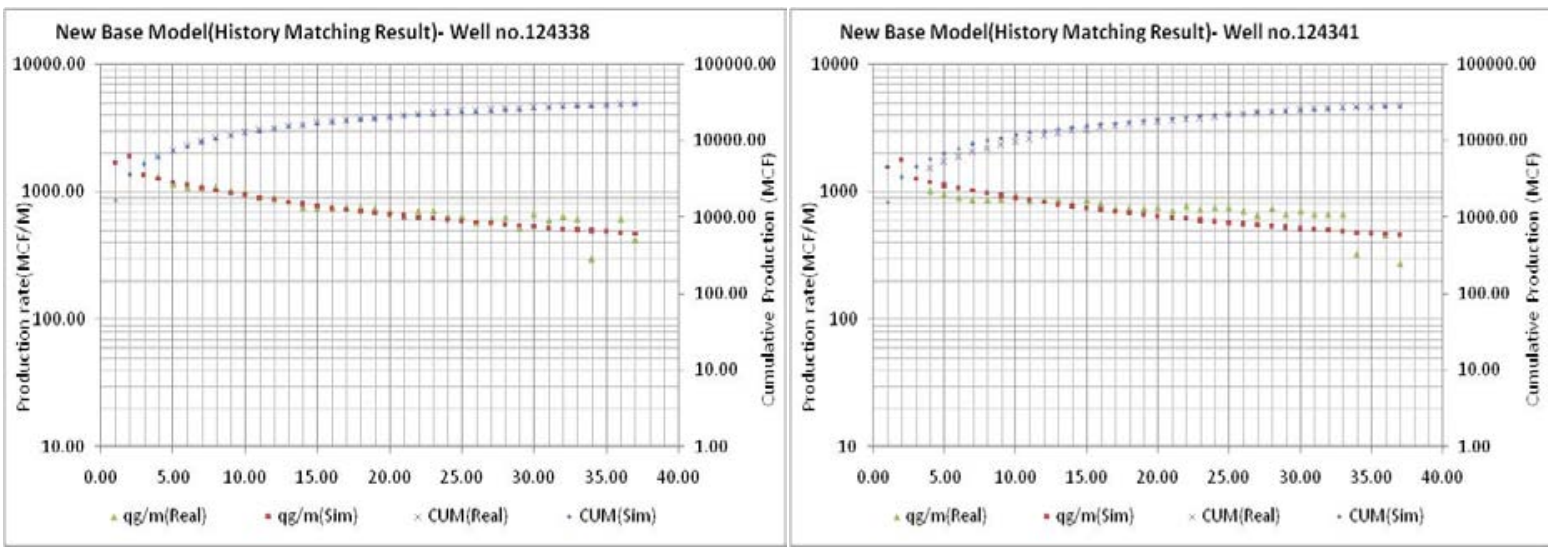

Figure A-45.History matching result well\#124338 Figure A-46.History matching result well\#124341

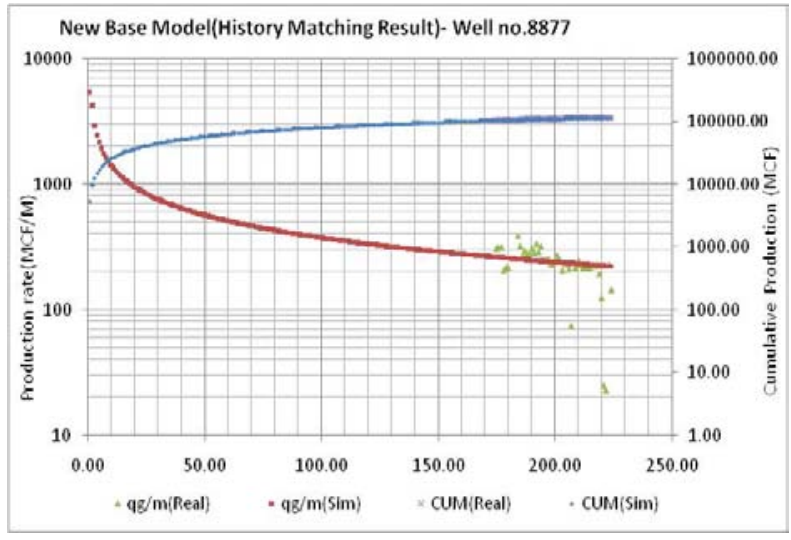

Figure A-47.History matching result well\#8877

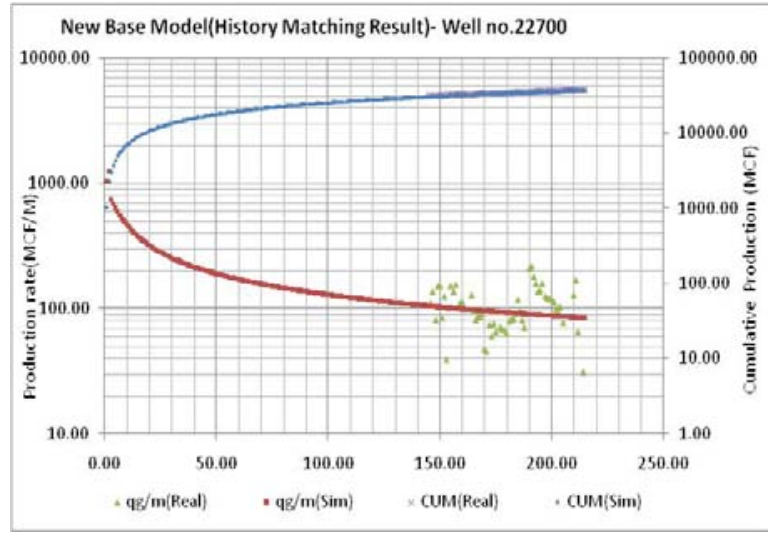

Figure A-48.History matching result well\#22700 

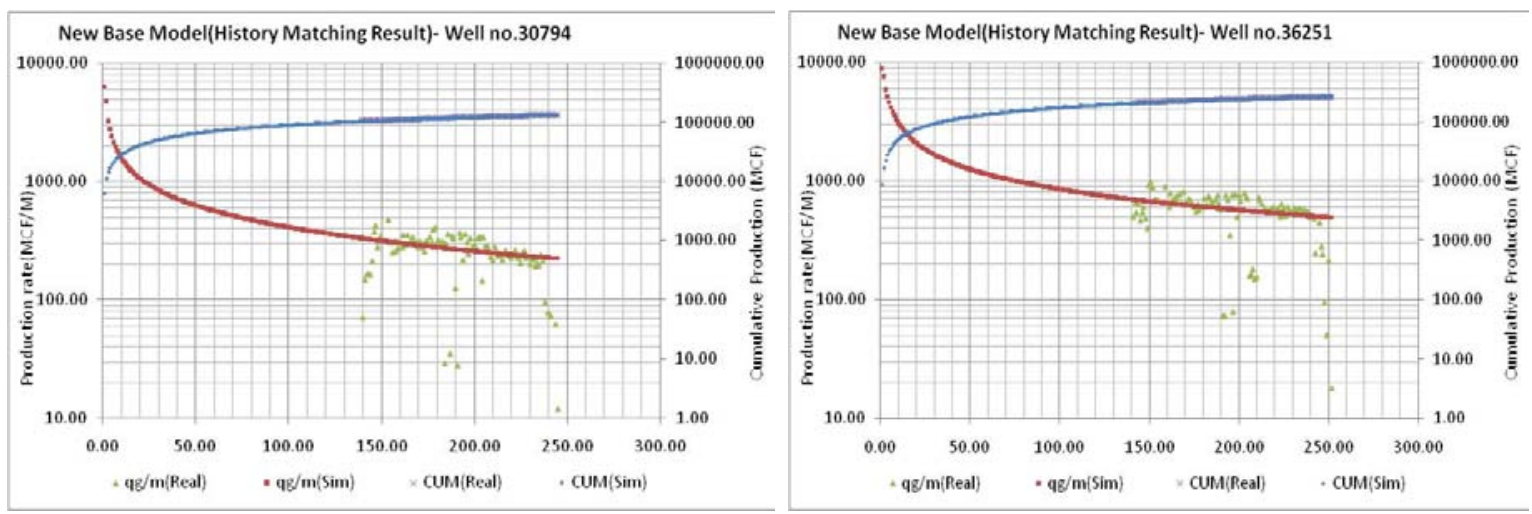

Figure A-49.History matching result well\#30794

Figure A-50.History matching result well\#36251
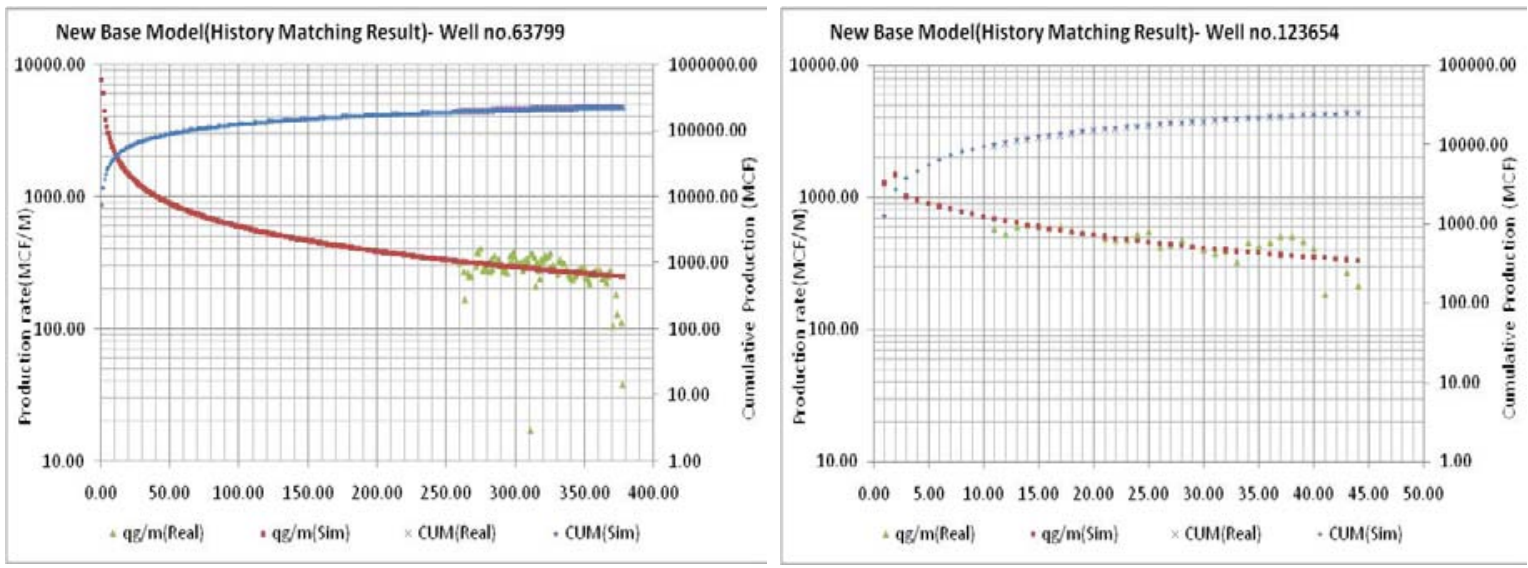

Figure A-51.History matching result well\#63799

Figure A-52.History matching result well\#123654
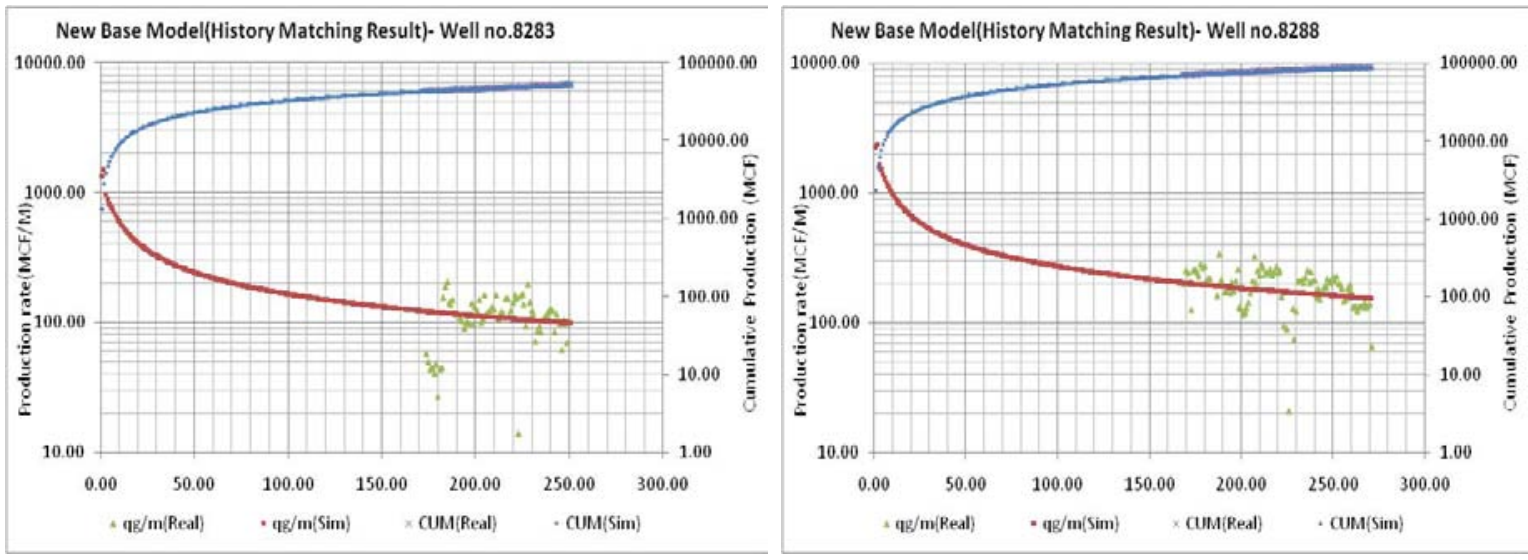

Figure A-53.History matching result well\#8283

Figure A-54.History matching result well\#8288 

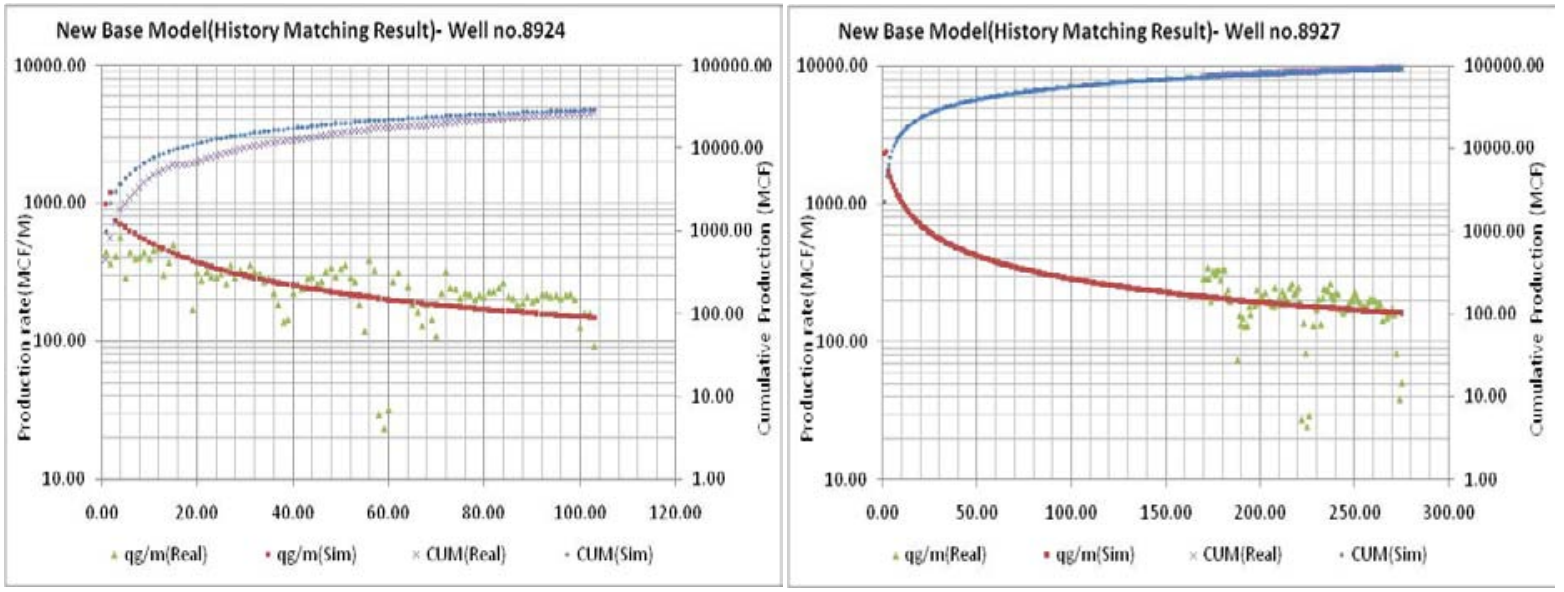

Figure A-55.History matching result well\#8924

Figure A-56.History matching result well\#8927
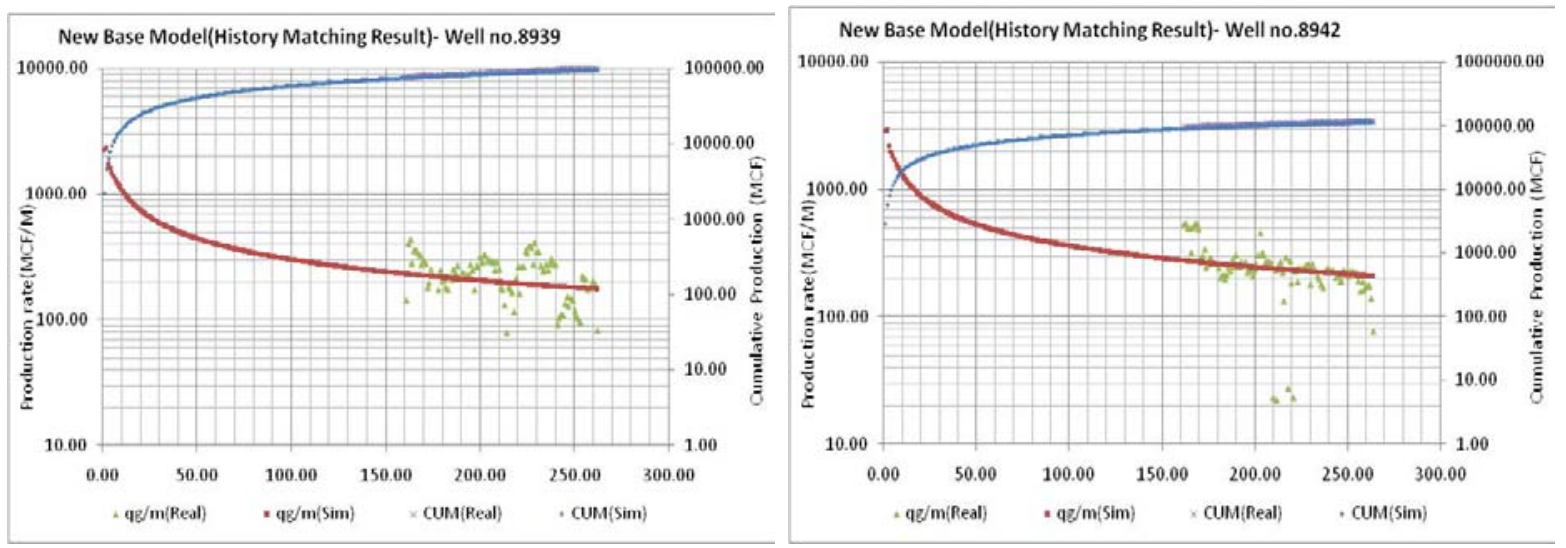

Figure A-57.History matching result well\#8939

Figure A-58.History matching result well\#8942
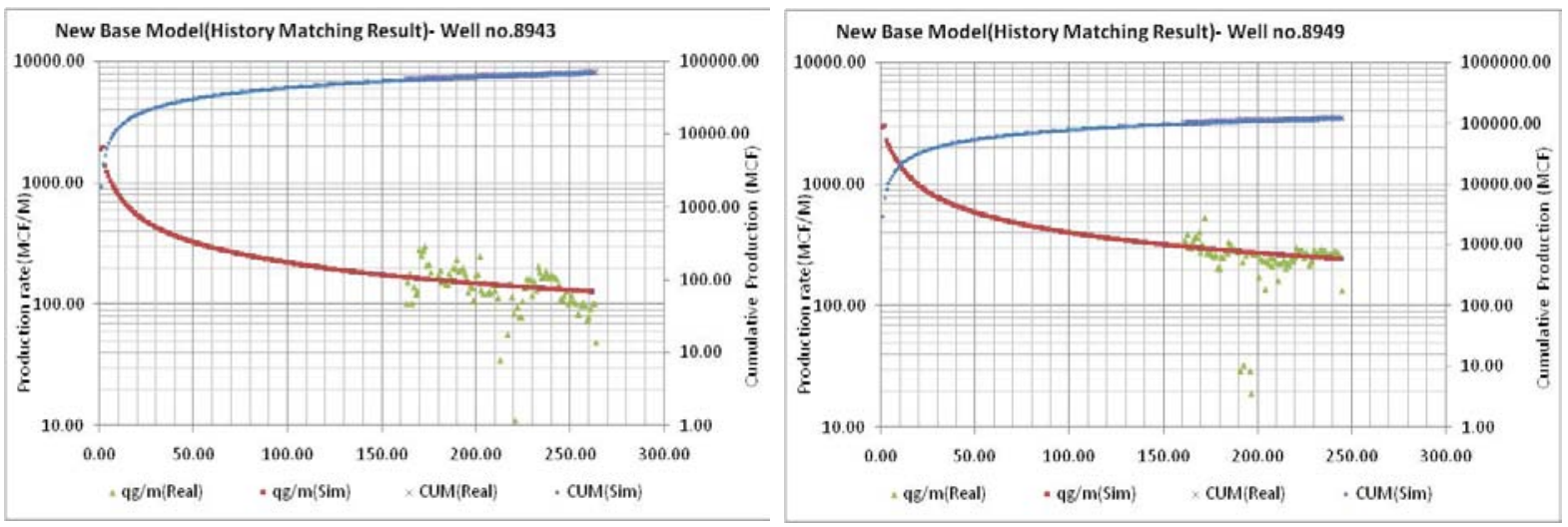

Figure A-59.History matching result well\#8943

Figure A-60.History matching result well\#8949 

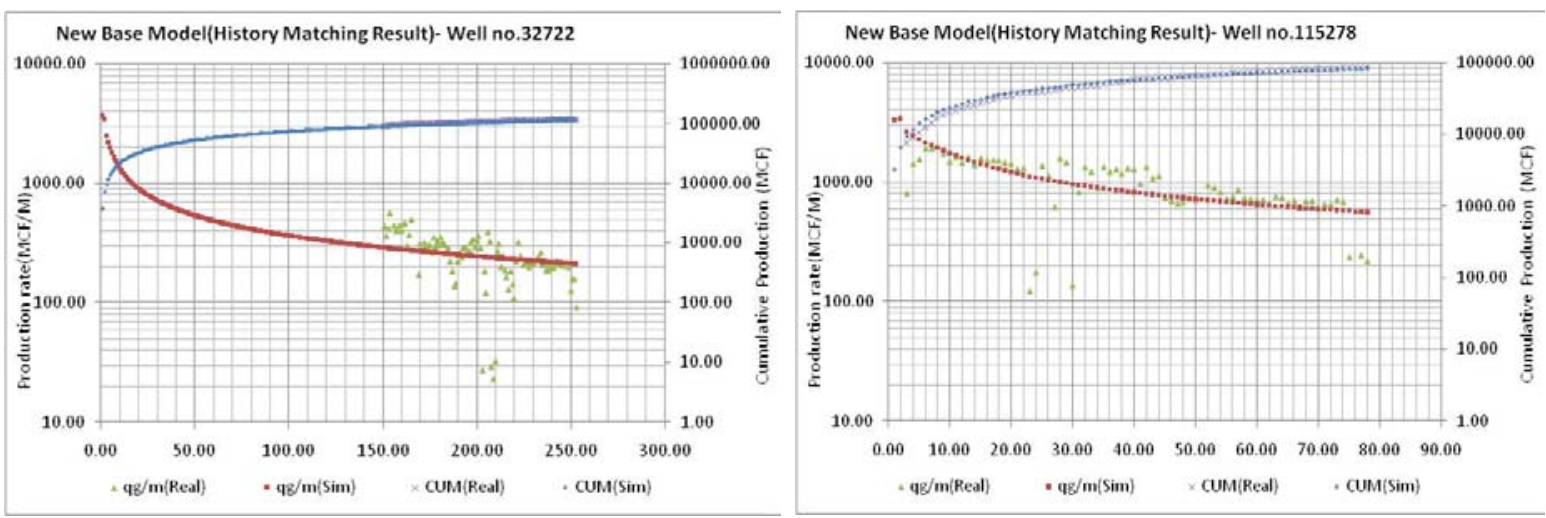

Figure A-61.History matching result well\#32722

Figure A-62.History matching result well\#115278
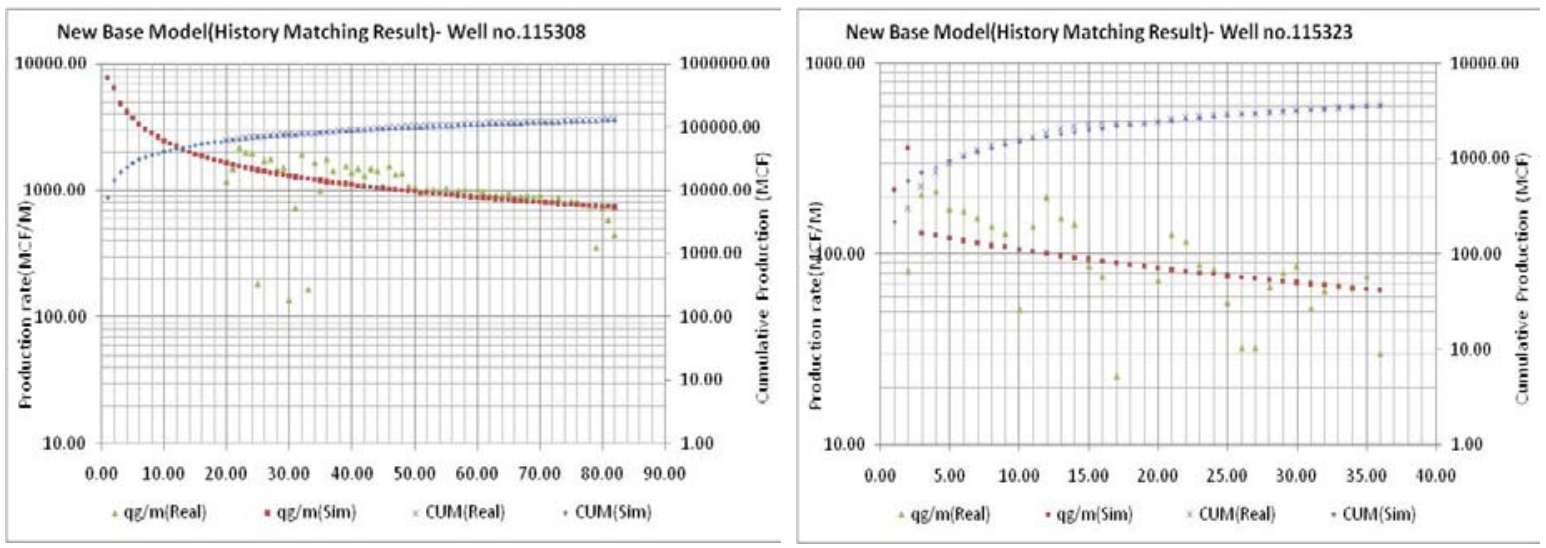

Figure A-63.History matching result well\#115308 Figure A-64.History matching result well\#115323
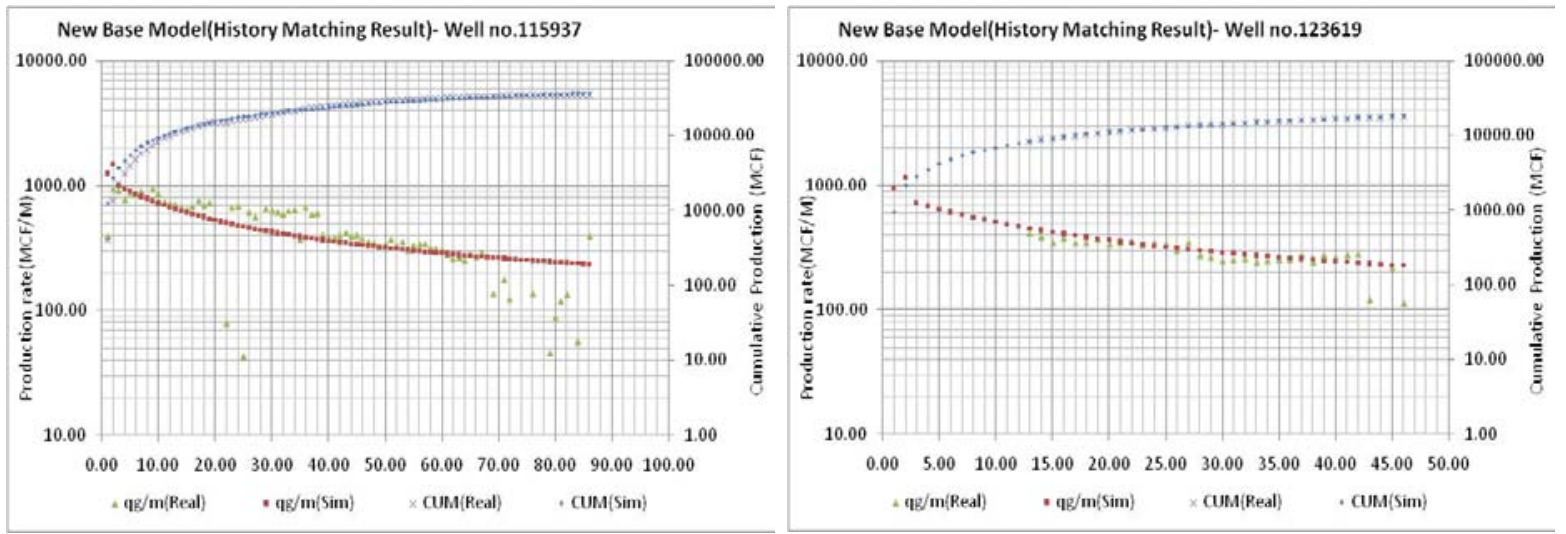

Figure A-65.History matching result well\#115937 Figure A-66.History matching result well\#123619 

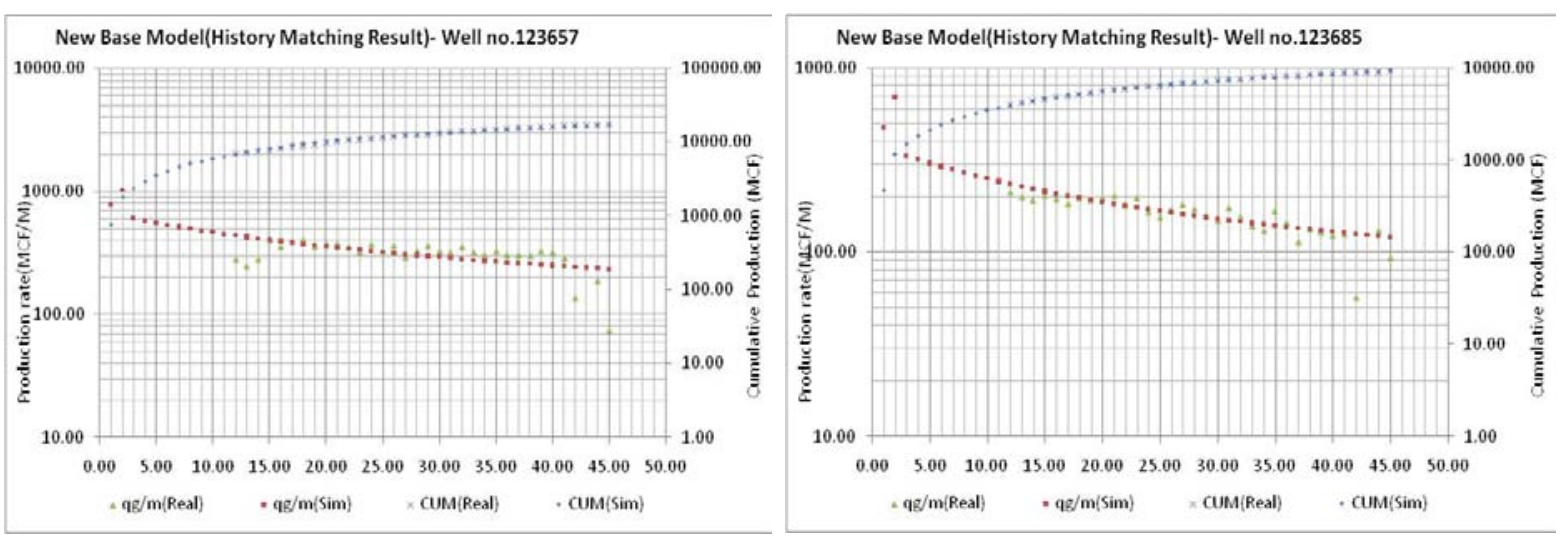

Figure A-67.History matching result well\#123657 Figure A-68.History matching result well\#123685
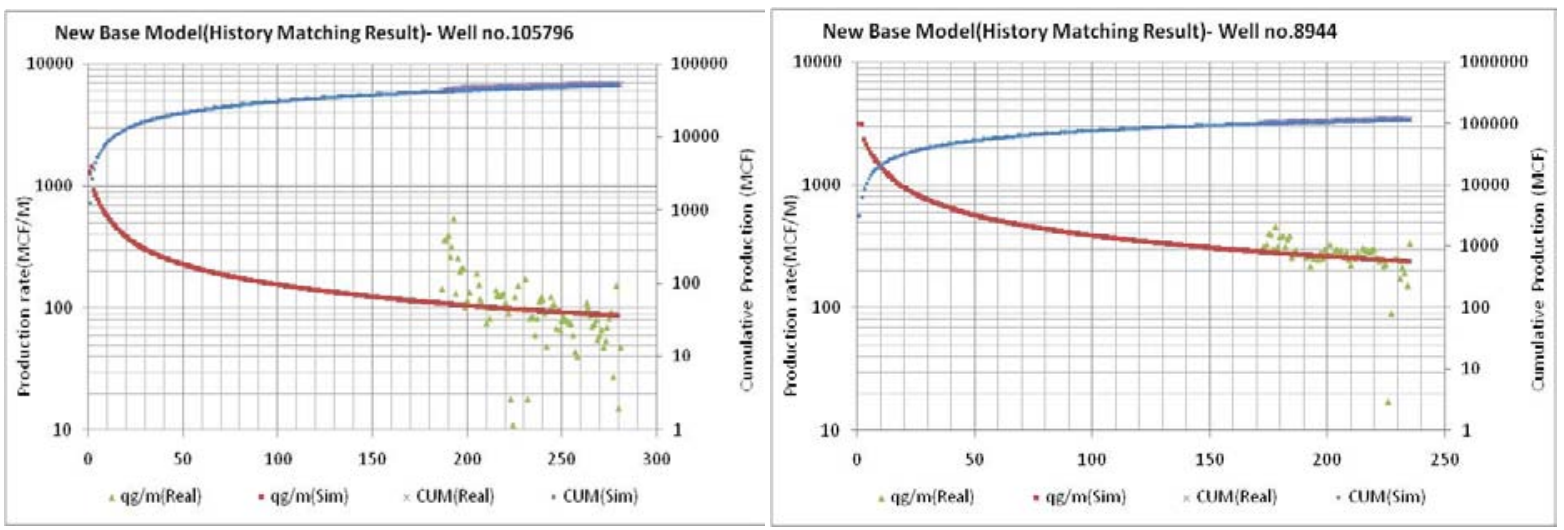

Figure A-69.History matching result well\#105796 Figure A-70.History matching result well\#8944

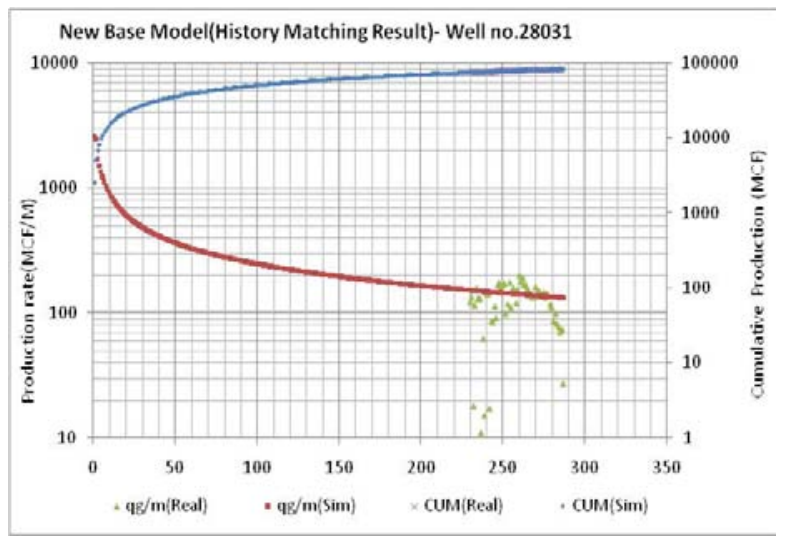

Figure A-71.History matching result well\#28031 